André da Costa Teves

\title{
Otimização de Acelerômetros MEMS Eletroestáticos de Alto Desempenho
}

Dissertação apresentada à Escola Politécnica da Universidade de São Paulo para obtenção do Título de Mestre em Engenharia. 


\section{Otimização de Acelerômetros MEMS Eletroestáticos de Alto Desempenho}

Dissertação apresentada à Escola Politécnica da Universidade de São Paulo para obtenção do Título de Mestre em Engenharia.

Área de concentração:

Engenharia de Controle e Automação

Orientador:

Prof. Dr. Emílio Carlos Nelli Silva 


\section{Ficha Catalográfica}

Teves, André da Costa

Otimização de Acelerômetros MEMS Eletroestáticos de Alto Desempenho. São Paulo, 2013. 109 p.

Dissertação (Mestrado) - Escola Politécnica da Universidade de São Paulo. Departamento de Engenharia Mecatrônica e de Sistemas Mecânicos.

1. Sistema Microeletromêcanicos. 2. Sensores Eletromecânicos. 3. Métodos Topológicos (Otimização;Confiabilidade). I. Universidade de São Paulo. Escola Politécnica. Departamento de Engenharia Mecatrônica e de Sistemas Mecânicos. II. Título. 
Aos meus pais e avós.

Por tudo que eles sempre representaram para mim. 


\section{Agradecimentos}

Ao meu orientador, Prof. Dr. Emilio Carlos Nelli Silva, pela confiança em mim depositada, pela paciência, apoio e dedicação fundamentais para a realização deste trabalho e por seu exemplo único de dedicação científica e acadêmica.

Ao projeto AcelerAD pelo apoio financeiro e pela oportunidade de me colocar em contato com o que há de mais avançado em termos de desenvolvimento de sensores MEMS dentro e fora do país. E em especial a seus membros, Dr. Angelo Passaro e Janderson Rocha, pelas elucidativas conversas a respeito do projeto do micro-acelerômetro que me guiaram no desenvolvimento deste trabalho.

Aos meus pais Adelmo e Terezinha e minhas avós Yvonne e Tereza, que sempre estiveram ao meu lado, física ou espiritualmente, oferecendo todo tipo de suporte que eu necessitei durante a graduação e o mestrado e por acreditarem nos meus sonhos. À minha namorada Bruna pelo apoio, carinho e compreensão nos momentos mais difícies dessa jornada.

A todos os amigos de pesquisa, em especial, Dr. Luis Mello, Dr. Sandro Vatanabe, Ricardo Amigo, Flávio Vasconcelos e Rubén Salas, pelos bons momentos de discussões acadêmicas e não acadêmicas.

E finalmente a todos os demais que direta ou indiretamente contribuíram para a realização deste trabalho. 


\section{Resumo}

Microssistemas eletromecânicos ou "Micro-Electro-Mechanical Systems (MEMS)", representam uma classe de dispositivos que combinam funções mecânicas e eletrônicas em escala micrométrica. Através do uso de técnicas de microfabricação, adaptadas da indústria de semicondutores, é realizada a integração entre estruturas móveis, sensores, atuadores e eletrônica, tornando possível a implementação de sistemas completos miniaturizados. Acelerômetros eletrostáticos estão entre os dispositivos MEMS mais comercializados hoje em dia, com venda anual em todo o mundo superior a 100 milhões de unidades e crescente a cada ano. Eles são geralmente fabricados utilizando-se três lâminas de silício espessas, coladas uma sobre a outra. A camada intermediária é obtida por processos de corrosão e consiste de uma 'grande' massa de prova suspensa por uma ou mais vigas. Ela é separada das lâminas superior e inferior por um pequeno espaço vazio (gap), dando origem a dois conjuntos de capacitores de placas paralelas. A flexibilidade das vigas permite que a massa se mova proporcionalmente à aceleração externa e o seu deslocamento é estimado pela variação da capacitância do conjunto. O projeto destes sensores é uma tarefa complexa, já que os seus diversos requisitos de desempenho são, na maioria das vezes, conflitantes, isto é, se o projeto é modificado para melhorar uma característica, as demais são inevitavelmente afetadas e por isso técnicas de otimização devem ser utilizadas na etapa de projeto. Com o intuito de melhorar o desempenho de micro-acelerômetros capacitivos, são então propostas e avaliadas no atual trabalho duas técnicas de otimização distintas, sendo uma delas baseada em Otimização Paramétrica (OP) e a outra no Método da Otimização Topológica (MOT). A OP parte de uma topologia previamente definida e adota algumas de suas características geométricas como variáveis de projeto. Para levar em consideração incertezas nas dimensões e propriedades dos materiais, que é um elemento-chave na concepção e fabricação de dispositivos MEMS, neste trabalho a OP é combinada com o método da Otimização de Projeto Baseado em Confiabilidade ou "Reliability-based Design Optimization (RBDO)". Análises de confiabilidade de primeira ordem através do Método de Confiabilidade de Primeira Ordem, ou "First-Order Reliability Method (FORM)", são utilizadas para o cálculo das probabilidades envolvidas nesta formulação. Já o MOT combina o Método dos Elementos Finitos (MEF) e um modelo de material com algoritmos de otimização para encontrar a distribuição ótima de material em um domínio de projeto pré-estabelecido. As variáveis de projeto são as pseudo-densidades que descrevem a quantidade de material em cada ponto do domínio. Na modelagem pelo MEF utiliza-se elementos de placa estrutural do tipo "Mixed Interpolation of Tensorial Components (MITC)". Exemplos práticos utilizando ambas as abordagens são apresentados e os seus resultados discutidos com o intuito de se avaliar o potencial de cada técnica para o projeto de micro-acelerômetros capacitivos. 


\section{Abstract}

Micro-Electro-Mechanical Systems (MEMS) are a class of devices that combine mechanical and electronic functions on a micrometric scale. Through the use of microfabrication techniques, adapted from the semiconductor industry, the integration of mobile structures, sensors, actuators and electronics is performed, allowing the implementation of fully miniaturized systems. Electrostatic accelerometers are among the highest volume MEMS products nowadays, with worldwide annual sales topping 100 million units and growing steadily. Bulk-type accelerometers are generally manufactured using three thick silicon wafers, bonded together one on top of the other. The intermediate layer is obtained by etching processes and consists of a 'big' proof mass suspended by one or more beams. It is separated from the upper and lower wafers by a small gap, resulting in two sets of parallel plate capacitors. The flexibility of the beams allows the mass to move proportionally to the external acceleration and its displacement is estimated by the change in capacitance of the set. The design of such sensors is a complex task, since they depend on many performance requirements, which are most often conflicting. If a design is modified to improve one characteristic, others are inevitably affected. Therefore, optimization techniques are regularly used in the design stage of MEMS sensors. Aiming to improve the performance of capacitive micro-accelerometers, in the present work two optimization techniques are presented, the first is based on Parametric Optimization (PO) and the other is the Topology Optimization Method (TOM). The PO starts from a predefined topology and uses some of its geometric characteristics as design variables. In order to account for uncertainties in the dimensions and material properties, which is a key element in the design and fabrication of MEMS devices, in this work the PO is combined with the Reliability-based Design Optimization (RBDO) method. The First-Order Reliability Method (FORM) is applied to calculate the probabilities involved in the RBDO formulation. The TOM combines the Finite Element Method (FEM) and a material model with optimization techniques to find the best constrained material distribution in a fixed design domain. The design variables are the pseudo-densities that describe the amount of material at each point of the domain. The FE model is discretized using the Reissner-Mindlin plate element with the Mixed Interpolation of Tensorial Components (MITC) formulation. Practical examples using both approaches are presented and discussed in order to evaluate the potential of each technique to the design of capacitive micro-accelerometers. 


\section{Sumário}

\section{Lista de Figuras}

Lista de Tabelas

Lista de Abreviaturas

Lista de Símbolos

1 Introdução 1

1.1 Medição de acelerações . . . . . . . . . . . . . . . . . . . . . 1

1.2 Acelerômetros MEMS . . . . . . . . . . . . . . . . . . . . . . . 2

1.3 Contexto do Projeto . . . . . . . . . . . . . . . . . . 7

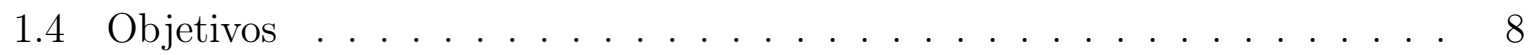

1.5 Motivação e Justificativa . . . . . . . . . . . . . . . . . . . . . . . . . . 9

2 Otimização de Acelerômetros MEMS $\quad 11$

2.1 Introdução . . . . . . . . . . . . . . . . . . . . . . . . . 11

2.2 Técnicas de Otimização f . . . . . . . . . . . . . . . . . . . . 12

2.3 Otimização com confiabilidade . . . . . . . . . . . . . . . 14

2.3.1 Formulação genérica do RBDO . . . . . . . . . . . . . . . 16

2.3.2 Cálculo de Probabilidades pelo FORM . . . . . . . . . . . . . . 17

2.3.3 Método PMA . . . . . . . . . . . . . . . . . . . . 22

3 Método da Otimização Topológica $\quad 25$

3.1 Introdução . . . . . . . . . . . . . . . . . . . . 25 
3.2 Conceitos Básicos do MOT . . . . . . . . . . . . . . . 26

3.2.1 Domínio Fixo Estendido de Projeto . . . . . . . . . . . . . . 26

3.2 .2 Modelo de Material . . . . . . . . . . . . . . . . . . . 27

3.3 Problemas Numéricos no MOT . . . . . . . . . . . . . . . . . . . . . . . . 29

3.3.1 Instabilidade de Tabuleiro . . . . . . . . . . . . . . . . . . . 29

3.3.2 Dependência da Malha . . . . . . . . . . . . . . . . . . 30

3.4 Técnica de projeção . . . . . . . . . . . . . . . . . 31

3.5 Formulação do problema de OT para o projeto de Acelerômetros MEMS . 34

3.5.1 Flexibilidade estrutural . . . . . . . . . . . . . . . . 34

3.5.2 Controle de Perímetro . . . . . . . . . . . . . . . . 36

4 Implementação Numérica $\quad 39$

4.1 Implementação da Otimização Paramétrica com confiabilidade . . . . . . . 39

4.1 .1 Análise de Sensibilidades . . . . . . . . . . . . . . . . . . . 39

4.1 .2 Fluxograma da Implementação . . . . . . . . . . . . . . . . . . . . 42

4.2 Implementação da Otimização Topológica . . . . . . . . . . . . . . . . . . 43

4.2.1 Modelagem de Placas através do Método dos Elementos Finitos . . 43

4.2 .2 Problema de OT na Forma Discreta . . . . . . . . . . . . . 46

4.2 .3 Análise de Sensibilidades . . . . . . . . . . . . . . . . . 48

4.2.4 Fluxograma da Implementação . . . . . . . . . . . . . . . . . . . 50

4.3 Método das Assíntotas Móveis . . . . . . . . . . . . . . . . . . . 51

5 Resultados e discussões $\quad 54$

5.1 Problema da treliça de 10 barras . . . . . . . . . . . . . . 54

5.2 Projeto de mola plana por OT . . . . . . . . . . . 56

5.3 Estudo de caso: projeto AcelerAD . . . . . . . . . . . . . . 63

5.4 RBDO aplicado ao projeto AcelerAD . . . . . . . . . . . . 67

5.4 .1 Otimização determinística . . . . . . . . . . . . . 67 
5.4.2 RBDO com incertezas nas propriedades do material . . . . . . . . . 69

5.4.3 RBDO com incertezas nas propriedades do material e nas dimensões do dispositivo . . . . . . . . . . . . . . . . . . . . 73

5.5 MOT aplicado ao projeto AcelerAD . . . . . . . . . . . . . 76

6 Conclusões e trabalhos futuros $\quad 82$

$\begin{array}{ll}\text { Referências } & 86\end{array}$

Apêndice A - Validação do algoritmo de otimização com confiabilidade

Apêndice B - Verificação das sensibilidades do problema de OT mediante o MDF

Apêndice C - Comunicação entre Comsol e Matlab

Apêndice D - Validação do algoritmo de otimização topológica

Apêndice E - Análise de sensibilidades para o problema da treliça de $\mathbf{1 0}$ barras 


\section{Lista de Figuras}

1.1 Correlação entre preço e desempenho de sensores. . . . . . . . . . . . . . . 3

1.2 O ADXL330 mede $4 \mathrm{~mm} \times 4 \mathrm{~mm} \times 1,45 \mathrm{~mm} \ldots \ldots \ldots . \ldots . \ldots$

1.3 Faixa de trabalho contra largura de banda necessária para aplicações diversas. 5

1.4 ADXL50: um dos primeiros acelerômetros de superfície fabricados pela empresa Analog Devices (KUEHNEL; SHERMAnB, 1994) . . . . . . . . . . . 6

1.5 Um dos primeiros acelerômetro "bulk" apresentados na literatura (RUDOLF et al., 1990). . . . . . . . . . . . . . . . . . . 6 6

1.6 Seção transversal de um projeto típico de acelerômetros do tipo "bulk". . . 6

1.7 Topologias típicas para acelerômetros do tipo "bulk":(a) uma única viga em balanço, (b) viga em torção, (c) estrutura em ponte com quatro vigas, (d),(e),(f) configurações simétricas com vigas retas, (g),(h) configurações simétricas com vigas dobradas. . . . . . . . . . . . . . . . . . . . 7

1.8 Topologia do Acelerômetro proposta pelo CSEM. . . . . . . . . . . . . . 8

2.1 otimização paramétrica. . . . . . . . . . . . . . . . . . . 12

2.2 otimização de forma. . . . . . . . . . . . . . . . . . . . . . . 12

2.3 otimização topológica. . . . . . . . . . . . . . . . . . . . . . 13

2.4 Espaço normal padrão 2D . . . . . . . . . . . . . . . . . . . . . . . . . . . . 19

2.5 Histórico ilustrativo das iterações envolvidas na busca pelo MPFP. . . . . . 21

2.6 Visão geral do processo FORM. . . . . . . . . . . . . . . . . . . . . . 22

2.7 Histórico ilustrativo das iterações envolvidas na busca pelo MPTP. . . . . . 23

3.1 Ciclo de projeto utilizando o MOT. . . . . . . . . . . . . 26

3.2 Exemplo de ocorrência de escalas de cinza. . . . . . . . . . . . . . . . . . 28

3.3 Surgimento de mínimos múltiplos locais a partir da penalização das variáveis de projeto. 
3.4 Exemplo de ocorrência de "instabilidade de tabuleiro". . . . . . . . . . . . . 30

3.5 Arranjo (a) de "tabuleiro de xadrez" e (b) uniforme. . . . . . . . . . . . . . 30

3.6 Dependência da malha nos resultados de OT. . . . . . . . . . . . . . 31

3.7 Os elementos localizados dentro do domínio $\Omega_{w}^{e}$ são incluídos na projeção para o elemento $e-\Omega_{w}^{e}$ não se altera quando a malha é refinada de (a) para

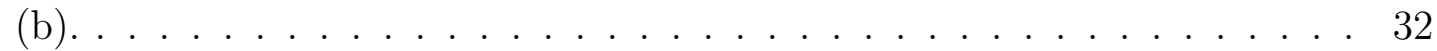

3.8 Diferentes funções peso para a técnica de projeção. . . . . . . . . . . . . . . 33

3.9 Corpo submetido a um carregamento $t$ em $\Gamma_{t} \ldots \ldots \ldots \ldots$

3.10 Dois exemplos de topologias que apresentam alta flexibilidade . . . . . . 36

4.1 Fluxograma da Implementação do RBDO. . . . . . . . . . . . . . . . . . . 42

4.2 Deformações por flexão e cisalhamento numa estrutura de placa. . . . . . . 45

4.3 Elemento de placa com 4 nós e 6 graus de liberdade por nó. . . . . . . . . 46

4.4 Implementação da variável de projeto por elemento (Q4/U). . . . . . . . . 47

4.5 Perímetro associado com uma aresta. . . . . . . . . . . . . . . . . . . 48

4.6 Fluxograma da Implementação do MOT. . . . . . . . . . . . . . . . . . . . 50

5.1 Problema de otimização de uma viga em balanço. . . . . . . . . . . . . 55

5.2 Domínio Fixo Estendido de Projeto para o problema da coluna cônica. . 57

5.3 Resultado obtido para restrição de volume de $50 \%$ com a formulação (4.15). 57

5.4 Diferentes topologias obtidas com a formulação (4.15) variando-se limite superior da restrição de volume. . . . . . . . . . . . . . . . . . . . . 58

5.5 Estrutura em zig-zag que possibilita alta flexibilidade. . . . . . . . . 58

5.6 Topologias obtidas com diferentes níveis de flexibilidade média especificados utilizando a formulação (4.16) . . . . . . . . . . . . . . . . . . . 59

5.7 Diferentes topologias obtidas utilizando a formulação (4.18) variando-se o nível de flexibilidade exigida e o perímetro da estrutura. . . . . . . . . . . 60

5.8 Topologias obtidas para diferentes valores de perímetro impostos e restrição de volume fixa em 10\%. . . . . . . . . . . . . . . . 61

5.9 Topologias obtidas após o pós-processamento dos resultados da Fig. 5.8. . . 62

5.10 Domínio de projeto com simetria e repetição de padrão. . . . . . . . . . . . 63 
5.11 Topologia obtida com o domínio de projeto considerando simetria e repetição de padrão. . . . . . . . . . . . . . . . . . . . . 63

5.12 Topologia obtida depois da etapa de pós-processamento. . . . . . . . . . 63

5.13 Seção transversal (esq.) e vista de topo (dir.) da geometria proposta. . . . 64

5.14 Representação da repetição de padrão considerada para o AcelerAD. . . . . 65

5.15 Comparativo da topologia obtida através do problema (5.4) com o projeto inicial. . . . . . . . . . . . . . . . . . . 68

5.16 Comparativo da seção transversal obtida através do problema (5.4) com o projeto inicial. A razão de aspecto foi exagerada para facilitar a comparação das espessuras. . . . . . . . . . . . . . . . . . . . . . . . . . . 68

5.17 Primeira frequência de ressonância (modo pistão): 2473,95 Hz. . . . . . . . 69

5.18 Comparativo das topologias obtidas através do problema (5.5) com o ótimo determinístico e com o projeto inicial. . . . . . . . . . . . . . . . . . . 71

5.19 Comparativo das seções transversais obtidas através do problema (5.5) com o ótimo determinístico e com o projeto inicial. A razão de aspecto foi exagerada para facilitar a comparação das espessuras. . . . . . . . . . . . . 71

5.20 Resultado do cálculo de probabilidades para a restrição de sensibilidade utilizando o método de Monte Carlo com 225.000 amostras. O eixo horizontal representa a variação no módulo de Young $E$ e o vertical na densidade do

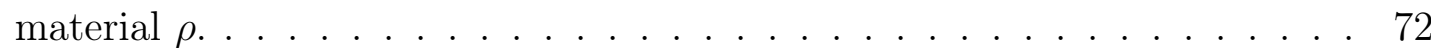

5.21 Resultado do cálculo de probabilidades para a restrição de freq. de ressonância utilizando o método de Monte Carlo com 225.000 amostras. O eixo horizontal representa a variação no módulo de Young $E$ e o vertical na densidade do material $\rho . \ldots \ldots$. . . . . . . . . . . . 73

5.22 Comparativo das topologias obtidas. . . . . . . . . . . . . . 75

5.23 Comparativo das seções transversais obtidas. A razão de aspecto foi exagerada para facilitar a comparação das espessuras. . . . . . . . . . . . . . 75

5.24 Domínio fixo estendido de projeto. . . . . . . . . . . . . . 77

5.25 Seção transversal do domínio fixo estendido de projeto. . . . . . . . . . . . 77

5.26 Estimativa inicial para as variáveis de projeto, similar ao projeto AcelerAD. 77 
5.27 Topologias ótimas obtidas através do problema (4.15) para diferentes volumes de material. . . . . . . . . . . . . . . . . . . 78

5.28 (esq) Topologia ótima obtida através do problema (4.16) com $L_{\max }=1$. $10^{-5}$; (dir) versão pós-processada. . . . . . . . . . . . . . . . . . . 79

5.29 Domínio fixo estendido de projeto. . . . . . . . . . . . . 80

5.30 Topologia ótima obtida com o novo domínio de projeto para $L_{\max }=1 \cdot 10^{-5}$. 80

5.31 (esq) Resultado obtido para a formulação (4.18); (dir) versão pós-processada. 81

A.1 O problema de otimização de uma viga em balanço. . . . . . . . . . . . . . 96

A.2 Histórico de iterações para o problema de otimização determinístico. . . . . 97

A.3 Histórico de iterações para o problema de otimização probabilístico com o PMA . . . . . . . . . . . . . . . . . . 98

B.1 Razão entre as sensibilidade com discretização de 16 elementos . . . . . . . 100

B.2 Razão entre as sensibilidade com discretização de 64 elementos . . . . . . . 100

B.3 Razão entre as sensibilidade com discretização de 256 elementos . . . . . . 101

C.1 Interpolação do vetor de densidades no software Comsol. . . . . . . . . . . 102

C.2 Distribuição do valor do módulo de Young E, resultante da aplicação do SIMP. . . . . . . . . . . . . . . . . . . . 103

D.1 Maximização da rigidez com a placa simplesmente apoiada nas bordas . . . 107

D.2 Maximização da rigidez com a placa engastada nas bordas . . . . . . . . . 107

E.1 Representação cartesiana 2D de uma barra de treliça e seus graus de liberdade. . . . . . . . . . . . . . . . . . . . . . . 108 


\section{Lista de Tabelas}

5.1 Valores ótimos para as médias das áreas das seções transversais $A_{i}$. . . . 55

5.2 Propriedades estatísticas para o problema da treliça de 10 barras . . . . . . 56

5.3 Resumo dos resultados obtidos nas Figuras 5.8 e 5.9 . . . . . . . . . . . 61

5.4 Comparativo das estruturas em zig-zag . . . . . . . . . . . . . 63

5.5 Dimensões do acelerômetro proposto . . . . . . . . . . . . . . . 64

5.6 Variáveis de projeto adotadas na otimização paramétrica . . . . . . . . 67

5.7 Distribuições estatísticas associadas às propriedades do material (silício) . . 69

5.8 Resultados da Otimização Paramétrica com e sem confiabilidade (dimen-

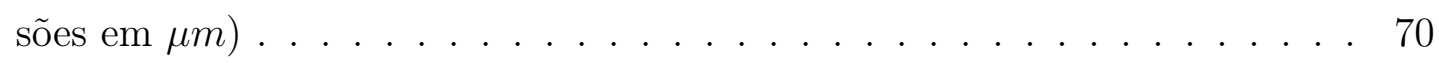

5.9 Comparativo dos valores de confiabilidade obtidos através dos métodos RIA e Monte Carlo para o AcelerAD . . . . . . . . . . . . . . . . . . 73

5.10 Propriedades estatísticas do problema . . . . . . . . . . . . . 74

5.11 Limites superior e inferior das variáveis de projeto consideradas . . . . . . 74

5.12 Comparativo dos resultados obtidos com a geometria proposta inicialmente pelo CSEM (dimensões em $\mu m) \ldots \ldots$. . . . . . . . . . . 76

5.13 Valores ótimos da função objetivo para o problema de OT (4.15). . . . . . 78

5.14 Valores de referência para o dispositivo AcelerAD. . . . . . . . . . . . 80

A.1 Distribuições das variáveis aleatórias envolvidas no problema da viga em balanço $\left({ }^{*}\right.$ denota mediana $\left.m_{0}\right) \ldots \ldots \ldots$. . . . . . . . . 96

A.2 Parâmetros característicos das distribuições probabilísticas envolvidas no problema da viga em balanço . . . . . . . . . . . . . . . . . 97

B.1 Comparação entre o custo computacional de $S_{1}$ e $S_{2} \ldots \ldots$. . . . . . 99 


\section{Lista de Abreviaturas}

AcelerAD Acelerômetro de Alto Desempenho

ASIC Application-Specific Integrated Circuit

CIs Circuitos Integrados

CoV Coeficiente de Variação

CSEM Centre Suisse d'Electronique et de Microtecnique da Suíça

CTI Centro de Tecnologia da Informação Renato Archer

DFEP Domínio Fixo Estendido de Projeto

DRIE Deep Reactive-Ion Etching

EPUSP Escola Politécnica da Universidade de São Paulo

FDP Função Densidade de Probabilidades

FEM Finite Element Method

FINEP Financiadora de Estudos e Projetos

FORM First-Order Reliability Method

IEAv Instituto de Estudos Avançados

LSI Laboratório de Sistemas Integráveis

LTCC Low-Temperature Co-Fired Ceramic

MDF Método de Diferenças Finitas

MEF Método dos Elementos Finitos

MEMS Micro-Electro-Mechanical Systems

MGF Material com Gradação Funcional

MITC Mixed Interpolation of Tensorial Components 
MMA Method of Moving Asymptotes

MOT Método da Otimização Topológica

MOTC Método da Otimização baseado em Confiabilidade

MPFP Most Probable Failure Point

MPTP Minimum Performance Target Point

OT Otimização Topológica

OP Otimização Paramétrica

PMA Performance Measure Approach

PO Parametric Optimization

RBTO Reliability-based Topology Optimization

RBDO Reliability-based Design Optimization

RDO Robust Design Optimization

RIA Reliability Index Approach

SIMP Simple Isotropic Material with Penalization

TOM Topology Optimization Method

VANT Veículos aéreos não tripulados

VT Variação Total 


\section{Lista de Símbolos}

Os seguintes símbolos serão utilizados:

\begin{tabular}{|c|c|}
\hline símbolo & descrição \\
\hline$g$ & unidade de aceleração equivalente a $9,81 \mathrm{~m} / \mathrm{s}^{2}$ \\
\hline$c$ & $\begin{array}{l}\text { função objetivo ou de custo do problema de otimização com con- } \\
\text { fiabilidade }\end{array}$ \\
\hline $\bar{c}$ & $\begin{array}{l}\text { custo mínimo aceitável do problema de otimização com confia- } \\
\text { bilidade }\end{array}$ \\
\hline$g_{i}$ & $\begin{array}{l}\text { restrições determinísticas do problema de otimização com confi- } \\
\text { abilidade }\end{array}$ \\
\hline $\mathbf{s}$ & $\begin{array}{l}\text { variáveis de projeto do problema de otimização com confiabili- } \\
\text { dade }\end{array}$ \\
\hline$S_{\text {inf }}$ & limites inferiores para as variáveis de projeto $\mathbf{s}$ \\
\hline $\mathrm{s}_{\text {sup }}$ & limites superiores para as variáveis de projeto $\mathbf{s}$ \\
\hline $\operatorname{Prob}(\cdot)$ & probabilidade \\
\hline$f_{i}$ & $\begin{array}{l}\text { função de estado limite associada às restrições probabilísticas do } \\
\text { problema de otimização com confiabilidade }\end{array}$ \\
\hline $\bar{P}_{i}$ & probabilidade de falha máxima aceitável associada a $f_{i}$ \\
\hline $\mathbf{r}$ & $\begin{array}{l}\text { variáveis aleatórias do problema de otimização com confiabili- } \\
\text { dade }\end{array}$ \\
\hline$f_{R}(\mathbf{r})$ & função densidade de probabilidades genérica \\
\hline$\beta$ & índice de confiabilidade das restrições probabilísticas \\
\hline $\mathbf{u}$ & $\begin{array}{l}\text { vetor de variáveis gaussianas mutuamente independentes de mé- } \\
\text { dia nula e covariância unitária (espaço normal padrão) }\end{array}$ \\
\hline$M$ & função de estado limite genérica linear \\
\hline$\mu_{[\cdot]}$ & valor esperado de uma variável aleatória \\
\hline $\operatorname{Cov}[\cdot, \cdot]$ & covariância entre duas variáveis aleatórias \\
\hline$\sigma_{[\cdot]}^{2}$ & variância de uma variável aleatória \\
\hline$P_{f}$ & probabilidade de falha \\
\hline
\end{tabular}




\begin{tabular}{|c|c|}
\hline símbolo & descrição \\
\hline$\Phi$ & $\begin{array}{l}\text { função densidade de probabilidades acumulada para a distribui- } \\
\text { ção normal padrão }\end{array}$ \\
\hline$Q$ & função de estado limite genérica não necessariamente linear \\
\hline$G_{\mathbf{u}^{(k)}}$ & $\begin{array}{l}\text { gradiente da função de estado limite Q em relação a u na iteração } \\
k\end{array}$ \\
\hline $\mathbf{T}_{\mathbf{u}}$ & $\begin{array}{l}\text { transformação que leva as variáveis aleatórias originais } \mathbf{r} \text { para o } \\
\text { espaço normal padrão } \mathbf{u}\end{array}$ \\
\hline$F_{r}$ & $\begin{array}{l}\text { função densidade de probabilidades acumulada para uma distri- } \\
\text { buição qualquer }\end{array}$ \\
\hline $\bar{\beta}_{i}$ & índice de confiabilidade alvo para as restrições probabilísticas \\
\hline$\Omega$ & domínio fixo estendido de projeto \\
\hline$\gamma$ & variáveis de projeto do problema de otimização topológica \\
\hline$\chi$ & função discreta que define o modelo de material no MOT \\
\hline$E$ & módulo de elasticidade do material \\
\hline$\rho$ & densidade do material \\
\hline$p_{e}$ & fator de penalização das pseudo-densidades \\
\hline$r_{\min }$ & raio da projeção \\
\hline$\overline{\mathrm{x}}^{e}$ & coordenadas do centroide do elemento $e$ \\
\hline$\Omega_{w}^{e}$ & domínio dos elementos vizinhos a $e$ \\
\hline$w(x)$ & função peso da projeção \\
\hline$\omega_{p}$ & exponente da função peso da projeção \\
\hline d & pseudo-densidades do problema de otimização topológica \\
\hline$S_{e}$ & conjunto dos elementos vizinhos a $e$ \\
\hline $\mathbf{v}$ & campo de deslocamentos do problema de elementos finitos \\
\hline$L$ & flexibilidade média ou "mean compliance" \\
\hline$V$ & volume de material \\
\hline$P$ & perímetro da topologia \\
\hline$L_{\max }$ & limite superior para a flexibilidade média \\
\hline$V_{\max }$ & limite superior para o volume de material \\
\hline$P_{\min }$ & limite inferior para a Variação Total ou Perímetro \\
\hline $\mathbf{F}$ & carregamento externo do problema de elementos finitos \\
\hline $\mathbf{K}$ & matriz de rigidez do problema de elementos finitos \\
\hline A & seções transversais das barras de uma treliça \\
\hline
\end{tabular}




\section{Introdução}

\subsection{Medição de acelerações}

Um acelerômetro é um dispositivo eletromecânico capaz de medir aceleração, isto é, a taxa de variação da velocidade. Estas acelerações podem ser estáticas, como a força da gravidade, ou dinâmicas, causadas por movimentação ou vibração. Sua unidade no Sistema Internacional (SI) é m/ $\mathrm{s}^{2}$, mas em muitos casos o valor de aceleração é especificado como um fator multiplicativo de "g". Nesse sentido, "g" é uma unidade de aceleração que equivale a força de gravidade da Terra ao nível do mar ou $9,81 \mathrm{~m} / \mathrm{s}^{2}$.

Basicamente, todos os tipos de acelerômetros traduzem o sinal externo de aceleração em um deslocamento correspondente de sua massa móvel, também conhecida como massa inercial ou de prova. Este deslocamento pode ser detectado através de diferentes esquemas de medição, sendo que os mais comuns são: capacitivo, piezoelétrico, piezoresistivo, ressonante e óptico (YADI; AYAZI; NAJAFI, 1998; KRISHNAN et al., 2007).

O foco deste trabalho são acelerômetros capacitivos. As principais vantagens deste esquema de transdução são alta sensibilidade, baixo nível de ruído, baixa sensibilidade à variações de temperatura e baixo consumo de energia. Por outro lado, existe a possibilidade de interferência eletromagnética se o dispositivo não estiver devidamente blindado (MACDONALD, 1990) e de colapso da massa móvel em direção aos eletrodos, fenômeno mais conhecido como "pull-in" (KAAJAKARI, 2009).

As principais especificações que devem ser consideradas na seleção de um acelerômetro são discutidas em seguida.

- Sensibilidade: fator de escala de um sensor, medida em termos de mudança na saída para uma alteração no sinal de entrada. É uma referência à habilidade do sensor em detectar movimento e é normalmente especificada em $\mathrm{mV} / \mathrm{g}$;

- Fundo de escala ("Full-scale range"): é a aceleração máxima que o dispositivo pode medir e é geralmente ditada pela aplicação pretendida para o acelerômetro. Por 
exemplo, se um acelerômetro é necessário para acionar um sistema de airbag automotivo, \pm 50 g é normalmente utilizado (COULTATE, 2007);

- Direção: acelerômetros de um único eixo são projetados para detectar acelerações sobre um eixo específico. Para a maioria das aplicações são necessários acelerômetros tri-axiais, os quais podem detectar acelerações em qualquer plano;

- Largura de Banda ("Bandwidth"): é a faixa de frequências para a qual o sensor é aplicável. É normalmente especificado em $\operatorname{Hertz}(\mathrm{Hz})$, sendo tipicamente limitada a $\frac{1}{5}$ da primeira frequência de ressonância (HARRIS; CREDE, 1976);

- Estabilidade: define o quão constante é o sinal de saída em condições de entrada constantes, sendo a alteração na saída chamada de deriva ("drift"). Acelerômetros para uso em aplicações de alto desempenho (aeroespaciais), devem apresentar alta estabilidade e por isso são muito mais caros que os utilizados em produtos de consumo, como videogames e celulares. O gráfico da Fig. 1.1, adaptado de Jean-Michel (2004), ilustra a importância desta característica na definição do preço de um sensor;

- Resolução: menor nível de aceleração detectável pelo sensor e é limitada pelo nível de ruído do sensor. É normalmente especificada em mili-g $(m g)$ ou micro- $g(\mu g)$;

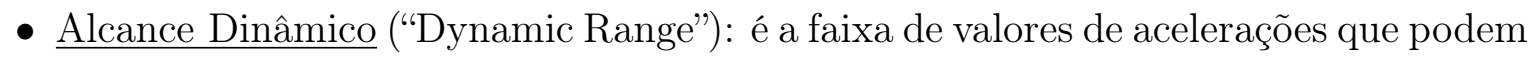
ser medidas pelo sensor. O limite inferior é determinado pela resolução do dispositivo e o superior pela sua saturação, que é o ponto a partir do qual o sensor perde a linearidade na sua resposta;

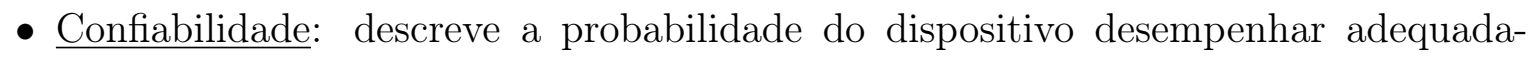
mente suas funções, durante um período de tempo especificado e dentro de condições operacionais pré-estabelecidas;

- $\underline{\text { Custo: }}$ tem importância menor para dispositivos de alto desempenho, no entanto, é talvez a característica mais importante em aplicações de consumo.

A norma IEEE 528-2001 (IEEE, 2001) apresenta uma listagem completa de termos e definições relacionadas com sensores inerciais. Em Kaajakari (2009) também são discutidas as principais especificações que definem o desempenho de sensores.

\subsection{Acelerômetros MEMS}

Sistemas microeletromecânicos, ou "Micro-Electro-Mechanical Systems (MEMS)", são dispositivos projetados em escala micrométrica. Através do uso de técnicas de microfabrica- 


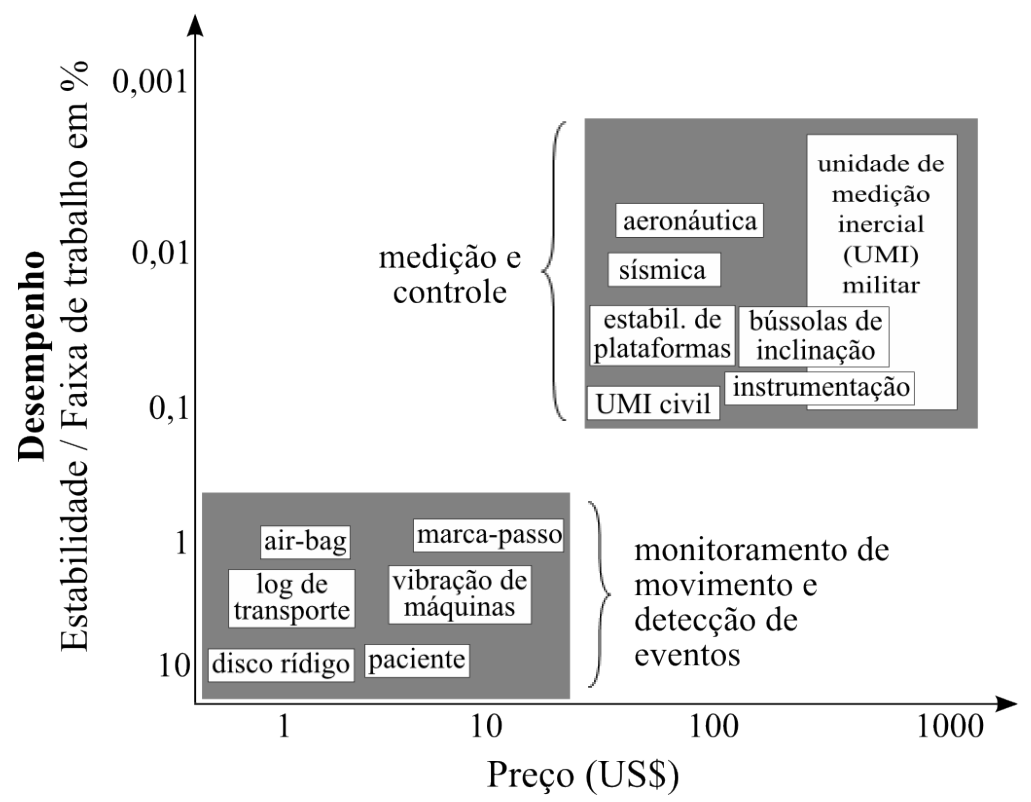

Figura 1.1: Correlação entre preço e desempenho de sensores.

ção, adaptadas da indústria de Circuitos Integrados (CIs), é realizada a integração entre estruturas móveis, sensores, atuadores e eletrônica, tornando possível a implementação de sistemas completos miniaturizados. A microeletrônica é o cérebro destes sistemas, possibilitando uma incrível capacidade de processamento de dados, já a tecnologia MEMS acrescenta olhos, ouvidos, narizes e músculos aos mesmos. Dessa forma, níveis sem precedentes de funcionalidade e sofisticação podem ser colocados em um pequeno chip de silício a um custo relativamente baixo.

O tamanho e a massa de um sensor podem alterar significativamente as características do objeto a ser monitorado, o que reforça a aplicação da tecnologia MEMS no desenvolvimento de sensores. Acelerômetros estão entre os dispositivos MEMS mais comercializados hoje em dia, com venda anual em todo o mundo superior a 100 milhões de unidades e crescente a cada ano (KAAJAKARI, 2009). Historicamente, a indústria automotiva tem sido a grande responsável por esse crescimento: atualmente, a maioria dos carros possui sensores de alta aceleração e choque para a liberação da almofada de ar (air-bag), além de sensores de baixa aceleração que são utilizados na suspensão ativa e controle de estabilização do veículo (MACDONALD, 1990).

Além da alta demanda da indústria automotiva por acelerômetros MEMS de baixo ou médio desempenho, a procura por dispositivos de alto desempenho visando navegação inercial, veículos não tripulados dos tipos aquáticos e aéreos, sismógrafos, instrumentos espaciais e aplicações militares, tem aumentado consideravelmente recentemente, devido principalmente ao diminuto tamanho, baixa dissipação de potência e alto desempenho (BARBOUR; SCHMIDT, 1998). 
Nos últimos seis anos, graças à queda significativa no preço dos acelerômetros MEMS, produtos de consumo também começaram a incorporá-los, proporcionando aos seus usuários experiências inovadoras. Uma das empresas pioneiras foi a Nintendo, que, em 2006, anunciou a incorporação do acelerômento ADXL330 iMEMS no controle do videogame Nintendo Wii (Fig. 1.2). Seguindo os seus passos, diversos fabricantes de celulares passaram a incluir acelerômetros em seus modelos para, entre outras coisas, indicar se o mesmo está na posição vertical ou horizontal e assim rotacionar a tela adequadamente, facilitando a leitura de conteúdos pelo usuário.

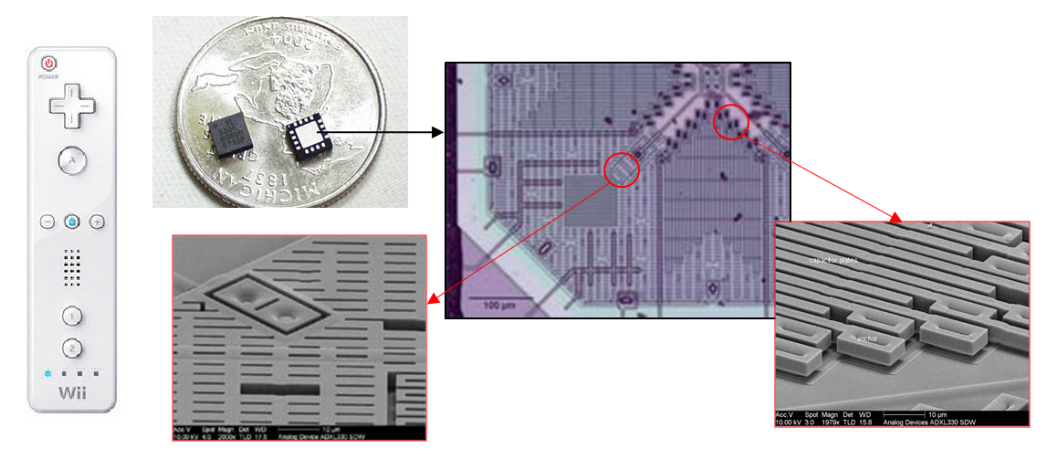

Figura 1.2: O ADXL330 mede $4 \mathrm{~mm}$ x $4 \mathrm{~mm}$ x 1,45mm.

Muitas outras aplicações de consumo já estão bastante difundidas: acelerômetros são utilizados por corredores profissionais para determinar sua velocidade, em câmeras digitais para estabilizar a imagem e em notebooks para detectar um princípio de queda livre e assim travar o disco rígido, protegendo-o de impactos. Com a contínua queda nos preços, o número de aplicações para acelerômetros MEMS deverá crescer nos próximos anos.

Acelerômetros MEMS para aplicações de alto desempenho foram discutidos e revisados em Krishnan et al. (2007), incluindo um estudo comparativo entre as características de diversos dispositivos comerciais. Já micro-acelerômetros de baixa a média resolução foram revisados em Bochobza-Degani et al. (2000) e Macdonald (1990). A Fig. 1.3 (KRISHNAN et al., 2007) mostra intervalos típicos de aceleração e largura de banda necessárias para as diferentes aplicações.

Os dois projetos mais comumente adotados em acelerômetros MEMS do tipo capacitivo são aqueles com sensibilidade à acelerações paralelas (COULTATE et al., 2008; LUO et al., 2002; MUKHERJEE; ZHOU; FEDDER, 1999) e perpendiculares (ALVAREZ et al., 2009; TAKAO; FUKUMOTO; ISHIDA, 2001; RUDOLF et al., 1990) à superfície do dispositivo. Eles são geralmente implementados, respectivamente, através de técnicas de microfabricação de superfície ("surface micromachining") e de volume ("bulk micromachining") (MADOU, 2002). Muito simplificadamente, pode-se dizer que microfabricação de superfície produz 


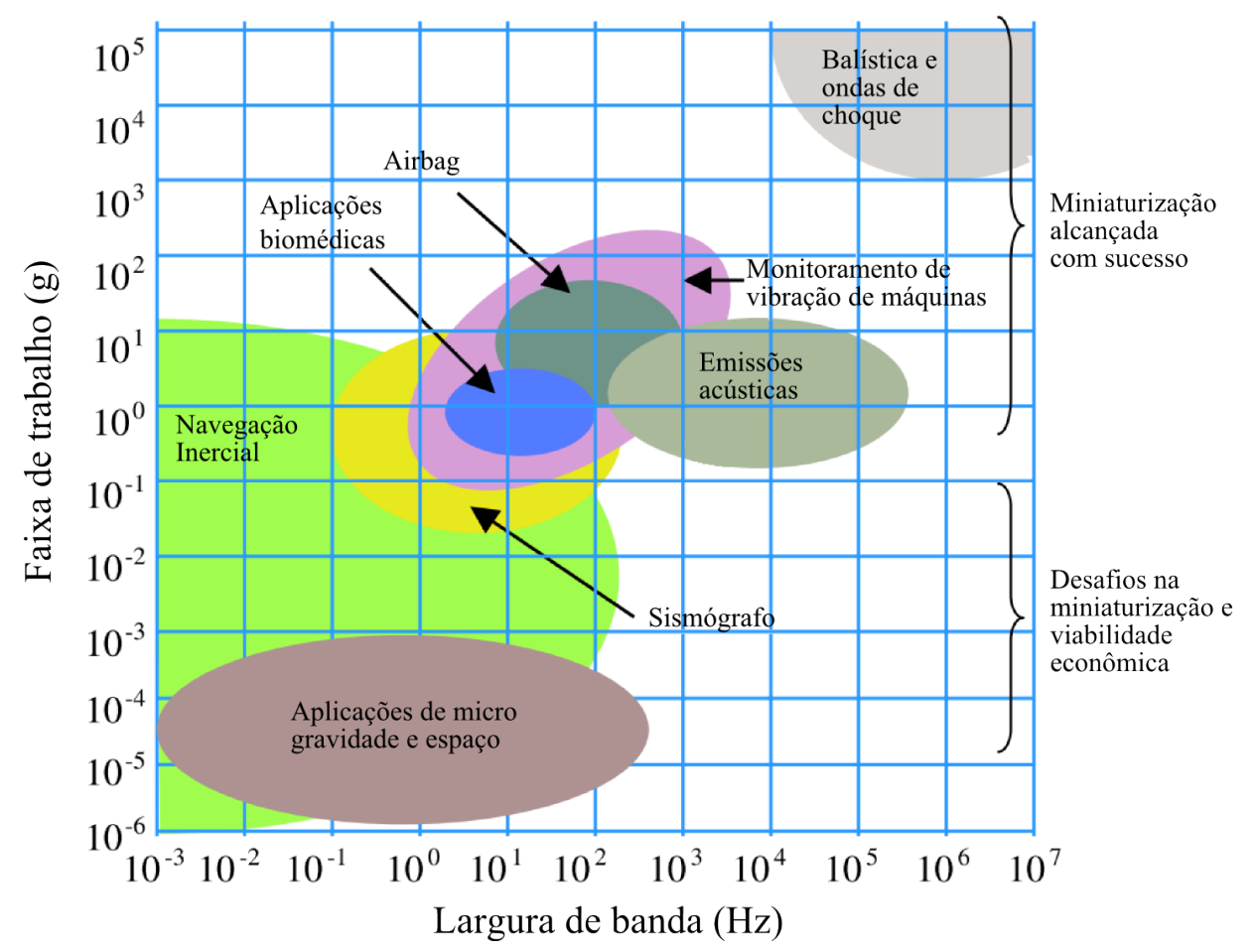

Figura 1.3: Faixa de trabalho contra largura de banda necessária para aplicações diversas.

estruturas finas, enquanto a de volume produz estruturas espessas.

Acelerômetros do primeiro tipo (Fig. 1.4) normalmente possuem eletrodos em formato de pentes ("comb-drives") e massa inercial pouco espessa, limitando assim o seu desempenho. Tipicamente, a resolução de acelerômetros de superfície comerciais está na faixa de mili-g $(m g)$ (BELIVEAU et al., 1999). Por outro lado, acelerômetros fabricados em volume ("bulk"), como o da Fig. 1.5, podem contar com massas inerciais muito maiores, permitindo que maiores resoluções e sensibilidades sejam alcançadas. Diversos autores já demonstraram resoluções próximas de $\mu g$ (CHAE; KULAH; NAJAFI, 2004; AMINI; AYAZI, 2005; YAZDI; NAJAFI, 2000; PARK et al., 1998; RUDOLF et al., 1990), que é o nível de desempenho necessário para navegação inercial. Neste trabalho, serão considerados apenas dispositivo desta segunda classe.

Em geral, acelerômetros do tipo "bulk" são fabricados utilizando três lâminas de silício espessas, coladas anodicamente uma sobre a outra, dando origem a dois conjuntos de capacitores de placas paralelas. A camada intermediária, o eletrodo móvel, é obtida por processos de corrosão e consiste de uma grande massa de prova suspensa por uma ou mais vigas. Ela é separada das lâminas superior e inferior por um pequeno espaço (gap), geralmente preenchido por ar ambiente (material dielétrico). A Fig. 1.6 ilustra a seção transversal de um projeto típico. 


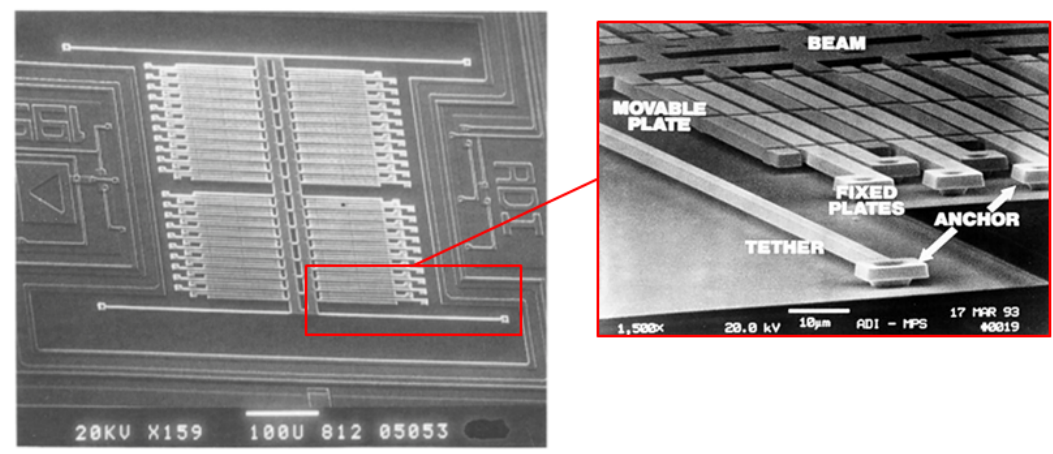

Figura 1.4: ADXL50: um dos primeiros acelerômetros de superfície fabricados pela empresa Analog Devices (KUEHNEL; SHERMANB, 1994).

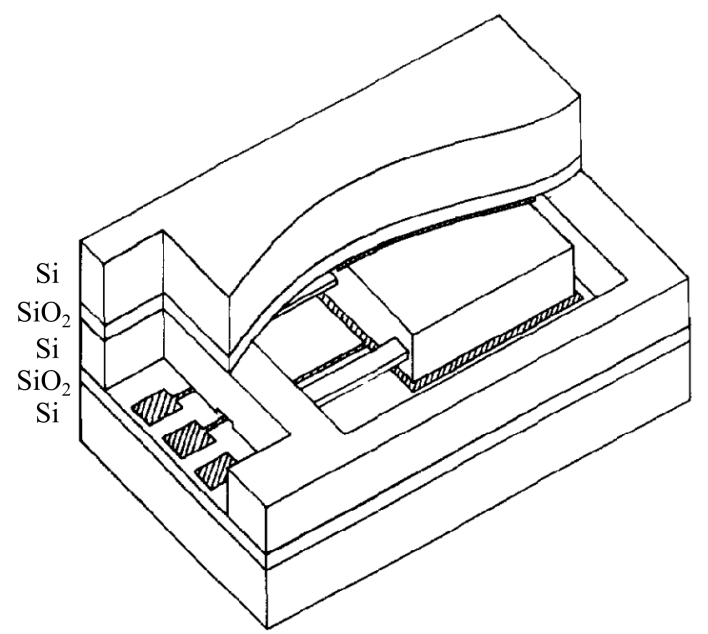

Figura 1.5: Um dos primeiros acelerômetro "bulk" apresentados na literatura (RUDOLF et al., 1990).

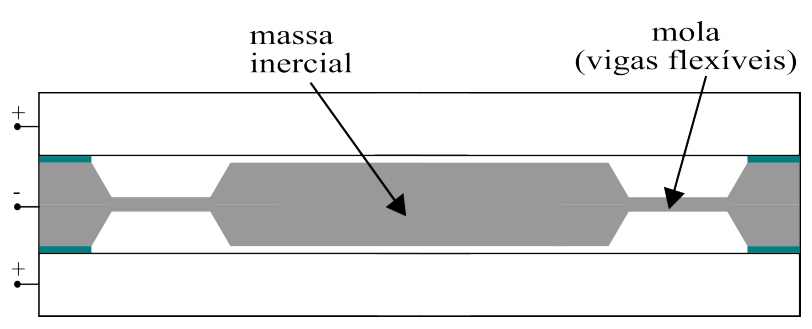

Figura 1.6: Seção transversal de um projeto típico de acelerômetros do tipo "bulk".

A principal característica que distingue um projeto de outro é a configuração das vigas que sustentam a massa ou eletrodo móvel. A massa de prova pode estar suspensa por uma ou mais vigas retas em balanço (ROYLANCE; ANGELL, 1979; RUDOLF et al., 1990), por uma viga em torção (SELVAKUMAR; AYAZI; NAJAFI, 1996) ou por varias vigas dobradas em balanço (TAKAO; FUKUMOTO; ISHIDA, 2001; QIAO et al., 2009). Topologias em ponte ou altamente simétricas com quatro ou mais vigas (SEIDEL et al., 1990; YAZDI; NAJAFI, 2000) têm sido amplamente adotadas atualmente por possuírem baixa sensibilidade à acelerações 
transversais, que são indesejáveis para sensores unidirecionais. Algumas topologias típicas são apresentadas na Fig. 1.7.

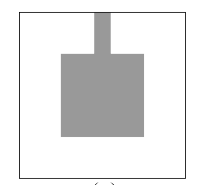

(a)

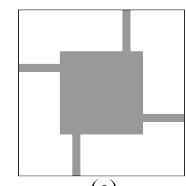

(e)

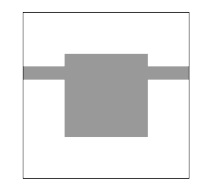

(b)

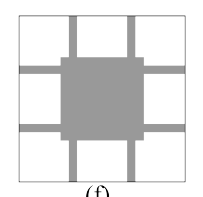

(f)

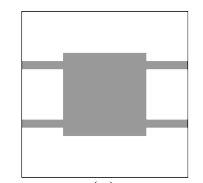

(c)

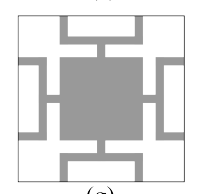

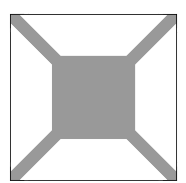

(d)

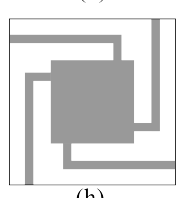

(h)

Figura 1.7: Topologias típicas para acelerômetros do tipo "bulk":(a) uma única viga em balanço, (b) viga em torção, (c) estrutura em ponte com quatro vigas, (d),(e),(f) configurações simétricas com vigas retas, (g),(h) configurações simétricas com vigas dobradas.

\subsection{Contexto do Projeto}

O autor e o seu orientador fazem parte da equipe do projeto Acelerômetro de Alto Desempenho (AcelerAD), financiado pela Financiadora de Estudos e Projetos (FINEP) e executado pelo Instituto de Estudos Avançados (IEAv), que está sendo realizado em regime de transferência de tecnologia da Suíça para o Brasil. As instituições envolvidas são o IEAv, a Escola Politécnica da Universidade de São Paulo (EPUSP), o Centro de Tecnologia da Informação Renato Archer (CTI) e o Centre Suisse d'Electronique et de Microtecnique da Suíça (CSEM).

O CSEM tem a responsabilidade de executar o projeto e simulação do acelerômetro, eletrônica e empacotamento, com acompanhamento das demais instituições de pesquisa. O processo completo foi inicialmente realizado nas instalações do CSEM, na Suiça. As especificações do dispositivo são discutidas na Seção 5.3 e serão buscadas no regime de "best effort", isto é, sem garantia de que as mesmas sejam atendidas. Na medida em que os processos de fabricação foram se estabelecendo, buscou-se reprodutibilidade do resultados no Laboratório de Sistemas Integráveis (LSI) da EPUSP.

O projeto teve início em Maio de 2010 e no início de 2012 um lote inicial de 50 acelerômetros foi enviado ao IEAv e testado para a conformidade com as especificações. Ao término do projeto, o dispositivo deverá ser fabricado e ensaiado totalmente no Brasil, ainda com assessoria do CSEM no acompanhamento técnico, porém sem dependência tecnológica. A topologia proposta está ilustrada na Fig. 1.8.

O objetivo principal do projeto é estimular as atividades na área de MEMS no Brasil 

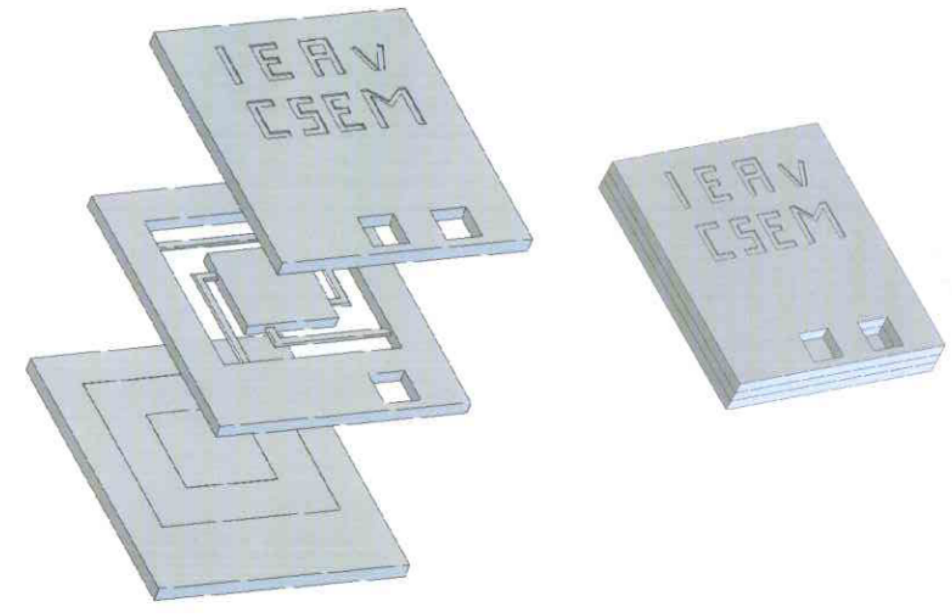

Figura 1.8: Topologia do Acelerômetro proposta pelo CSEM.

e desenvolver pessoas que dominem as etapas de projeto, simulação, fabricação e caracterização de dispositivos MEMS de alto desempenho, no caso um acelerômetro do tipo eletrostático. As principais responsabilidades do autor no projeto são: (a) modelagem e simulação do acelerômetro proposto pelo CSEM, utilizando o software comercial Comsol; (b) acompanhamento e análise crítica dos resultados obtidos pelo CSEM de maneira a garantir que as especificações de projeto do acelerômetro sejam efetivamente atingidas; (c) aumento do desempenho do acelerômetro proposto pelo CSEM através da utilização de métodos de otimização.

Esta última é o foco principal deste trabalho. Espera-se que os resultados aqui obtidos possam contribuir diretamente em uma segunda etapa do projeto AcelerAD, na qual, sem mais dependência tecnológica, uma versão otimizada do sensor será concebida, fabricada e testada no Brasil, assegurando assim o domínio pleno desta tecnologia no País.

\subsection{Objetivos}

Os objetivos específicos deste trabalho estão alinhados com os do projeto AcelerAD. Em primeiro lugar, a geometria proposta pelo CSEM é reavaliada, de maneira a assegurar que ela é realmente adequada e que conseguirá satisfazer todos os requisitos de projeto. Para isso, é desenvolvido um algoritmo de Otimização Paramétrica, no qual as diversas incertezas envolvidas no problema, como variações geométricas e de propriedades do material, também são consideradas, possibilitando assim o controle adicional sobre a confiabilidade do microssistema.

Em segundo lugar, o Método da Otimização Topológica, uma técnica sistemática de 
projeto, é utilizado para se propor uma topologia ótima para as vigas flexíveis do sensor. Espera-se com essa ferramenta atingir um patamar de desempenho completamente novo.

Em ambos estudos são considerados especialmente os requisitos de sensibilidade, largura de banda e área ("footprint area") dos micro-acelerômetros.

\subsection{Motivação e Justificativa}

Entre outras aplicações, acelerômetros de alto desempenho são dispositivos fundamentais para navegação inercial, controle de aeronaves e de mísseis de última geração. Por isso, são de difícil aquisição e, normalmente, estão indisponíveis para compra no mercado internacional. O domínio de tal tecnologia permitirá ao Brasil reduzir sua dependência nessa área estratégica para a missão da Força Aérea. Atualmente, o País investe pesado na independência tecnológica em navegação inercial, no entanto, acelerômetros continuam sendo importados e não há um desenvolvimento em curso que seja capaz de suprir as necessidades de médio e longo prazo.

A tendência mundial da tecnologia, em sua forma mais avançada, baseia-se largamente na tecnologia de sensores MEMS. Estes sensores podem ser fabricados em massa com elevada reprodutibilidade, além de possuírem características altamente desejáveis nas aplicações aeroespaciais, como baixo tempo de resposta, baixo consumo de energia, diminutos volume e peso e elevada resistência mecânica a choques e vibrações. Porém, os sensores disponíveis para compra no mercado internacional não atendem requisitos inerciais, o que também afeta empresas nacionais com competitividade global, como a Petrobrás e a Embraer.

Como explicado anteriormente, o projeto ocorrerá em regime de transferência tecnológica da Suíça para o Brasil. Para que a independência tecnológica seja efetiva, além de se conseguir reproduzir os resultados obtidos no exterior, é necessário também o domínio sobre as fases iniciais do ciclo de projeto, com as quais as instituições brasileiras envolvidas pouco contribuíram e que foram entregues praticamente prontas pelo CSEM. Entre elas, talvez uma das mais importantes seja a etapa de concepção e definição da geometria do acelerômetro.

Como é possível constatar a partir da análise da Fig. 1.7, uma enorme variedade de topologias para micro-acelerômetros eletrostáticos já foram propostas na literatura. A escolha deve ser baseada na aplicação final objetivada para o dispositivo. No entanto, é necessária muita experiência por parte do projetista para essa tomada de decisão, já que os requisitos de desempenho são em geral conflitantes. Além disso, não há estudos 
na literatura que se propõem a encontrar a topologia ótima para as vigas flexíveis de micro-acelerômetros, em geral parte-se de uma configuração pré-estabelecida e busca-se apenas otimizar os seus parâmetros geométricos.

Este trabalho busca, portanto, contribuir nestas duas frentes. Técnicas de simulação, projeto e otimização serão utilizadas para explorar sistematicamente o universo de soluções possíveis e assim propor versões otimizadas para o acelerômetro. Uma nova perspectiva também poderá ser ganha através da inclusão, em parte destes estudos, das aleatoriedades envolvidas no problema.

De forma mais ampla, este trabalho contribui para o desenvolvimento, fixação e domínio desta importante tecnologia de sensoriamento no País. 


\section{Otimização de Acelerômetros MEMS}

\subsection{Introdução}

Desde sempre o projeto de estruturas ocupa grande parte dos esforços dos engenheiros. Mesmo sendo um atividade antiga, as fases do processo não se alteraram muito ao longo do tempo. Inicialmente definem-se os materiais e a proposta preliminar de uma geometria e em seguida verifica-se se os requisitos de projeto solicitados estão sendo atendidos. Porém, muito mais do que apenas verificar o atendimento aos requisitos, o engenheiro deve buscar sempre melhorar o custo-benefício da sua solução. Essa busca pela melhor solução é realizada com o auxílio de técnicas de otimização.

No projeto de sensores MEMS também é fundamental a utilização de técnicas de otimização, já que os seus diversos requisitos de desempenho são, na maioria das vezes, conflitantes, isto é, se o projeto é modificado para melhorar uma característica, as demais são inevitavelmente afetadas.

No caso de acelerômetros MEMS a necessidade de se obter soluções de compromisso é evidenciada através do seguinte exemplo. Para se conseguir alta sensibilidade é necessário diminuir o espaçamento (gap) entre os eletrodos e aumentar o tamanho da massa móvel (área e espessura). No entanto, a redução do gap implica na diminuição do alcance dinâmico do sensor e no aumento do amortecimento devido ao filme fino de ar ("squeeze film damping") (BAO; YANG, 2007) e consequentemente na redução do tempo de resposta. Além disso, um gap muito pequeno, combinado com uma grande massa móvel e com eventuais constantes de molas baixas, pode reduzir consideravelmente a voltagem de "pull-in" (KAAJAKARI, 2009), resultando no colapso dos eletrodos para baixas voltagens aplicadas.

Um segundo agravante é que devido a complexidade dos processos de fabricação de sensores MEMS, cada novo protótipo construído é muito caro e por isso métodos de tentativa e erro costumam ser proibitivos.

Por estas razões, técnicas de otimização são regularmente utilizadas na fase de projeto 
de sensores MEMS, com o objetivo de reduzir o tempo de desenvolvimento e os custos envolvidos, ajudando o projetista a explorar os "trade-offs" de forma eficiente.

\subsection{Técnicas de Otimização}

Basicamente, a otimização estrutural busca a melhor configuração possível de maneira a extremizar uma dada funcão objetivo e simultaneamente satisfazer as restrições do problema. As três abordagens conhecidas para se obter configurações ótimas são: otimização paramétrica ("size optimization"), otimização de forma ("shape optimization") e otimização topológica ("topology optimization").

A primeira delas, a Otimização Paramétrica (OP), parte de uma forma já estabelecida previamente e adota algumas características geométricas (por exemplo, as dimensões $b$, $t$ e $h$ da viga em "I" ilustrada na Fig. 2.1) como variáveis de projeto, que são os únicos parâmetros que podem ser alterados durante o processo de otimização. Utiliza-se um algoritmo computacional (otimizador) para encontrar a combinação desses parâmetros que resultam em um projeto ótimo, isto é, a configuração que otimiza uma dada função objetivo, por exemplo, maximização da rigidez estrutural sujeita a restrição de volume máximo de material a ser utilizado.
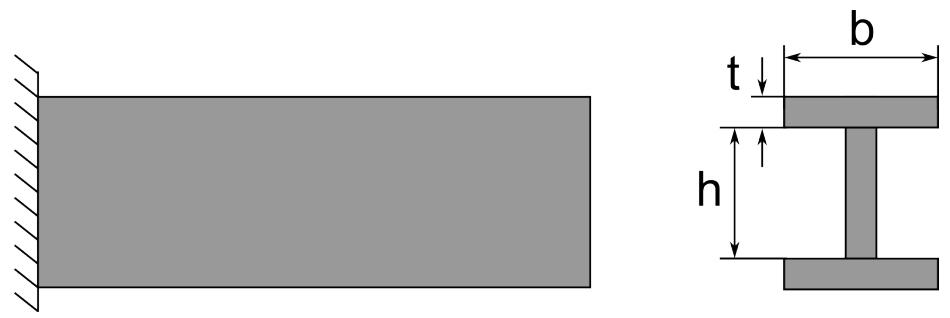

Figura 2.1: otimização paramétrica.
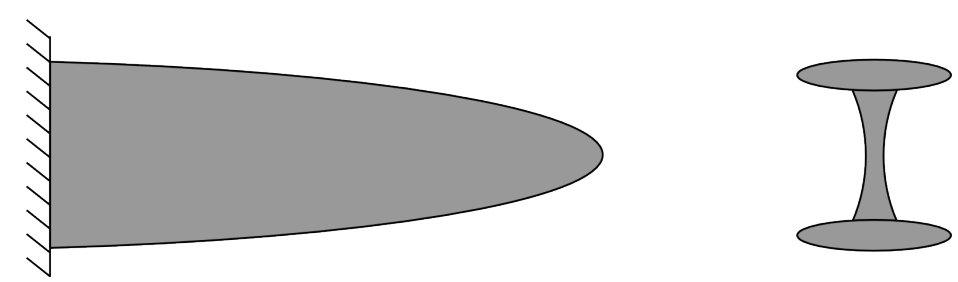

Figura 2.2: otimização de forma.

Na segunda abordagem (Fig. 2.2) parametrizam-se os contornos da estrutura através de curvas "splines" e os parâmetros que definem essas curvas (pontos de controle) constituem as variáveis de projeto. Uma "spline" é uma curva definida matematicamente por dois ou mais pontos de controle. Os pontos de controle que ficam na curva são chamados 

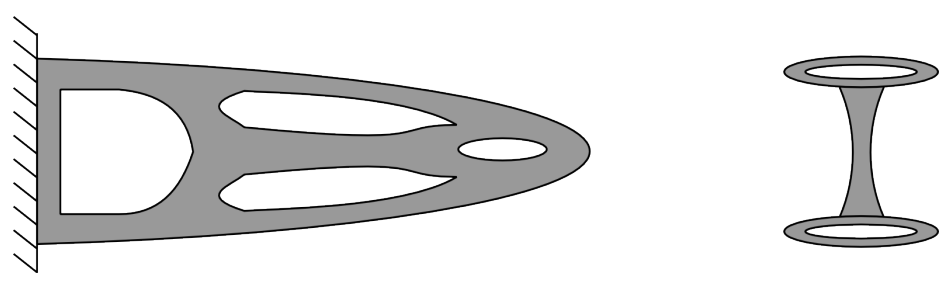

Figura 2.3: otimização topológica.

de nós, os demais pontos definem a tangente à curva em seus respectivos nós. Da mesma forma que na otimização paramétrica, utiliza-se um otimizador para encontrar a combinação ótima desses parâmetros. A otimização de forma é considerada mais genérica que a paramétrica justamente por permitir a alteração da forma da estrutura e assim expandir o espaço de soluções possíveis para o problema. No entanto, como o Método dos Elementos Finitos (MEF) costuma ser empregado no processo de otimização, é necessário que o mesmo acompanhe as mudanças de forma na estrutura de maneira eficiente, o que traz a necessidade de complexos algoritmos de remalhamento para uma análise adequada das mudanças na estrutura durante a otimização, que pode gerar elementos demasiadamente distorcidos, comprometendo os resultados da análise.

Finalmente, a Otimização Topológica (OT) busca a distribuição ótima de material no interior da estrutura, permitindo a criação de "vazios" nas regiões onde não houver necessidade de material (Fig. 2.3). As pseudo-densidades de material em cada ponto costumam ser adotadas como variáveis de projeto e o otimizador deve encontrar a combinação de densidades dos elementos que produza uma estrutura otimizada. A OT, também conhecida como otimização de leiaute ("layout"), é a abordagem mais genérica entre as aqui apresentadas, sendo as configurações obtidas através dessa abordagem superiores em desempenho quando comparadas aos dois métodos anteriores. Além disso, neste método é eliminado o problema de remalhamento da malha de elementos finitos, pois se trabalha desde o início com um domínio fixo, com cargas e restrições pré-estabelecidas. Esse método será analisado em detalhe no Capítulo 3.

Essencialmente todos os métodos apresentados poderiam ser considerados como paramétricos, no entanto, na literatura sobre otimização costuma-se agrupá-los nos três grupos expostos acima devido às grandes diferenças entre as suas implementações.

Até o momento, grande parte das pesquisas em otimização de micro acelerômetros capacitivos focou-se principalmente em análises paramétricas. Alvarez et al. (2009) buscou maximizar a largura de banda de um acelerômetro "bulk". Liu, Jiang e Wang (2009) implementaram uma otimização robusta (FRANGOPOL, 2008) considerando tanto a largura de banda quanto a sensibilidade de um dispositivo similar. Desrochers, Pasini e Angeles 
(2010) primeiro realizaram uma otimização de forma nas juntas vivas ("hinges") utilizadas em um dispositivo "bulk" e, então, recorreram à otimização paramétrica para maximizar a sensibilidade e minimizar a razão entre as duas primeiras frequências naturais, de forma a diminuir a sensibilidade cruzada (transversal ao eixo principal de sensoriamento). Todos utilizaram modelagem computacional baseada no MEF em seus trabalhos.

Já Mukherjee, Zhou e Fedder (1999) e mais recentemente Coultate et al. (2008), Tosserams, Etman e Rooda (2010) e Engesser et al. (2010) modelaram analiticamente um acelerômetro semelhante aos da família ADXL da empresa Analog Devices (ANALOGDEVICES, 2010) e também propuseram projetos ótimos considerando diferentes requisitos. O primeiro considerou a minimização do ruído e da área do dispositivo, de forma separada e combinada, além da maximização do fundo de escala. O segundo também buscou a maximização do fundo de escala, além da minimização da aceleração limite. Por fim, Tosserams, Etman e Rooda (2010) e Engesser et al. (2010) objetivaram a minimização da área do dispositivo, sendo que o último também propôs várias técnicas para encontrar mais facilmente o mínimo global de problemas de otimização envolvendo sensores do tipo MEMS.

Na literatura encontram-se poucos artigos sobre otimização topológica de MEMS eletrostáticos de maneira geral e menos ainda abordando especificamente acelerômetros. Krishnan e Ananthasuresh (2008), Pedersen e Seshia (2004) propuseram projetos ótimos para as vigas de suspensão de acelerômetros de superfície, com abordagens ligeiramente distintas. Já Raulli e Maute (2005), Liu, Maute e Frangopol (2007) abordaram o complexo problema eletromecânico completo e propuseram topologias ótimas para mecanismos inversores de força, utilizando análise escalonada e monolítica, respectivamente. Até onde se sabe, não há nenhum artigo publicado especificamente sobre otimização topológica de micro-acelerômetros do tipo bulk, além de um trabalho do próprio autor (TEVES; SILVA, 2011) no qual são discutidas diferentes formulações para este problema, utilizando largura de banda e sensibilidade como funções objetivos.

Com base na revisão bibliográfica apresentada, conclui-se que sensibilidade, largura de banda, área e robustez estão entre os critérios mais comumente adotados no projeto de acelerômetros MEMS. Dessa forma, estes serão os critérios considerados neste trabalho.

\subsection{Otimização com confiabilidade}

Embora o potencial dos MEMS em melhorar aplicações existentes ou permitir o desenvolvimento de novas aplicações seja amplamente reconhecido, a prevalência desta tecnologia 
é prejudicada por problemas de confiabilidade, isto é, os dispositivos podem falhar antes que o tempo de vida requerido seja atingido ou então o seu desempenho pode se degradar rapidamente, caindo abaixo de níveis aceitáveis.

Incertezas associadas com as dimensões e as propriedades do material de microssistemas são inevitáveis devido a uma variedade de fatores, como erros ou imperfeições de fabricação, tensões térmicas residuais, superfícies irregulares, contaminação química, entre outros (KOVACS, 1998). Estas incertezas podem produzir tolerâncias superiores a 10\% (MADOU, 2002) em valores nominais e assim representam desafios significativos para a previsão realista do desempenho de microssistemas. Restringir as tolerâncias de fabricação para obter dimensões mais precisas nem sempre é possível. Além disso, o próprio carregamento ao qual o dispositivo está submetido pode sofrer variações dependendo das condições ambientais e operacionais.

A diferença entre o desempenho esperado e o real é ainda maior quando uma estrutura é otimizada, pois qualquer excesso de material acaba sendo removido, tornando a estrutura ótima ainda mais sensível a incertezas. Metodologias de projetos determinísticos convencionais lidam com a questão das incertezas através da utilização de fatores de segurança. No entanto, os fatores de segurança são calibrados para situações médias de projeto e por isso não conseguem garantir níveis de confiabilidade condizentes com condições de projeto específicas e com isso conduzem tipicamente a dois cenários: projetos conservadores, superestimados e por isso ineficientes; ou projetos inconscientemente perigosos, subestimados devido às incertezas presentes. Por isso, metodologias de otimização devem considerar os efeitos aleatórios de maneira mais consistente.

Duas principais metodologias foram propostas para contornar este problema: 1) Otimização de Projeto Robusto ou "Robust Design Optimization (RDO)", que visa minimizar a dispersão das respostas estruturais, medidas por momentos estatísticos de baixa ordem (RENAUD, 1997; MESSAC; ISMAIL-YAHAYA, 2002; COUlTATE, 2007); 2) Otimização de Projeto baseado em Confiabilidade ou "Reliability-based Design Optimization (RBDO)", que visa maximizar o desempenho com restrições probabilísticas, permitindo o projeto de estruturas com probabilidades de falha especificadas (ENEVOLDSEN; SøRENSEN, 1994; MAUTE; FRANGOPOL, 2003; ALLEN et al., 2004). Em outras palavras, o conceito de confiabilidade (ou seu complemento, a probabilidade de falha) do RBDO refere-se a ocorrência de eventos extremos, ao passo que a robustez do RDO refere-se à baixa dispersão das respostas estruturais, mesmo com grande variação dos parâmetros de entrada. Uma revisão mais detalhada sobre essas duas metodologias é apresentada em Schuëller e Jensen (2008) e detalhes de suas formulações e implementações podem ser encontrados em Frangopol 
(2008).

Neste trabalho foi adotado o RBDO. A seguir, a formulação de um problema genérico de RBDO é apresentada e a teoria associada é analisada. Cabe ressaltar que os métodos de otimização baseados em confiabilidade estão relativamente difundidos, são aplicados nas mais diversas áreas (MAUTE; FRANGOPOL, 2003; KHARMANDA et al., 2004; ALLEN et al., 2004; JUNG; CHO, 2004; YOUN et al., 2004; MOGAMI et al., 2006; MELLO, 2010) e que muitos esforços na área da teoria estão sendo realizados para torná-los cada vez mais eficientes (LIU; KIUREGHIAN, 1991; LEE; YANG; RUY, 2002; KHARMANDA; MOHAMED; LEMAIRE, 2002; QU; HAFTKA, 2004; YANG; GU, 2004; YOUN; CHOI, 2004b; AOUES; CHATEAUNEUF, 2010).

\subsubsection{Formulação genérica do RBDO}

Na presença de incertezas o problema de otimização pode incluir critérios de projeto determinísticos e probabilísticos. Esses últimos são, na maioria das vezes, incorporados nas restrições do problema, atuando para restringir uma probabilidade de falha específica, mas podem também estar presentes na função objetivo.

Uma formulação padrão para problemas determinísticos é descrita abaixo:

$$
\begin{array}{cl}
\underset{\mathbf{s}}{\operatorname{Minimizar}} & c(\mathbf{s}) \\
\text { Sujeito a } & g_{i}(\mathbf{s}) \geq 0 \\
& \mathbf{s}_{\mathbf{i n f}} \leq \mathbf{s} \leq \mathbf{s}_{\mathbf{s u p}}
\end{array}
$$

onde $c$ é a função objetivo ou de custo a ser minimizada, variando-se as variáveis de projeto $\mathbf{s}$ e ao mesmo tempo satisfazendo as restrições $g_{i}$ e os limites inferiores e superiores $\mathbf{s}_{\mathbf{i n f}}$ e S sup.

Em contraste, uma formulação RBDO típica é dada por:

$$
\begin{array}{cl}
\underset{\mathbf{s}}{\operatorname{Minimizar}} & \operatorname{Prob}(c(\mathbf{s}, \mathbf{r}) \geq \bar{c}) \\
\text { Sujeito a } & \bar{P}_{i}-\operatorname{Prob}\left(f_{i}(\mathbf{s}, \mathbf{r})<0\right) \geq 0 \\
& g_{i}(\mathbf{s}) \geq 0 \\
& \mathbf{s}_{\mathbf{i n f}} \leq \mathbf{s} \leq \mathbf{s}_{\text {sup }}
\end{array}
$$

onde $\mathbf{r}$ são as variáveis aleatórias. O objetivo é minimizar a probabilidade da função de custo $c(\mathbf{s}, \mathbf{r})$ ser maior do que $\bar{c}$. Um conjunto de restrições limita a probabilidade de falha associada com as funções de estado limite $f_{i}(\mathbf{s}, \mathbf{r})$, sendo que $f_{i}<0$ representa uma 
situação de falha. $\bar{P}_{i}$ é a probabilidade de falha máxima aceitável. Um segundo conjunto de restrições, $g_{i}$, contém todas as restrições determinísticas. Nesta formulação, genérica, assumem-se que as variáveis de projeto s podem ser determinísticas ou não-determinística, isto é, representam um parâmetro característico de uma distribuição estatística, como por exemplo a média ou o desvio padrão.

$$
\operatorname{Prob}(c(\mathbf{s}, \mathbf{r})-\bar{c} \geq 0)=\int_{c(\mathbf{s}, \mathbf{r})-\bar{c} \geq 0} f_{R}(\mathbf{r}) d \mathbf{r}
$$

Na solução do problema (2.2), umas das principais dificuldades reside em encontrar a Função Densidade de Probabilidades (FDP) $f_{R}(\mathbf{r}$ ) associada a $c-\bar{c}$ (função objetivo) ou a $f_{i}$ (restrições do problema), explicitamente nas variáveis aleatórias r. Mesmo nos casos em que $f_{R}(\mathbf{r})$ é conhecida, em geral não é possível determinar analiticamente a integral ilustrada na Eq.(2.3), que está associada ao cálculo de probabilidades.

Nesses casos, dois métodos aproximados são muitas vezes aplicados: simulações estocásticas, como por exemplo Monte Carlo, ou método dos momentos (HASOFER; LIND, 1974). O cálculo da probabilidade por simulação consome muito tempo, o que torna a sua utilização impraticável em algoritmos de otimização (AOUES; CHATEAUNEUF, 2010). Propõe-se, então, neste trabalho, a utilização de um método de momentos de primeira ordem ou "First-Order Reliability Method (FORM)" para o cálculo de probabilidades, o qual é descrito em seguida.

\subsubsection{Cálculo de Probabilidades pelo FORM}

A metodologia proposta para o cálculo das probabilidades é baseada no conceito do índice de confiabilidade $\beta$ e no FORM (MAUTE; FRANGOPOL, 2003; MADSEN H.O.; KRENK, 2006; FRANGOPOL, 2008; MELLO, 2010). Inicialmente, descreve-se o procedimento do cálculo de probabilidades no caso em que as funções de estado limite $c-\bar{c}$ e $f_{i}$ são lineares nas variáveis aleatórias e, logo em seguida, generaliza-se a análise através da aproximação pelo FORM. A primeira etapa serve de motivação e ajuda na explicação do método.

Chamando-se, genericamente, as funções de estado limite $c-\bar{c}$ e $f_{i}$ de $M$ tem-se, no caso em que são lineares, a seguinte representação:

$$
M=a_{1} r_{1}+\ldots+a_{n} r_{n}+b=\mathbf{A}^{T} \mathbf{r}+b
$$

onde $r_{i}(i=1,2, \ldots, n)$ são variáveis aleatórias quaisquer e $a_{i}(i=1,2, \ldots, n)$ e $b$ são coeficientes constantes. É importante ressaltar que as variáveis aleatórias consideradas neste trabalho são modeladas como variáveis gaussianas. 
Agora, suponha que é feita uma mudança de variável de tal forma que:

$$
\mathbf{r}=\mathbf{B u}+\mathbf{c} \quad \Rightarrow \quad \mathbf{u}=\mathbf{B}^{-1}(\mathbf{r}-\mathbf{c})
$$

onde $\mathbf{u}$ é um vetor de variáveis gaussianas mutuamente independentes de média nula e covariância unitária (espaço normal padrão), ou seja:

$$
\mu_{\mathbf{u}}=\mathbf{0} \quad \operatorname{Cov}\left[\mathbf{u}, \mathbf{u}^{\mathbf{T}}\right]=\mathbf{I}
$$

o que é mostrado ser possível de se realizar em Mello (2010). Dessa forma, tem-se que:

$$
M=\left(\mathbf{A}^{T} \mathbf{B}\right) \mathbf{u}+b+\mathbf{A}^{T} \mathbf{c}=\mathbf{A}_{\mathbf{1}}^{T} \mathbf{u}+b_{1}
$$

e, como variáveis gaussianas de covariância unitária são não-correlacionadas e, portanto, independentes, e a combinação linear de variáveis gaussianas independentes é também uma variável gaussiana, $\mathrm{M}$ é gaussiana de média:

$$
\mu_{M}=b+\mathbf{A}^{T} \mathbf{c}=b_{1}
$$

e variância:

$$
\sigma_{M}^{2}=\mathbf{A}^{T} \mathbf{B B}^{T} \mathbf{A}=\mathbf{A}_{\mathbf{1}}^{T} \mathbf{A}_{\mathbf{1}}
$$

Assim, a probabilidade de ocorrer um evento dado por $M \leq 0$ é (NETO; CYMBALISTA, 2000):

$$
\begin{aligned}
\operatorname{Prob}(M \leq 0)= & \frac{1}{\sqrt{2 \pi \mathbf{A}_{\mathbf{1}}^{T} \mathbf{A}_{\mathbf{1}}}} \int_{-\infty}^{0} e^{-\frac{1}{2 \frac{\left(\xi-b_{1}\right)^{2}}{\mathbf{A}_{\mathbf{1}}^{T} \mathbf{A}_{\mathbf{1}}}}} d \xi= \\
= & \frac{1}{2 \pi} \int_{-\infty}^{-\frac{b_{1}}{\sqrt{\mathbf{A}_{\mathbf{1}} T \mathbf{A}_{\mathbf{1}}}}} e^{-\frac{1}{2} \nu^{2}} d \nu=\Phi\left(-\frac{b_{1}}{\sqrt{\mathbf{A}_{\mathbf{1}}{ }^{T} \mathbf{A}_{\mathbf{1}}}}\right)
\end{aligned}
$$

onde $\Phi(\cdot)$ representa a distribuição normal padrão acumulada. A seguinte mudança de variável foi utilizada na segunda igualdade:

$$
\xi=\nu \sqrt{\mathbf{A}_{1}^{T} \mathbf{A}_{1}}+b_{1}
$$

Mudando-se um pouco de enfoque, é possível afirmar que a distância do hiperplano $M=0$ à origem é igual ao valor absoluto da projeção do vetor posição sobre o vetor unitário normal ao plano, como pode ser compreendido a partir da análise da Fig. 2.4. Um versor normal a $M=0$ no espaço das variáveis $\mathbf{u}$ (espaço normalizado) é $\frac{\mathbf{A}_{\mathbf{1}}}{\sqrt{\mathbf{A}_{\mathbf{1}}{ }^{T} \mathbf{A}_{\mathbf{1}}}} \mathrm{e}$, 


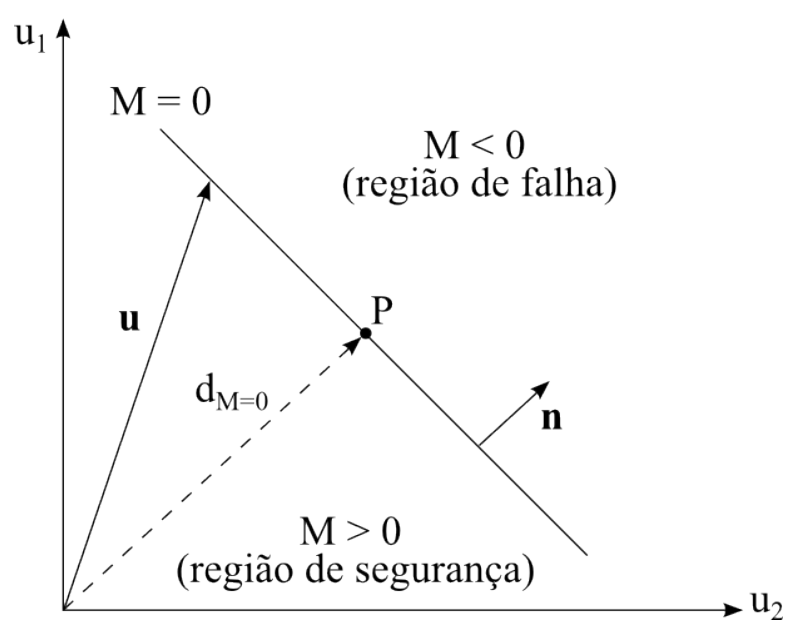

Figura 2.4: Espaço normal padrão 2D.

como a posição é dada pelo vetor $\mathbf{u}$, a distância mencionada é igual a:

$$
d_{M=0}=\frac{\mathbf{A}_{\mathbf{1}}}{\sqrt{\mathbf{A}_{\mathbf{1}}^{T} \mathbf{A}_{\mathbf{1}}}} \mathbf{u}=\left|\frac{b_{1}}{\sqrt{\mathbf{A}_{\mathbf{1}}^{T} \mathbf{A}_{\mathbf{1}}}}\right|=\beta
$$

sendo que na segunda igualdade utilizou-se o resultado da Eq. (2.7):

$$
M=0 \quad \Rightarrow \quad \mathbf{A}_{\mathbf{1}}^{T} \mathbf{u}=-b_{1}
$$

Voltando a Eq.(2.10), a probabilidade de falha, $P_{f}$ ou $\operatorname{Prob}(M \leq 0)$, pode ser dada alternativamente por:

$$
P_{f}=\Phi\left(-\frac{b_{1}}{\sqrt{\mathbf{A}_{\mathbf{1}}^{T} \mathbf{A}_{\mathbf{1}}}}\right)=\Phi\left(-\operatorname{sinal}\left(b_{1}\right) \beta\right)
$$

ou seja, por uma função da distância do hiperplano à origem, sendo o termo $\beta$ igual a essa distância. Tal termo é chamado de índice de confiabilidade para o caso especial em que $M$ é linear nas variáveis aleatórias. Generalizando-se, o índice de confiabilidade $\beta$ será definido como a distância entre a origem e a função de estado limite, $Q=0$, no espaço normalizado, sendo $Q$ uma função qualquer não necessariamente linear.

Para o cálculo da probabilidade de $M \leq 0$, uma função linear, não seria necessário definir a variável $\beta$. Porém, como já mencionado, o exposto acima serve apenas como motivação para o caso não-linear descrito a seguir em que $\beta$ tem papel fundamental.

Agora, considerando uma função não-linear $Q$ nas variáveis aleatórias, não se pode afirmar que a Eq.(2.14) ainda seja válida. Porém, no caso em que uma aproximação linear no ponto mais próximo da origem é satisfatória, ou seja, se a função não-linear é bem aproximada por uma função linear na vizinhança do ponto dado por $\beta$ no espaço 
normalizado, a equação é uma boa aproximação para a probabilidade de $Q \leq 0$. O cálculo da probabilidade empregando-se tal aproximação é conhecido por FORM, sendo o método mais utilizado na teoria de RBDO atualmente. É importante salientar que, mesmo que a função não-linear seja conhecida explicitamente nas variáveis aleatórias, não se pode dizer que a aproximação linear é satisfatória, sendo necessário, em primeiro lugar, obter a função no espaço normalizado (MADSEN H.O.; KRENK, 2006).

Mello (2010) avalia que a região que dá a maior contribuição à probabilidade de $Q \leq 0$ (ou $M \leq 0$ ) está localizada nas proximidades do ponto mais próximo à origem, por isso esse ponto é conhecido como 'ponto mais provável de falha' ou "Most Probable Failure Point (MPFP)". Assim, a aproximação da função não-linear pela linear no MPFP determina a precisão do FORM no cálculo das probabilidades envolvidas.

No espaço normal padrão, o MPFP é encontrado através da solução de um problema de otimização não-linear, com uma restrição de igualdade:

$$
\begin{array}{cl}
\underset{\mathbf{u}}{\operatorname{Minimizar}} & |\mathbf{u}|=\sqrt{\mathbf{u}^{T} \mathbf{u}} \\
\text { Sujeito a } & Q(\mathbf{s}, \mathbf{u})=0
\end{array}
$$

Um estudo comparativo dos algoritmos de otimização utilizados para resolver o problema (2.15) é realizado em Liu e Kiureghian (1991). Os autores comprovaram a robustez e a eficiência do algoritmo HL-RF (HASOFER; LIND, 1974; RACKWITZ; FIESSLER, 1978), que resolve um problema de otimização não-linear com uma restrição. Este é o algoritmo adotado neste trabalho. A fórmula de atualização deste método é dada por (LEE; YANG; RUY, 2002):

$$
\mathbf{u}^{(k+1)}=\frac{G_{\mathbf{u}^{(k)}}^{T} \mathbf{u}^{(k)}-Q\left(\mathbf{u}^{(k)}\right)}{G_{\mathbf{u}^{(k)}}^{T} G_{\mathbf{u}^{(k)}}} G_{\mathbf{u}^{(k)}}
$$

onde $G_{\mathbf{u}^{(k)}}=\left\{\frac{\partial Q}{\partial u_{1}}, \frac{\partial Q}{\partial u_{2}}, \ldots,{\frac{\partial Q}{\partial u_{n}}}^{T}\right\}$ é o gradiente da função de estado limite $Q$ em relação à u na iteração $k$. Várias iterações com o uso de (2.16) são necessárias para se encontrar a superfície de falha dada por $Q=0$. A busca iterativa pelo MPFP através de (2.16) é ilustrada na Fig. 2.5.

Consolidando o que foi discutido até aqui, a Fig. 2.6 mostra uma visão geral do processo FORM. Em primeiro lugar, as variáveis aleatórias $\mathbf{r}$ devem ser mapeadas no espaço normal padrão através de uma transformação

$$
\mathbf{u}=\mathbf{T}_{\mathbf{u}}(\mathbf{r})
$$

Como já visto, no caso de variáveis gaussianas, a transformação é dada por (2.5). Para 


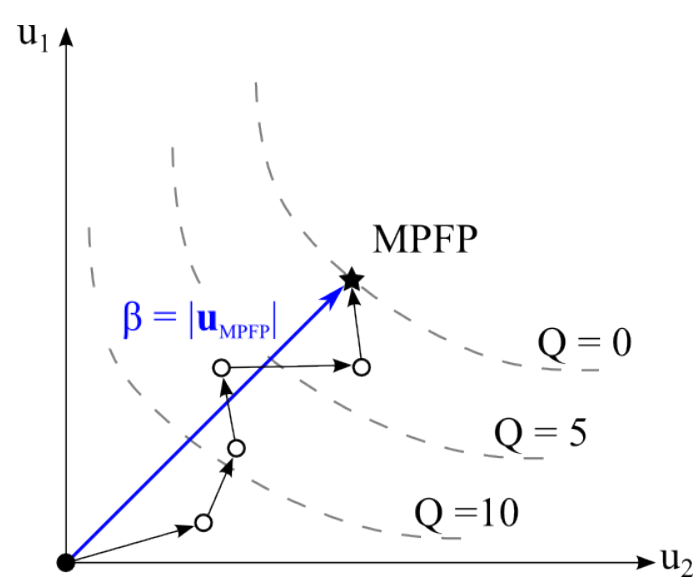

Figura 2.5: Histórico ilustrativo das iterações envolvidas na busca pelo MPFP.

casos mais genéricos, em que distribuições não-gaussianas estão envolvidas, o princípio da aproximação pela cauda normal (MADSEN H.O.; KRENK, 2006) pode ser utilizado:

$$
F_{r}\left(r_{i}\right)=\Phi\left(u_{i}\right)
$$

onde $F_{r}(\cdot)$ é a função densidade de probabilidades acumulada associada a variável aleatória $r_{i}$. A transformação $T_{u}$ faz com que o ponto médio no espaço-r corresponda a origem do espaço-u. Em seguida, a solução do problema (2.15), o MPFP, é obtida através de sucessivas iterações de (2.16). Finalmente, a probabilidade de falha $P_{f}$ é encontrada integrando-se a aproximação de primeira ordem da função de estado limite no MPFP: $P_{f}=\Phi(-\beta)$. No exemplo da Fig. 2.6, como a função de estado limite é concava em relação a origem, o valor de $P_{f}$ estará subestimado em relação ao valor exato.

Adotando-se desenvolvimento idêntico no cálculo de probabilidades para o caso do problema (2.2), são obtidos um MPFP e um índice de confiabilidade para cada restrição de probabilidade, e um para a função objetivo. Tal abordagem é conhecida na literatura relacionada a RBDO como 'abordagem do índice de confiabilidade' ou "Reliability Index Approach (RIA)" (ENEVOLDSEn; SøRENSEN, 1994; NIKOLAIDIS; BURDISSO, 1988). Nessa abordagem, o problema (2.2) costuma ser reescrito da seguinte maneira:

$$
\begin{array}{cl}
\underset{\mathbf{s}}{\operatorname{Maximizar}} & \beta(c(\mathbf{s}, \mathbf{r}) \geq \bar{c}) \\
\text { Sujeito a } & \beta\left(f_{i}(\mathbf{s}, \mathbf{r})>0\right)-\bar{\beta}_{i} \geq 0 \\
& g_{i}(\mathbf{s}) \geq 0 \\
& \mathbf{s}_{\mathbf{i n f}} \leq \mathbf{s} \leq \mathbf{s}_{\mathbf{s u p}}
\end{array}
$$

onde $\bar{\beta}_{i}$ é o índice de confiabilidade mínimo exigido. Note que as restrições probabilísticas são simplesmente substituídas pelas restrições de índice de confiabilidade. 
Espaço das variáveis randômicas $\underset{\mathbf{u}=\mathrm{T}_{\mathrm{u}}(\mathbf{r})}{\stackrel{\text { Transformac̃o }}{\longrightarrow}}$ Espaço normal padrão

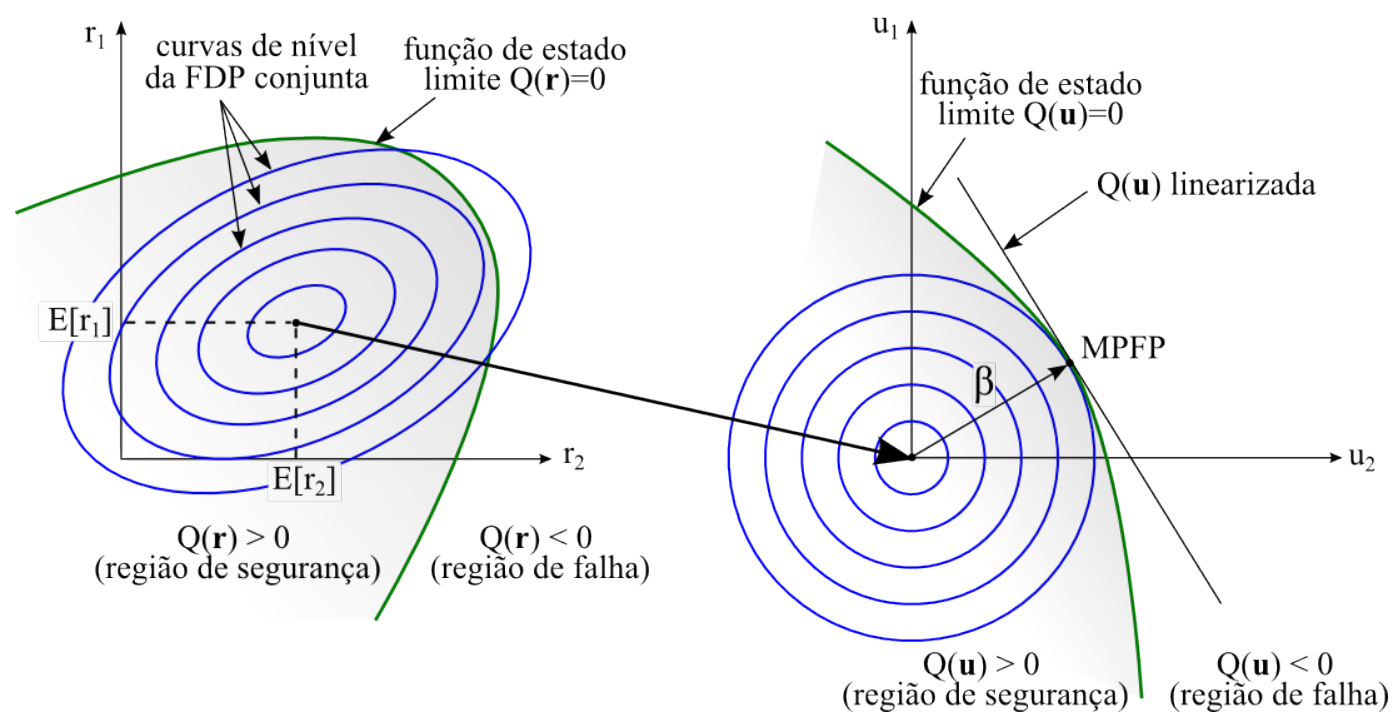

Figura 2.6: Visão geral do processo FORM.

Desta forma, a solução do problema (2.19) ou (2.2) ocorre em dois níveis, isto é, a cada iteração global, o laço externo resolve o problema de otimização em termos das variáveis de projeto s e o laço interno resolve o problema (2.15) para obtenção dos índices de confiabilidade.

De acordo com Maute e Frangopol (2003), em casos nos quais o projeto médio está muito longe da superfície de falha, a abordagem RIA pode afetar a robustez do procedimento global por problemas de convergência e assim um método mais robusto deve ser utilizado. Aoues e Chateauneuf (2010) apresentam um estudo comparativo entre diferentes abordagens já propostas na literatura para resolver o problema (2.2). Uma abordagem tão simples quanto o RIA, também em dois níveis, porém mais robusta, é o PMA (TU; CHOI; PARK, 1999; LEE; YANG; RUY, 2002), que será discutido em seguida.

\subsubsection{Método PMA}

A 'abordagem do desempenho-alvo' ou Performance Measure Approach (PMA) se baseia no princípio de que minimizar uma função complexa sob restrições simples é mais eficiente do que minimizar uma função simples sob restrições complexas (AOUES; CHATEAUNEuf, 2010). Para um dado índice de confiabilidade desejado $\bar{\beta}$, o seguinte problema 
de otimização é resolvido no espaço normal padrão:

$$
\begin{array}{cc}
\underset{\mathbf{u}}{\operatorname{Minimizar}} & Q(\mathbf{s}, \mathbf{u}) \\
\text { Sujeito a } & |\mathbf{u}|=\bar{\beta}
\end{array}
$$

Como o resultado de (2.20) deve coincidir com o resultado de (2.15) quando $\beta=\bar{\beta}$, a fórmula de atualização para a busca do problema (2.20) é dada por:

$$
\mathbf{u}^{(k+1)}=-\bar{\beta} \frac{G_{\mathbf{u}^{(k)}}}{\sqrt{G_{\mathbf{u}^{(k)}}^{T} G_{\mathbf{u}^{(k)}}}}
$$

O valor da função de estado limite $Q$ no ponto ótimo de (2.20) é chamado de 'desempenhoalvo' e representa o pior desempenho possível para o índice de confiabilidade $\bar{\beta}$ exigido. A solução deste problema é conhecida como 'ponto de desempenho mínimo exigido' ou "Minimum Performance Target Point (MPTP)". Em comparação com a formulação padrão RIA (2.15), é garantido que a restrição de igualdade em (2.20) pode ser satisfeita (MAUTE; FRANGOPOL, 2003). A robustez do PMA é estabelecida e comparada com a do RIA em Lee, Yang e Ruy (2002).

Como ilustrado na Fig. 2.7, o procedimento de cálculo do desempenho-alvo é o inverso do utilizado no cálculo do índice de confiabilidade. Em outras palavras, primeiro buscamse os pontos no espaço-u cuja distância da origem seja igual ao índice de confiabilidade desejado $\bar{\beta}$. Posteriormente, o ponto em que a equação de estado limite $Q$ adquire valor mínimo é selecionado.

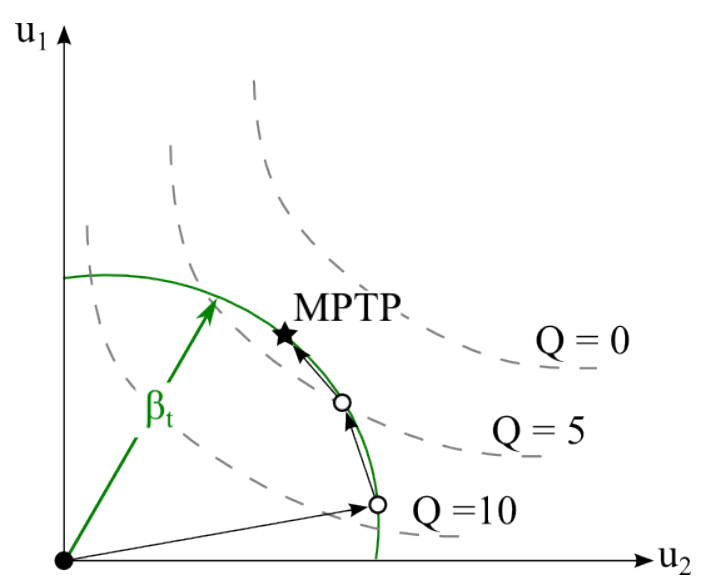

Figura 2.7: Histórico ilustrativo das iterações envolvidas na busca pelo MPTP.

Como os requisitos de confiabilidade já foram assegurados na análise de confiabilidade, o problema de otimização com o PMA é normalmente posto da seguinte forma: 


$$
\begin{array}{cl}
\underset{\mathbf{s}}{\operatorname{Maximizar}} & f_{c}(\mathbf{s}, \mathbf{r}) \\
\text { Sujeito a } & f_{i}(\mathbf{s}, \mathbf{r}) \geq 0 \\
& g_{i}(\mathbf{s}) \geq 0 \\
& \mathbf{s}_{\mathbf{i n f}} \leq \mathbf{s} \leq \mathbf{s}_{\mathbf{s u p}}
\end{array}
$$

onde o desempenho $f_{c}$ da função objetivo é medido em relação a $\bar{\beta}_{c}$ e o desempenho das restrições probabilísticas é medido com relação a $\bar{\beta}_{i}$. Uma vez que um desempenho negativo indica a ocorrência de falha, o seu sinal no ponto MPTP pode ser utilizado para determinar se a restrição probabilística está satisfeita ou não. 


\section{Método da Otimização Topológica}

\subsection{Introdução}

A origem da Otimização Topológica (OT) remonta ao trabalho de Michell (1904). Desde então muitos engenheiros e matemáticos se envolveram no seu desenvolvimento teórico, mas somente com o trabalho de Bendsoe e Kikuchi (1988) é que surge um algoritmo computacional para a OT, o Método da Otimização Topológica (MOT). Segundo os próprios autores, o método se baseia fortemente na contribuição de diversos outros pesquisadores (CHENG; OLHOFF, a, b; LURIE; CHERKAEV; FEDOROV, 1982a, 1982b; ROZVANY et al., 1982; STRANG; KOHN, 1986).

Resumidamente, o MOT permite obter a topologia ótima de estruturas de forma sistemática, segundo um dado critério de custo, por exemplo, máxima rigidez para um dado volume de material, através da distribuição de material em um domínio de projeto sujeito à cargas e restrições de deslocamento, denominado Domínio Fixo Estendido de Projeto (DFEP) (ver Seção 3.2.1). No MOT, o material em cada ponto do domínio pode variar de "vazio" (sem material) até sólido (total presença de material), podendo assumir densidades intermediárias entre "vazio" e sólido de acordo com um modelo de material definido, conceito que será discutido na Seção 3.2.2

Inicialmente são fornecidos o domínio de projeto, o carregamento aplicado e as condições de contorno (vínculos) da estrutura. Em seguida, o domínio é discretizado em elementos finitos. A partir disto, a estrutura inicial é analisada e, em seguida, modificada por um algoritmo de otimização de modo a se obter uma melhora no valor da função objetivo. Com os valores atualizados das variáveis de projetos em cada elemento da malha, são feitas sucessivas iterações até que se obtenha a estrutura ótima. O resultado final deve ser interpretado e verificado em um software de elementos finitos antes de ser fabricado. Esse processo é ilustrado na Fig. 3.1.

Desde a sua introdução no final da década de 80 por Bendsoe e Kikuchi (1988), o MOT tem ganho muito destaque não somente no meio acadêmico como também na 


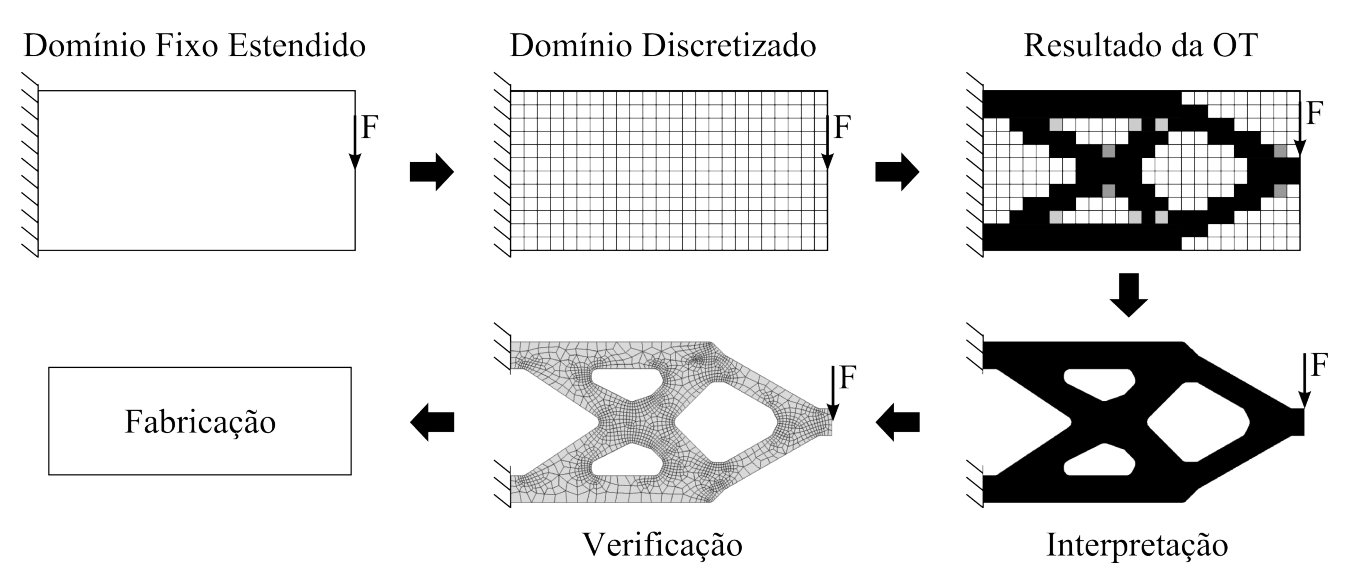

Figura 3.1: Ciclo de projeto utilizando o MOT.

indústria. Originalmente foi desenvolvido para projetos de maximização de rigidez de estruturas mecânica (SUZUKI; KIKUCHI, 1991), mas atualmente é aplicado com sucesso em diversas outras áreas, tais como no projeto de MEMS eletrotermomecânicos (JONSMANN; SIGMUND; BOUWSTRA, 1999; SIGMUND, 2001), eletroestáticos (RAULLI; MAUTE, 2005; YOON; SIGMUND, 2008), piezelétricos (SILVA E. C. N.; NISHIWAKI, 2000) e piezoresitivos (RUBIO; SILVA; NISHIWAKI, 2008), projeto de sensores com maximização das frequências de ressonância (MA; KIKUCHI; CHENG, 1995; PEDERSEN, 2000), projetos de estruturas sob atuação de campos magnéticos (YOO JEONGHOON; KIKUCHI, 2000), tomografia por impedância elétrica (KOHN; VOGELIUS, 1987; MELLO, 2010); projeto de estruturas de cristal fotônico (JENSEN; SIGMUND, 2004), projeto de motores de indução (WANG; KANG; NOH, 2004), projeto estrutural utilizando Material com Gradação Funcional (MGF) (PAULINO; SILVA, 2005), entre outras (BENDSOE; SIGMUND, 2003).

\subsection{Conceitos Básicos do MOT}

O MOT baseia-se em dois conceitos fundamentais: Domínio Fixo Estendido de Projeto (DFEP) e o modelo de material, que serão descritos a seguir.

\subsubsection{Domínio Fixo Estendido de Projeto}

O DFEP $\Omega$, é um domínio de dimensões fixas, contendo as restrições da estrutura e os carregamentos aplicados sobre ela, dentro do qual será distribuído material, dando origem a estrutura desconhecida (Fig. 3.1a). Na implementação numérica, o DFEP é discretizado em elementos finitos, sendo que a malha nunca é alterada durante o processo de otimização, alterando-se apenas a distribuição de material no interior de cada elemento (Fig. 3.1b). Na análise de sensibilidades, que é utilizada como entrada para o algoritmo 
de otimização, esse fato torna a OT um processo muito vantajoso, pois, sendo o domínio fixo, a derivada de uma função $q$ com relação à variável de projeto $\gamma_{i}$, dada pela Eq. (3.1), é válida para todos os elementos do domínio.

$$
\frac{\partial}{\partial \gamma_{i}} \int_{\Omega} q d \Omega=\int_{\Omega} \frac{\partial q}{\partial \gamma_{i}} d \Omega
$$

sendo $q$ uma função contínua e diferenciável em $\Omega$.

\subsubsection{Modelo de Material}

O modelo de material é a função que define a mistura entre os materiais envolvidos no processo de otimização (um deles pode ser o "vazio"). Pode ser considerada, por exemplo, uma função $\chi(\Omega)$ discreta que possui somente valores 0 ou 1, na ausência ou presença de material, que contenha a informação sobre as densidades de material em cada ponto do domínio.

$$
\chi(\Omega)= \begin{cases}1 & \text { presença de material } \\ 0 & \text { ausência de material }\end{cases}
$$

No entanto, a otimização para valores discretos, ou problema 0-1, não possui solução única (SIGMUND; PETERSSON, 1998), uma vez que é observada a presença de vários mínimos locais, sendo sempre possível a determinação de um novo conjunto de parâmetros para cada discretização utilizada que melhore a função objetivo inicialmente proposta. Uma maneira de relaxar o problema é permitir que as variáveis de projeto assumam valores intermediários entre 0 e 1, obtendo um espaço de solução fechado e assim viabilizando a solução do problema.

Diversos modelos de materiais já foram discutidos na literatura (BENDSOE; KIKUCHI, 1988; ROZVANY; ZHOU; BIRKER, 1992; STOLPE; SVANBERG, 2001). Dentre eles o método de densidades ou "Simple Isotropic Material with Penalization (SIMP)" (BENDSOE, 1989; ROZVANY; ZHOU; BIRKER, 1992; MLEJNEK, 1992) é o mais adotado atualmente devido a sua simplicidade de implementação e menor custo computacional. Sua equação é dada por:

$$
C(x)=\gamma(x) C_{0}
$$

onde $\gamma(x)$ é uma função de distribuição contínua da variável de projeto (pseudo-densidade) com $0 \leq \gamma(x) \leq 1$ e $x \in \Omega$. $C(x)$ é o valor da propriedade do material em cada ponto do domínio, $C_{0}$ é a propriedade do material base isotrópico, que pode ser o módulo de elasticidade $\left(E_{0}\right)$ ou a densidade $\left(\rho_{0}\right)$, por exemplo.

Matematicamente, a ocorrência de valores intermediários para a variável de projeto 
estabelece a relaxação do problema, no entanto, produz resultados com regiões de propriedades intermediárias, conhecidas como "escalas de cinza" (Fig. 3.2). Do ponto de vista prático isso não é interessante pois dificulta a interpretação final da topologia e pode tornar inviável a sua fabricação. Sendo assim, para evitar o aparecimento de escalas de cinza, deve-se penalizar os valores intermediários de $\gamma(x)$ da seguinte maneira, já substituindo a propriedade base $C$ pelo módulo de elasticidade:

$$
E(x)=\gamma(x)^{p_{e}} E_{0}
$$

onde $p_{e}$ é o fator que penaliza as pseudo-densidades, fazendo com que os valores intermediários se aproximem de 0 e 1 , e portanto, reduzindo a ocorrência de escalas de cinza.

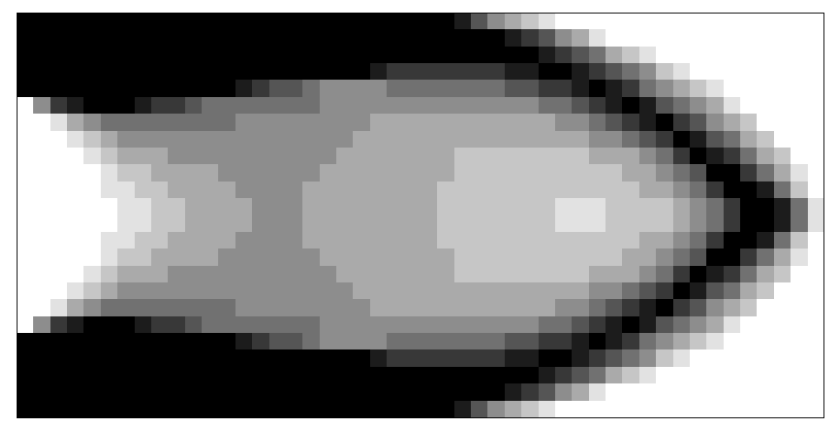

Figura 3.2: Exemplo de ocorrência de escalas de cinza.

Os problemas penalizados são geralmente não convexos, apresentando múltiplos mínimos locais. Por isso eles devem vir acompanhados da utilização do método da continuação, de forma a aumentar a possibilidade de obtenção de um ótimo global. O método da continuação inicia a penalização com, por exemplo, $p_{e}=1$, de tal forma que a solução inicie sua convergência para o mínimo global, e, posteriormente, com aumentos sucessivos de $p_{e}$, a solução deve convergir para um mínimo local na vizinhança do mínimo global. Este procedimento é repetido até que $p_{e}$ atinja seu valor limite, que é usualmente estabelecido como $p_{e}=3$ para problemas estruturais (BENDSOE; SIGMUND, 2003).

Um exemplo ilustrativo dessa situação está exposto na Fig. 3.3, onde se verifica que a função $f(\gamma)$ é convexa, enquanto a função $f\left(\gamma^{p}\right)$ é mal comportada pois possui vários ótimos locais.

Embora a abordagem da continuação combinada às técnicas de penalização produzam bons resultados na maioria dos casos, não é possível provar qualquer tipo de convergência de resultados. Além disso, essa abordagem também não garante a eliminação total das escalas de cinza. 


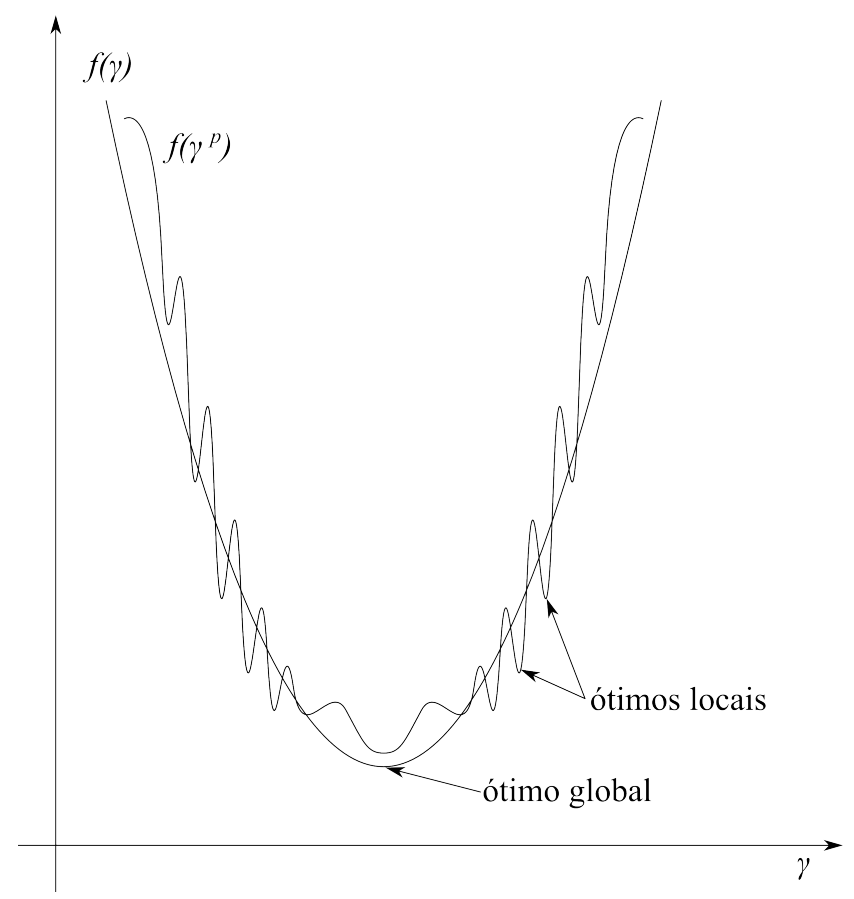

Figura 3.3: Surgimento de mínimos múltiplos locais a partir da penalização das variáveis de projeto.

\subsection{Problemas Numéricos no MOT}

A seguir, são descritos problemas numéricos derivados da implementação do MOT, que, juntamente com as "escalas de cinza", necessitam ser contornados para não comprometer a solução do problema.

\subsubsection{Instabilidade de Tabuleiro}

A 'instabilidade de tabuleiro' é caracterizada pela alternância entre elementos na cor escura (presença de material) e elementos na cor branca (ausência de material), disposto na forma de tabuleiro, como mostrado na Fig. 3.4. Trata-se de um fenômeno indesejado na solução do problema, pois não representa uma distribuição ótima de material e sim uma instabilidade numérica que aparece devido à formulação do elemento finito utilizado no processo de otimização. Além disso, essas soluções não são fabricáveis, já que é impossível construir geometrias com contato pontual.

De acordo com (DíAZ; SIGMUND, 1995), o arranjo do material em forma de tabuleiro de xadrez (Fig. 3.5a) é mais rígido ao cisalhamento do que o arranjo uniforme (Fig. 3.5b), considerando o mesmo volume de material. Assim, como geralmente a maximização de rigidez é uma característica implícita nos problemas de OT, o MOT acaba optando pela formação da instabilidade de xadrez na busca da solução ótima. 


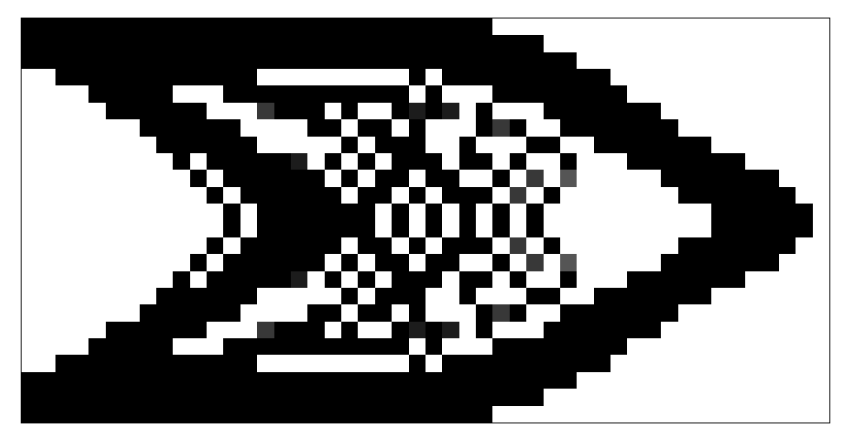

Figura 3.4: Exemplo de ocorrência de "instabilidade de tabuleiro".

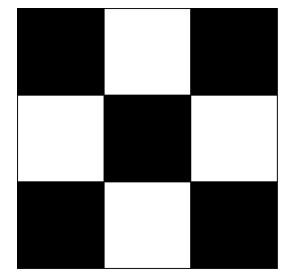

(a)

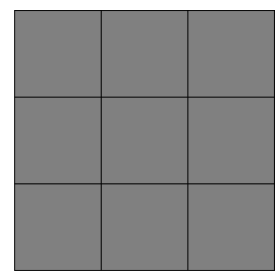

(b)

Figura 3.5: Arranjo (a) de "tabuleiro de xadrez" e (b) uniforme.

Na literatura, sugerem-se duas formas para a eliminação da instabilidade de tabuleiro nos problemas de OT. A primeira é aumentar a ordem do elemento finito (DíAZ; SIGMUND, 1995; BENDSOE; SIGMUND, 2003), ou seja, aumentar o numero de nós por elemento, o que torna o custo computacional do algoritmo mais alto. A segunda é utilizar métodos de filtragem ou de controle de gradientes (BOURDIN, 2001). Neste trabalho será implementado um método derivado do segundo grupo, o qual é discutido em detalhes na Seção 3.4.

\subsubsection{Dependência da Malha}

Seria natural imaginar que quanto maior o número de elementos finitos em uma malha, mais refinado é o resultado final ótimo. No entanto, mantendo-se o DFEP e aumentandose a sua discretização, o que se observa é que a topologia ótima tende a se modificar, dando origem a um numero maior de membros estruturais. Na Fig. 3.6 são apresentados diferentes resultados para um mesmo problema de otimização, alterando-se apenas a discretização da malha.

Uma forma de eliminar a dependência de malha é a utilização de uma restrição de perímetro, limitando o perímetro total da estrutura (AMBROSIO; BUTTAZZO, 1993). Um ponto negativo dessa abordagem é que a solução passa a depender também do tamanho dos furos. Sigmund e Petersson (1998) utiliza uma restrição local de gradiente que limita a variação em $\gamma$ entre elementos adjacentes, o que produz resultados independentes de malha 


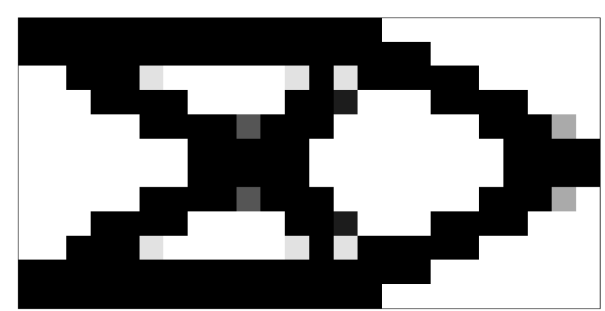

(a) $24 \times 12$ elementos

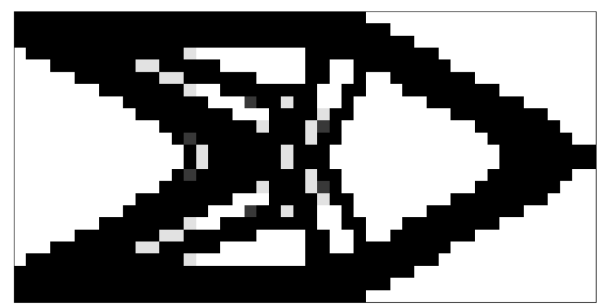

(b) $48 \times 24$ elementos

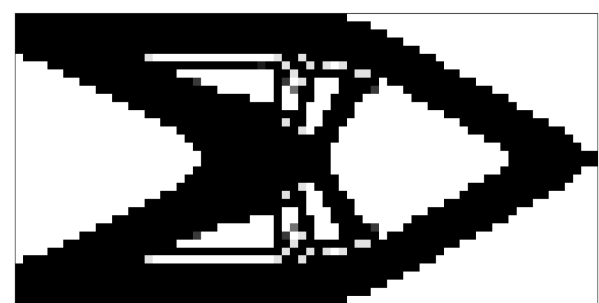

(c) $72 \times 36$ elementos

Figura 3.6: Dependência da malha nos resultados de OT.

e sem padrões de tabuleiro. O inconveniente nesse caso é o grande número de restrições locais impostas ao problema de otimização, que em geral é difícil de ser tratado.

O problema de dependência de malha também pode ser resolvido pela implementação de filtros (BOURDIN, 2001), que são menos custosos computacionalmente. Neste trabalho é utilizado um filtro espacial proposto por Bruns e Tortorelli (2001) baseado em densidades, que será discutido na Seção 3.4. Ele previne o problema de dependência de malha e também o aparecimento de padrões de tabuleiro de xadrez, mas favorece o aparecimento de escalas de cinza.

\subsection{Técnica de projeção}

O objetivo da técnica de projeção (BRUNS; TORTORELLI, 2001; GUEST; PRéVOST; BELYTSCHKO, 2004), além de eliminar a dependência da malha e o padrão de tabuleiro de xadrez, é obter estruturas ótimas com tamanho de membro mínimo especificado, o que costuma ser uma restrição de fabricação bastante comum. 
Originalmente essa técnica é definida para variáveis de projeto nodais, no entanto, como demonstrado por Sigmund (2007), é possível adapta-lá para a utilização de variáveis por elemento, que é a abordagem adotada neste trabalho.

Para a utilização da técnica de projeção, inicialmente é necessário definir a região de abrangência do raio da projeção $\left(r_{\text {min }}\right)$ de um determinado elemento $(e)$. A ideia básica pode ser compreendida através da observação da Fig. 3.7. Traçando-se uma circunferência de raio $r_{\min }$ a partir da centróide do elemento $e$ (com coordenadas $\overline{\mathrm{x}}^{e}$ ), os elementos vizinhos cujos centróides se encontram na região interna a esta circunferência, ou seja, dentro do domínio $\Omega_{w}^{e}$, influenciam o valor da pseudo-densidade deste elemento. Esta busca pelos elementos vizinhos a $e$ apresenta um custo computacional bastante elevado, no entanto ela é realizada somente uma vez, no início do algoritmo de OT.

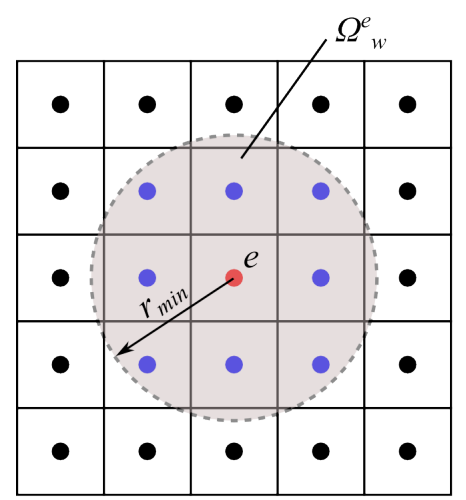

(a)

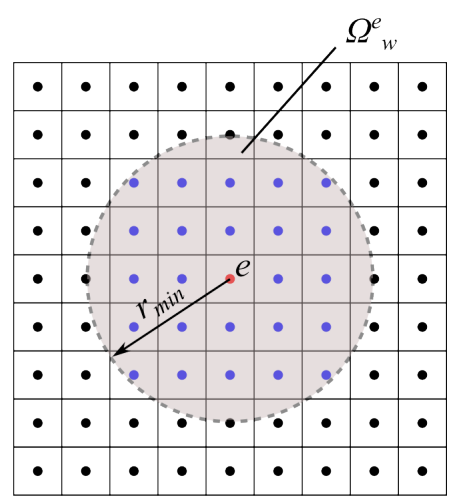

(b)

Figura 3.7: Os elementos localizados dentro do domínio $\Omega_{w}^{e}$ são incluídos na projeção para o elemento $e-\Omega_{w}^{e}$ não se altera quando a malha é refinada de (a) para (b).

Através da análise da Fig. 3.7 fica claro a eliminação da dependência de malha, já que para uma malha mais refinada, há um maior número de elementos vizinhos a $e$, mas a região $\Omega_{w}^{e}$ não é alterada. Essa característica permite também obter um tamanho de membro mínimo, isto é, todos os membros terão dimensão mínima de $2 r_{\min }$.

A influência, ou peso, de cada um dos elementos vizinhos ao elemento e, isto é, pertencentes ao domínio $\Omega_{w}^{e}$, é baseada em proximidade e é definida através da chamada "função peso" $w(x)$. A Fig. 3.8 ilustra algumas funções peso possíveis. Esta função tem valor unitário no centróide do elemento $e, \overline{\mathbf{x}}^{e}$, e vai a zero em um distancia $r_{\text {min }}$ em todas as direções. No caso linear, cria-se essencialmente um cone de altura unitária e base $2 r_{\text {min }}$. É importante notar que o valor efetivo de $r_{\text {min }}$ é reduzido com o aumento do grau da função peso. 


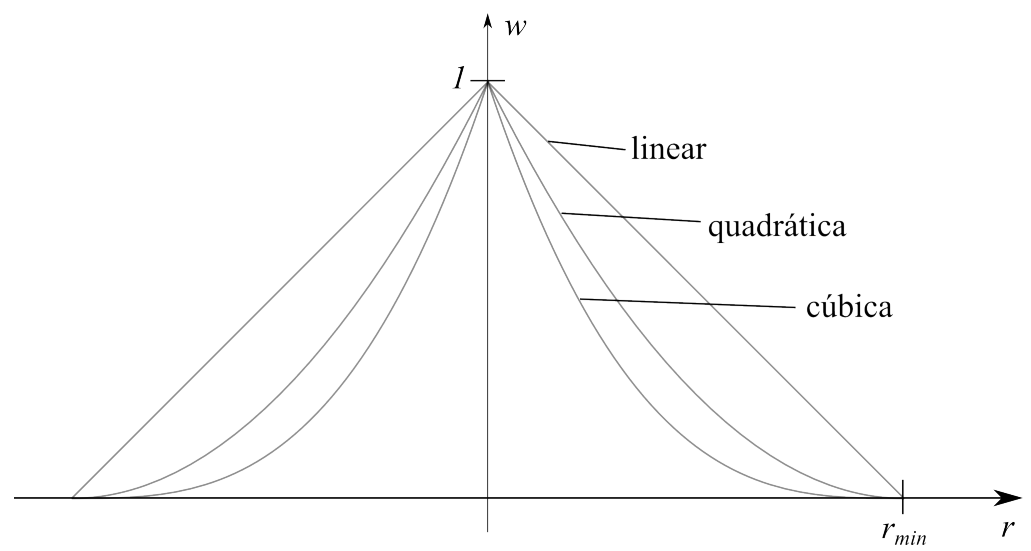

Figura 3.8: Diferentes funções peso para a técnica de projeção.

Matematicamente, o domínio $\Omega_{w}^{e}$ é definido como:

$$
\overline{\mathbf{x}}^{i} \in \Omega_{w}^{e} \text { se } r_{i}=\left\|\overline{\mathbf{x}}^{i}-\overline{\mathbf{x}}^{e}\right\| \leq r_{\text {min }}
$$

em que $\overline{\mathrm{x}}^{i}$ e $\overline{\mathrm{x}}^{e}$ são as coordenadas dos centros de um elemento arbitrário $i$ e do elemento $e$, cuja vizinhança está sendo mapeada. A função peso pode ser generalizada como:

$$
w\left(\overline{\mathbf{x}}^{i}-\overline{\mathbf{x}}^{e}\right)= \begin{cases}\left(\frac{r_{\text {min }}-r_{i}}{r_{i}}\right)^{\omega_{p}} & \text { se } \overline{\mathbf{x}}^{i} \in \Omega_{w}^{e} \\ 0 & \text { se } \overline{\mathbf{x}}^{i} \ni \Omega_{w}^{e}\end{cases}
$$

onde $\omega_{p}$ é o exponente da função peso que define se a sua ordem será linear, quadrática ou cúbica.

Os conceitos de variável de projeto e pseudo-densidade que até agora foram utilizados indistintamente, devem ser separados para facilitar a compreensão desta abordagem. Ao se utilizar o filtro de projeção, a pseudo-densidade de um dado elemento passa a ser uma função linear das variáveis de projeto associadas a sua vizinhança. Dessa forma, a pseudo-densidade e a variável de projeto de um elemento terão valores distintos.

Definindo-se $d_{e}$ como o valor da pseudo-densidade do elemento $e$ e sendo $\gamma_{i}$ as variáveis de projeto de sua vizinhança, tem-se que:

$$
d_{e}=f(\gamma)
$$

onde $f$ é a função projeção definida por:

$$
f(\gamma)=\frac{\sum_{i \in S_{e}} \gamma_{i} w\left(\overline{\mathbf{x}}^{i}-\overline{\mathbf{x}}^{e}\right)}{\sum_{i \in S_{e}} w\left(\overline{\mathbf{x}}^{i}-\overline{\mathbf{x}}^{e}\right)}
$$

sendo $S_{e}$ o conjunto de elementos que pertencem a vizinhança do elemento $e\left(\Omega_{w}^{e}\right)$.

Inerente a essa técnica está o aparecimento de escalas de cinza nas regiões próximas 
às fronteiras. Uma solução para contornar esse problema é, após obter a topologia final, desligar a projeção e deixar o algoritmo prosseguir por mais algumas iterações (CARDOSO, 2000). Após algumas iterações penalizando densidades intermediárias sem a projeção, o MOT elimina a maioria das escalas de cinza remanescentes, sem comprometer o resultado. Entretanto, este artifício deve ser feito de maneira que não ocorra novamente a formação do tabuleiro de xadrez, ou seja, deve-se ter cuidado com o excesso de iterações adicionais (RUBIO, 2005).

Mesmo desligando o filtro nas iterações finais, na maioria dos casos é ainda necessário o pós-processamento da topologia final obtida, que é realizado através da definição de uma densidade de corte, abaixo da qual o material é considerado como "vazio" $(\gamma=0)$ e acima como "cheio" $(\gamma=1)$. Dessa forma é possível garantir o caráter discreto da topologia final, desejável para viabilizar a sua fabricação.

\subsection{Formulação do problema de OT para o projeto de Acelerômetros MEMS}

No caso da otimização topológica não se pode utilizar a área do dispositivo ("footprint area") como função objetivo, dado que as dimensões máximas do domínio (DFEP) são um dos parâmetros de entrada para o algoritmo de otimização e portanto fixas ao longo de todo o processo (ver Seção 3.2.1). Além disso, como ficará claro mais adiante, as topologias obtidas por OT atendem naturalmente ao requisito de largura de banda e assim, para aliviar o custo computacional, o mesmo não é considerado no processo de otimização. No entanto, todos os projetos ótimos são checados a posteriori com relação a este requisito. Portanto, nesse caso é avaliada apenas a flexibilidade da estrutura, que está diretamente relacionada com a sensibilidade do acelerômetro.

\subsubsection{Flexibilidade estrutural}

A formulação clássica do MOT é a maximização da rigidez estrutural, com restrição de volume de material. Esse caso é inicialmente apresentado para em seguida ser adaptado para a solução do problema em estudo neste trabalho, isto é, a obtenção de estruturas de alta flexibilidade.

O problema de maximização de rigidez de uma estrutura linear elástica sob a ação de um único caso de carga é equivalente ao problema de minimização da flexibilidade (SUZUKI; KIKUCHI, 1991), definida como o trabalho realizado pelas forças externas. 
Considere um corpo tridimensional, constituído de um material elástico linear, com domínio $\Omega$, submetido a um carregamento $\mathbf{t}$ na superfície $\Gamma_{t}$ e fixo na região $\Gamma_{d}$, como ilustrado na Fig. 3.9. O campo de deslocamentos resultante é dado por $\mathbf{v}=\left\{v_{1}, v_{2}, v_{3}\right\}$.

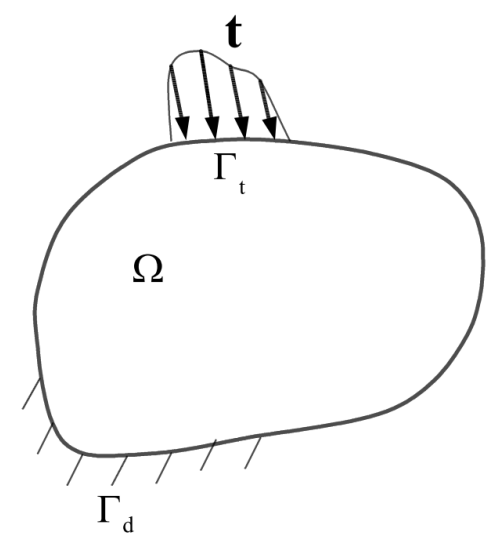

Figura 3.9: Corpo submetido a um carregamento $t$ em $\Gamma_{t}$.

Para simplificar a formulação, as forças de volume que agem no corpo (como por exemplo, o peso próprio) não são consideradas. Assim, pela teoria da mecânica do meio contínuo (REDDY, 2007), sabe-se que a forma linear da flexibilidade média (ou "mean compliance") é dada por:

$$
L(\mathbf{v})=\int_{\Gamma_{t}} \mathbf{t} \cdot \mathbf{v} d \Gamma_{t}
$$

Dessa forma o problema de minimização da flexibilidade média, que é equivalente a maximização da rigidez estrutural pode ser dado por:

$$
\begin{array}{cl}
\underset{\gamma}{\operatorname{Minimizar}} & L(\mathbf{v})=\int_{\Gamma_{t}} \mathbf{t} \cdot \mathbf{v} d \Gamma_{t} \text { (flexibilidade média) } \\
\text { Sujeito a } & \int_{\Omega} \varepsilon(\mathbf{v})^{T} \mathbf{C} \varepsilon(\delta \mathbf{v}) d \Omega=L(\mathbf{v}) \text { (equilíbrio estático) } \\
& \int_{\Omega} \gamma d \Omega-\Omega_{\max } \leq 0 \text { (restrição de volume de material) } \\
& 0 \leq \gamma \leq 1
\end{array}
$$

A sensibilidade mecânica do acelerômetro está diretamente relacionada com flexibilidade de sua estrutura, isto é, quanto mais flexível for a configuração das vigas utilizadas, mais a massa móvel irá se deslocar para um mesmo valor de aceleração e portanto, maior será a sensibilidade do dispositivo. No entanto, como é de se esperar, a formulação apresentada em (3.10) resultará em estruturas muito rígidas, o que é indesejável para o projeto de acelerômetros pois sua sensibilidade seria baixíssima. Sendo assim, a formulação in- 
versa (CARDOSO, 2000) é utilizada:

$$
\begin{array}{cl}
\underset{\gamma}{\text { Minimizar }} & \int_{\Omega} \gamma d \Omega \text { (volume) } \\
\text { Sujeito a } & \int_{\Omega} \varepsilon(\mathbf{v})^{T} \mathbf{C} \varepsilon(\delta \mathbf{v}) d \Omega=L(\mathbf{v}) \text { (equilíbrio estático) } \\
& \int_{\Gamma_{t}} \mathbf{t} \cdot \mathbf{v} d \Gamma_{t}-L_{\max } \leq 0 \text { (restrição de flexibilidade média) } \\
& 0 \leq \gamma \leq 1
\end{array}
$$

O motivo da inversão é permitir o projeto de estruturas com nível especificado de flexibilidade $\left(L_{\max }\right)$, o que era possível apenas indiretamente através do problema $(3.10)$.

\subsubsection{Controle de Perímetro}

A Otimização Topológica tende naturalmente a gerar estruturas do tipo junta viva nos casos em que se buscam altas flexibilidades (Fig. 3.10a). No entanto, é evidente que existe um limite prático para a fabricação e utilização de geometrias como essas, por isso o ideal seria a obtenção de resultados como aquele ilustrado na Fig. 3.10b. Considerando o mesmo material e dimensões equivalentes, a topologia em (b) é geralmente mais simples de ser fabricada, mais robusta e ao mesmo tempo possibilita alta flexibilidade, tanto para deslocamentos no plano como fora do plano. No entanto, por representar um mínimo local muito difícil, não é alcançável pelas formulações tradicionais de OT.

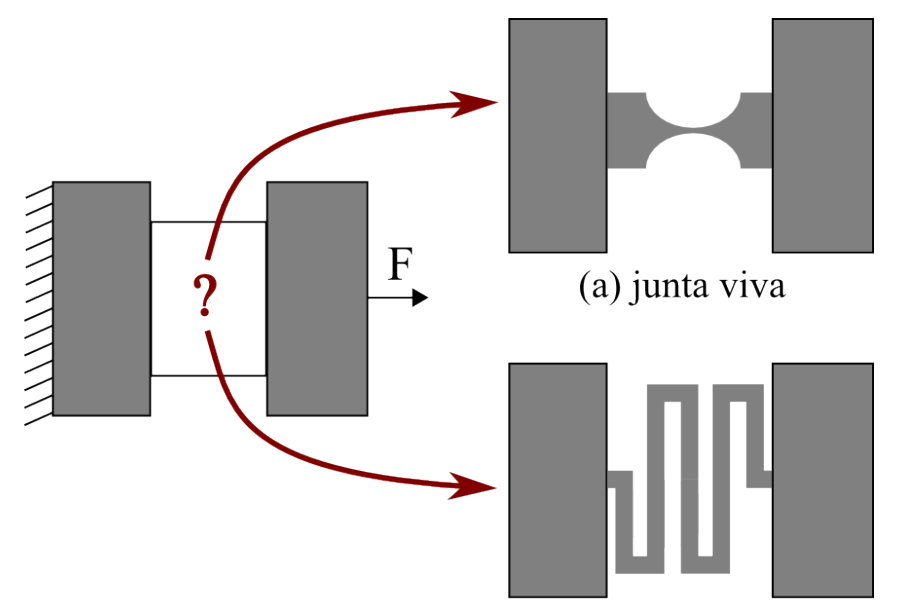

(b) padrão de zig zag

Figura 3.10: Dois exemplos de topologias que apresentam alta flexibilidade

Observando a Fig. 3.10, percebe-se que uma das características que mais diferenciam (a) de (b) é o perímetro da sua topologia, sendo que o perímetro total de (b) é cerca de $30 \%$ superior ao de (a). Com base nessa importante observação e com a ideia de 
que estruturas longas e esguias resultam em alta flexibilidade, propõe-se então uma nova formulação para o problema aqui considerado.

O perímetro de uma estrutura é uma medida da fronteira de sua região sólida $|\delta \Omega|$. Para o cálculo do comprimento desta fronteira, a Variação Total (VT) de $\gamma$ foi introduzida por Haber, Jog e Bendsoe (1996) e posteriormente refinada por Beckers (1999). A variação total em $\Omega$ de uma função $\gamma \in L^{1}(\Omega)$ é definida como:

$$
V T(\gamma)=\int_{\Omega}|\nabla \gamma| d x
$$

O valor de VT coincide com o perímetro de $|\Omega|$ quando $\gamma$ tem valor unitário em $|\Omega|$ e zero fora dele. Em situações diferentes dessa, quando a densidade dos diferentes subdomínios varia linearmente entre o vazio e o cheio (como é o caso do modelo de material adotado neste trabalho), a definição acima ainda é aplicável, no entanto, não mais representa o verdadeiro perímetro da estrutura, mas sim uma aproximação deste.

O controle sobre o perímetro, através da VT, é tradicionalmente utilizado como uma forma alternativa à técnica de projeção (Seção 3.4) para limitar a ocorrência da instabilidade de tabuleiro e assim garantir a existência da solução (AMBROSIO; BUTTAZZO, 1993). Para isso, um limite superior $P_{\max }$ é imposto sobre VT na forma de uma restrição global adicional ao problema de otimização, isto é, $V T(\gamma)<P_{\max }$.

Adaptando esta ideia para o problema em questão, a seguinte formulação é proposta:

$$
\begin{array}{cl}
\underset{\gamma}{\operatorname{Minimizar}} & \int_{\Omega} \gamma d \Omega \text { (volume) } \\
\text { Sujeito a } & \int_{\Omega} \varepsilon(\mathbf{v})^{T} \mathbf{C} \varepsilon(\delta \mathbf{v}) d \Omega=L(\mathbf{v}) \text { (equilíbrio estático) } \\
& \int_{\Gamma_{t}} \mathbf{t} \cdot \mathbf{v} d \Gamma_{t}-L_{\max } \leq 0 \text { (restrição de flexibilidade média) } \\
& \int_{\Omega}|\nabla \gamma| d x-P_{\min } \geq 0 \text { (restrição de perímetro) } \\
& 0 \leq \gamma \leq 1
\end{array}
$$

Note que em relação a formulação (3.11) foi adicionada a restrição de perímetro (Eq. 3.12). Por ser utilizada de forma inversa ao convencional, a restrição de perímetro induziria o surgimento de padrões de tabuleiro no resultado. Para contornar esse problema, utiliza-se em conjunto com esta, a técnica de projeção (Seção 3.4).

A formulação (3.13) é uma abordagem nova para um problema que, no conhecimento do autor, nunca foi estudado pela comunidade científica de Otimização Topológica. Por exemplo, não há solução conhecida para a concepção de molas helicoidais. O que existe 
são formulações já bem estabelecidas de projeto de mecanismos flexíveis (NISHIWAKI et al., 2008; SIGMUND, 2001), que são estruturas mecânicas, sem partes móveis, que transferem uma força de entrada em um ponto para um deslocamento em um ponto diferente do domínio, com energia sendo armazenada na forma de energia de deformação nos membros flexíveis. No entanto estas formulações não se aplicam para o problema aqui considerado pois o ponto de aplicação do carregamento de entrada e do deslocamento de saída desejado são coincidentes. 


\section{Implementação Numérica}

Neste capítulo, é discutida a implementação de dois algoritmos de otimização, desenvolvidos pelo autor, para o projeto de acelerômetros MEMS. O primeiro deles implementa uma otimização paramétrica e o segundo uma otimização topológica. No caso da paramétrica, é adotada a metodologia RBDO (Seção 2.3.1) para o projeto de estruturas com níveis especificados de confiabilidade. Por último, o otimizador utilizado neste trabalho é discutido em detalhes.

\subsection{Implementação da Otimização Paramétrica com con- fiabilidade}

\subsubsection{Análise de Sensibilidades}

Otimizadores baseados em gradientes, como o usado neste trabalho, exigem o cálculo das derivadas primeiras (ou gradientes) da função objetivo e restrições, que são mais conhecidos na área de otimização como sensibilidades. A validade dos resultados obtidos depende diretamente da precisão no cálculo das sensibilidades. Dessa forma a sensibilidade deve ser calculada de forma precisa, caso contrário o algoritmo caminhará numa direção errada, se afastando da solução ótima.

Existem três métodos para o cálculo de sensibilidade: Método de Diferenças Finitas (MDF), método semi-analítico e analítico. A precisão de cálculo aumenta do primeiro para o último e a utilização de um ou outro vai depender da informação disponível sobre a expressão matemática da função objetivo, por exemplo.

O custo computacional de uma otimização determinística padrão está diretamente relacionado com o número de análises realizadas (análises estruturais por MEF, por exemplo). Métodos de diferenças finitas para o cálculo de sensibilidades são geralmente muito custosos devido ao grande número de análises adicionais requeridas. Este raciocínio é amplificado em otimizações envolvendo confiabilidade, onde cada avaliação dos critérios de confiabilidade, seja na função objetivo ou nas restrições, requer múltiplas análises determi- 
nísticas e de sensibilidade. Assim, aplicar diferenças finitas para os critérios probabilísticos conduzirá a custos computacionais proibitivos. Felizmente, quando a abordagem FORM é adotada (Seção 2.3.1), a sensibilidade dos critérios probabilísticos pode ser calculada de forma muito eficiente analiticamente (ALLEN; MAUTE, 2004), como será visto a seguir.

A derivada da probabilidade de falha $P_{f}$ com relação à variável de projeto $s_{i}$ pode ser calculada da seguinte maneira:

$$
\frac{d P_{f}}{d s_{i}}=\frac{d \Phi(-\beta)}{d s_{i}}=\frac{\partial \Phi(-\beta)}{\partial \beta} \frac{d \beta}{d s_{i}}
$$

onde, por simplicidade, foi considerado $b_{1}>0$ na Eq.(2.14).

Substituindo a expressão da função densidade de probabilidades acumulada da distribuição normal padrão, $\Phi$, em (4.1), tem-se:

$$
\frac{\partial \Phi(-\beta)}{\partial \beta}=\frac{\partial\left(\frac{1}{2 \pi} \int_{-\infty}^{-\beta} e^{-\frac{x^{2}}{2}} d x\right)}{\partial \beta}=-\frac{1}{2 \pi} e^{\frac{-\beta^{2}}{2}}=-\varphi(-\beta)
$$

onde $\varphi$ é a função densidade de probabilidade da distribuição normal padrão.

Substituindo (4.2) em (4.1), obtém-se a seguinte expressão para a sensibilidade da probabilidade de falha com relação à variável de projeto $s_{i}$ :

$$
\frac{d P_{f}}{d s_{i}}=-\varphi(-\beta) \frac{d \beta}{d s_{i}}=-\frac{1}{2 \pi} e^{\frac{-\beta^{2}}{2}} \frac{d \beta}{d s_{i}}
$$

Para calcular a sensibilidade de $\beta$ com respeito à variável de projeto $s_{i}, \frac{d \beta}{d s_{i}}$, deve-se primeiro lembrar que a partir da análise de confiabilidade usando o FORM e o RIA, uma vez que a confiabilidade é determinada, tem-se que:

$$
\beta=\left(\mathbf{u}^{* T} \mathbf{u}^{*}\right)^{\frac{1}{2}}
$$

onde $\mathbf{u}^{*}$ representa o MPFP. Assim, a derivada parcial de $\beta$ com relação a $\mathbf{u}^{*}$ pode ser calculada como segue:

$$
\frac{\partial \beta}{\partial \mathbf{u}^{*}}=\frac{1}{2}\left(\mathbf{u}^{* T} \mathbf{u}^{*}\right)^{-\frac{1}{2}} 2 \mathbf{u}^{*}=\frac{1}{\beta} \mathbf{u}^{*}
$$

e assim a derivada de $\beta$ com relação a variável de projeto $s_{i}$ é dada por:

$$
\frac{d \beta}{d s_{i}}=\frac{1}{\beta} \mathbf{u}^{*} \frac{d \mathbf{u}^{*}}{d s_{i}}
$$

A partir do problema de otimização (2.16), o MPFP, ou u* é derivado da primeira 
condição de optimalidade de Karush-Kuhn-Tucker(KKT) como:

$$
\mathbf{u}^{*}=-\beta \frac{\frac{d Q}{d \mathbf{u}}}{\left\|\frac{d Q}{d \mathbf{u}}\right\|}
$$

onde $Q$ representa a função limite de estado considerada.

Substituindo (4.7) em (4.6) e rearranjando o resultado obtém-se:

$$
\frac{d \beta}{d s_{i}}=-\frac{\frac{d Q}{d \mathbf{u}}}{\left\|\frac{d Q}{d \mathbf{u}}\right\|} \frac{d \mathbf{u}^{*}}{d s_{i}}
$$

A derivada de $Q$ com relação à $\mathbf{u}$ e a derivada de $\mathbf{u}$ com relação à $s_{i}$ podem ser expandidas em termos das variáveis aleatórias originais $\mathbf{r}$ :

$$
\begin{gathered}
\frac{d Q}{d \mathbf{u}^{*}}=\frac{d Q}{d \mathbf{r}} \frac{d \mathbf{T}_{\mathbf{u}}^{-1}(\mathbf{u})}{d \mathbf{u}} \\
\frac{d \mathbf{u}^{*}}{d s_{i}}=\frac{d \mathbf{T}_{\mathbf{u}}(\mathbf{r})}{d \mathbf{r}} \frac{d \mathbf{r}^{*}}{d s_{i}}
\end{gathered}
$$

sendo que $\mathbf{T}_{\mathbf{u}}{ }^{-1}$ denota o mapeamento inverso de (2.17), do espaço normal padrão $\mathbf{u}$ no espaço das variáveis aleatórias originais $\mathbf{r}$.

A continuação da derivação depende do tipo da variável de projeto $s_{i}$. No caso de variável determinística, o fato de que a variação total da função de estado limite $Q$ com relação à variável de projeto $s_{i}$ é zero em $\mathbf{u}^{*}$ (ALLEN et al., 2004) é usado junto com (4.8) para formular a seguinte expressão:

$$
\frac{d \beta}{d s_{i}}=\frac{1}{\left\|\frac{d Q}{d \mathbf{u}}\right\|} \frac{d Q}{d s_{i}}
$$

onde o último termo é a sensibilidade determinística da função de estado limite $Q$ com relação à variável de projeto $s_{i}$. Voltando a (4.12), tem-se que:

$$
\frac{d P_{f}}{d s_{i}}=-\frac{1}{2 \pi} e^{\frac{-\beta^{2}}{2}} \frac{1}{\left\|\frac{d Q}{d \mathbf{u}}\right\|} \frac{d Q}{d s_{i}}
$$

Uma variável de projeto pode também ser não-determinística. Por exemplo, a média ou o desvio padrão de uma dada distribuição estatística pode ser tratada como variável de projeto. Nesses casos, o gradiente do índice de confiabilidade é derivado como:

$$
\frac{d \beta}{d s_{i}}=\frac{1}{\beta} \mathbf{u}^{*} \frac{d \mathbf{u}^{*}}{d s_{i}}=\frac{1}{\beta} \mathbf{u}^{*} \frac{d \mathbf{T}_{\mathbf{u}}\left(\mathbf{r}^{*}, \mathbf{s}\right)}{d s_{i}}
$$

Com relação ao método PMA, como o desempenho-alvo é simplesmente o valor da 
função de estado limite no MPTP, a sua sensibilidade é obtida de forma mais simples do que a do índice de confiabilidade $\beta$. A sensibilidade do desempenho-alvo é igual ao gradiente da função de estado limite $Q$ com relação à variável de projeto $s_{i}$, isto é, $\frac{d Q}{d s_{i}}$.

\subsubsection{Fluxograma da Implementação}

O procedimento para a implementação do software de otimização paramétrica com confiabilidade está ilustrado na Fig. 4.1. O software Matlab foi o adotado para esta implementação.

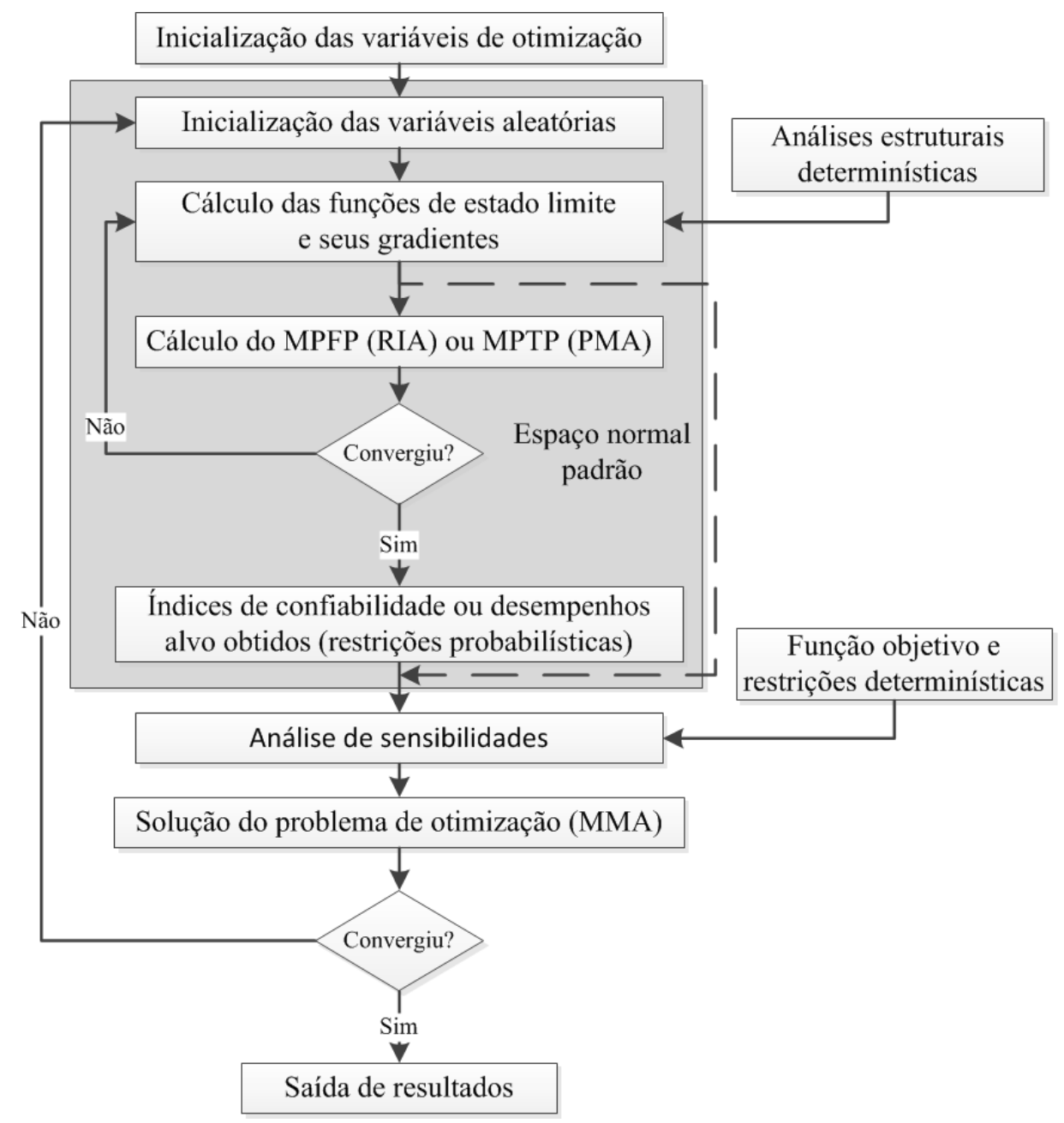

Figura 4.1: Fluxograma da Implementação do RBDO.

Em primeiro lugar, devem ser fornecidas todas as informações geométricas da estrutura a ser otimizada, como comprimento das vigas, espessura da massa, etc. Esses dados serão utilizados como valor inicial para as variáveis de projeto. Em seguida é necessário fornecer as informações relativas às distribuições estatísticas que regem as incertezas do problema, como o tipo da distribuição e os seus parâmetros estatísticos, por exemplo, média e desvio padrão para a distribuição normal. 
Como fica evidente no fluxograma da Fig. 4.1, o software é estruturado em dois ciclos aninhados. O primeiro é o responsável pelas análises de confiabilidade, que são uma das entradas para a otimização propriamente dita a ser realizada no segundo ciclo.

No ciclo interno, que ocorre no espaço normal padrão, análises estruturais são combinadas com repetidas iterações de (2.16) ou (2.21) até que sejam estimados os valores das restrições probabilísticas em termos do índice de confiabilidade, no caso da abordagem RIA, ou do desempenho alvo, para a abordagem PMA. No primeiro problema de RBDO discutido no próximo capítulo, são utilizadas fórmulas analíticas para as análises estruturais, enquanto no segundo é utilizado o MEF com elementos de treliça.

Na sequência, são agregadas ao problema também as informações sobre a função objetivo e demais restrições determinísticas. Os valores dessas funções e as suas sensibilidades são fornecidos ao otimizador, no caso o "Método das Assíntotas Móveis" (SVANBERG, 1987), que é o responsável pela atualização dos valores das variáveis de projeto.

Após algumas iterações, o processo pela busca do ponto ótimo é interrompido quando é verificada a convergência no valor da função objetivo, isto é, quando a mesmo não apresenta mais variação significativa.

No Apêndice A é realizada a validação do algoritmo implementado pelo autor através de comparação com o trabalho de Lee, Yang e Ruy (2002).

\subsection{Implementação da Otimização Topológica}

Nesta seção é discutido inicialmente o algoritmo de elementos finitos para placas, que é o responsável pelas análises estruturais necessárias para o MOT. Além disso, o problema de OT, previamente definido na sua forma contínua e integral no Capítulo 3, é apresentado em sua forma discreta e com base nessa formulação serão obtidas as sensibilidades de suas funções objetivo e restrições. Finalmente, é também apresentado o fluxograma da implementação do software de OT.

\subsubsection{Modelagem de Placas através do Método dos Elementos Finitos}

Um método genérico, como o Método dos Elementos Finitos (MEF), é necessário para as análises estruturais com topologias complexas inerentes ao MOT. Para se iniciar um análise de elementos finitos é necessário que o modelo a ser analisado seja discretizado em uma malha de elementos finitos, que é a divisão do domínio de projeto em subdomínios, 
cujas dimensões devem ser pequenas o bastante para permitir a aproximação satisfatória do problema (BATHE, 1996).

As estruturas consideradas neste trabalho foram discretizadas através de elementos de placa pois esta é a configuração mais simples e menos custosa capaz de modelar adequadamente os exemplos propostos. A palavra 'placa' se refere a corpos sólidos que são delimitados por dois planos paralelos, cujas dimensões laterais são maiores do que a distância que os separa. Em geral eles são submetidos apenas a carregamento transversal, isto é, perpendicular ao plano das placas. Este elemento permite trabalhar somente com modelos bidimensionais (2D), o seu equivalente em 3D é o elemento de casca.

As duas principais abordagens para a simulação através do MEF de estruturas de placa são a teoria de Kirchhoff-Love, também conhecida como teoria clássica, e a teoria de Reissner-Mindlin. A primeira é uma extensão da teoria de vigas de Euler-Bernoulli para placas, enquanto a segunda vem da teoria de vigas de Timoshenko.

A teoria de Kirchhoff-Love é baseada na suposição de que uma linha reta, normal ao plano médio da placa é (1) inextensível, (2) permanece reta e (3) rotaciona de maneira que continua normal à superfície média na posição deformada. Assim, apenas as deformações por flexão estariam sendo consideradas, conforme ilustrado na Fig. 4.2(a). Esta teoria é limitada apenas para os casos em que a espessura da placa é muito menor do que seu comprimento e largura.

O elemento de placa utilizado neste trabalho segue a teoria de Reissner-Mindlin, na qual a condição de normalidade (hipótese 3) é retirada e assim, uma linha reta, normal à superfície média da placa em sua posição indeformada, deverá permanecer reta, mas não necessariamente normal à superfície média na posição deformada. Dessa forma, a teoria permite tanto a consideração de deformações por flexão, quanto por cisalhamento, ilustradas na Fig. 4.2(a) e Fig. 4.2(b), respectivamente.

O modelo de Reissner-Mindlin permite o estudo tanto de placas delgadas quanto moderadamente espessas, no entanto, está sujeito ao problema conhecido como 'travamento por cisalhamento' ou "shear locking", que pode comprometer seriamente os resultados. Existem duas principais abordagens encontradas na literatura para a lidar com este problema:

- Integração reduzida, que consiste, basicamente, na utilização de um número de pontos de Gauss menor do que o necessário para a obtenção do valor exato da integral numérica avaliada;

- Deformações naturais, ou "assumed natural strains", que normalmente não são de- 


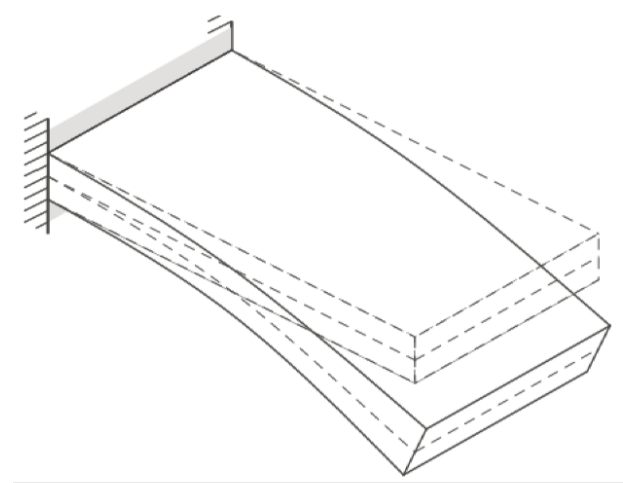

(a) Deformação por flexão

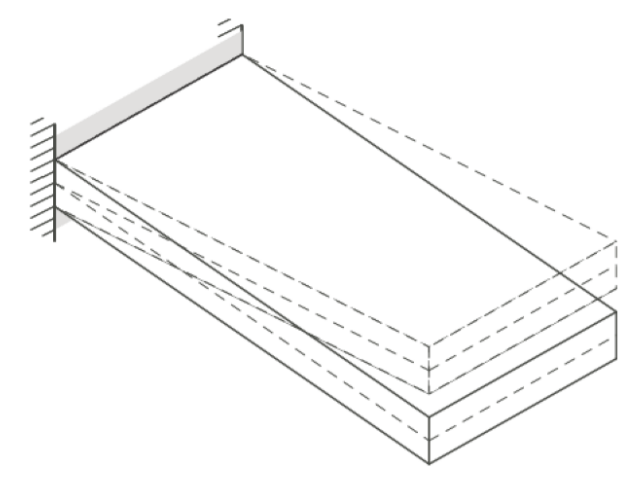

(b) Deformação por cisalhamento

Figura 4.2: Deformações por flexão e cisalhamento numa estrutura de placa.

riváveis diretamente a partir dos deslocamentos obtidos pelo MEF.

Bathe (1996) enfatiza que a utilização de uma abordagem de integração reduzida resolve o problema ao acrescentar um erro numérico à avaliação das integrais, além de ocasionar os 'modos de ampulheta', que são modos de energia nulos que interferem nos resultados do MEF. Bathe e Dvorkin (1985) propõem uma abordagem de deformações naturais denominada 'interpolação mista das componentes tensoriais', ou MITC.

Além disso, a importância da utilização de um elemento de placa de formulação genérica e robusta em projetos através do MOT é enfatizada por Long, Loveday e Groenwold (2009), que mostram que a utilização de modelos de Kirchhoff são insensíveis a variação de espessura, produzindo topologias que independem desta variável. Os autores mostram ainda que a utilização da integração reduzida sem controle de modos de ampulheta produz resultados espúrios na OT, inviabilizando a sua utilização. Dentre os elementos testados por Long, Loveday e Groenwold (2009), os que se mostraram adequados para o uso no projeto utilizando o MOT foram: modelos com integração reduzida com controle de modos de ampulheta e os modelos baseados em deformações naturais, com a abordagem MITC.

Este trabalho utiliza o modelo de Chapelle e Bathe (2003), que combina a teoria de placas de Reissner-Mindlin e a abordagem MITC para contornar o problema de 'travamento por cisalhamento'. O elemento de placa utilizado é mostrado na Fig. 4.3. As variáveis dependentes são os deslocamentos $u, v$, e $w$ nas direções $x, y$, e $z$, respectivamente e os deslocamentos $\theta_{x}, \theta_{y}$ e $\theta_{z}$ das normais aos planos $y z, x z$ e $x y$. Para uma análise padrão apenas três graus de liberdade são necessários: o deslocamento fora do plano $w$ e os deslocamentos das normais aos planos yz e $x z\left(\theta_{x}\right.$ e $\left.\theta_{y}\right)$. No entanto, é possível ativar todos os seis graus de liberdade, de modo que qualquer tipo de configuração para uma 


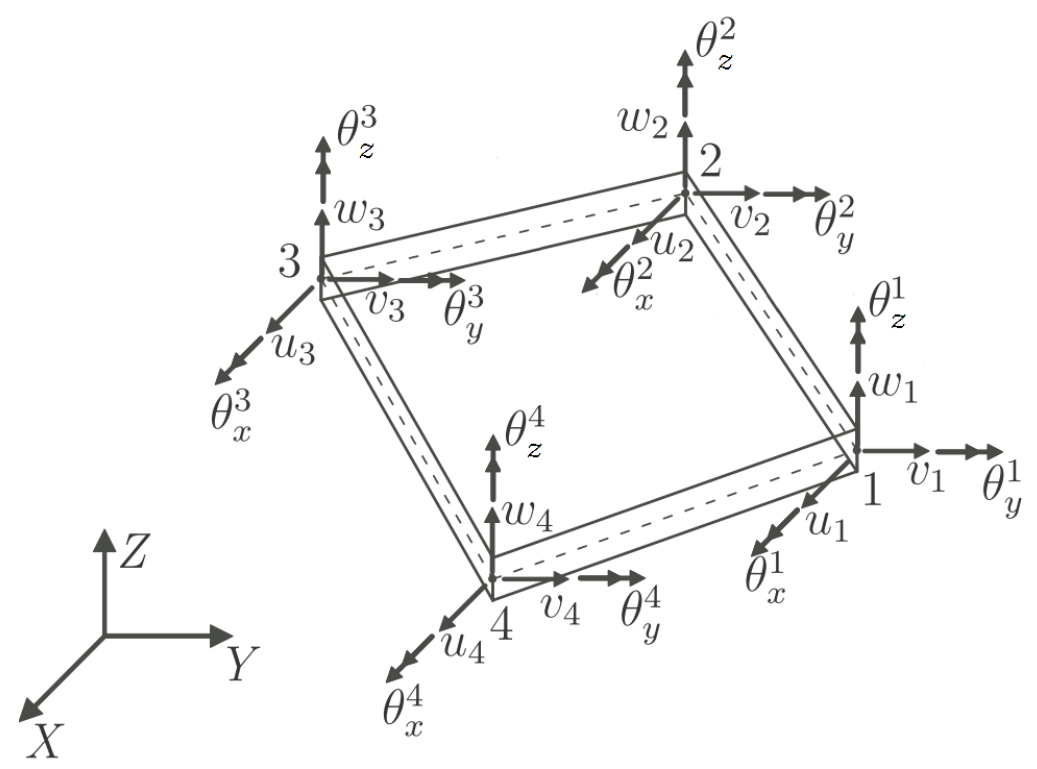

Figura 4.3: Elemento de placa com 4 nós e 6 graus de liberdade por nó.

placa inicialmente posicionada no plano $x y$ possa ser avaliada.

É importante mencionar que o modelo de Chapelle e Bathe (2003) não foi implementado pelo autor, ao invés disso foi utilizado o software de elementos finitos comercial Comsol, que já possui este elemento implementado. Este é um software amplamente reconhecido e utilizado pela comunidade científica, inclusive na área de OT (LIU; KORVINK; HUANG, 2005; OLESEN; OKKELS; BRUUS, 2006; LEMKE; LIU; KORVINK, 2006; DEDE, 2009). A comunicação entre o Comsol e o algoritmo de otimização desenvolvido neste trabalho será explicada na Seção 4.2.4.

\subsubsection{Problema de OT na Forma Discreta}

Como o domínio de projeto, $\Omega$, deve ser discretizado em elementos finitos para se obter uma solução numérica para o problema de otimização, deve-se adotar um modelo para o campo de densidades que determina a topologia da estrutura, ou seja, é necessário definir as variáveis de projeto do problema de OT. Neste trabalho foi utilizada a implementação de variável de projeto por elemento (BENDSOE, 1989), também denominada implementação Q4/U (ver Fig.4.4).

Nesta implementação os graus de liberdade do elemento estão interpolados por funções de forma bilineares, enquanto a variável de projeto é uniforme dentro do elemento. Os problemas de instabilidade de tabuleiro e dependência da malha são contornados através da utilização da técnica de projeção (Seção 3.4). O elemento utilizado para discretizar o domínio é o elemento de placa descrito na Seção 4.2.1. 


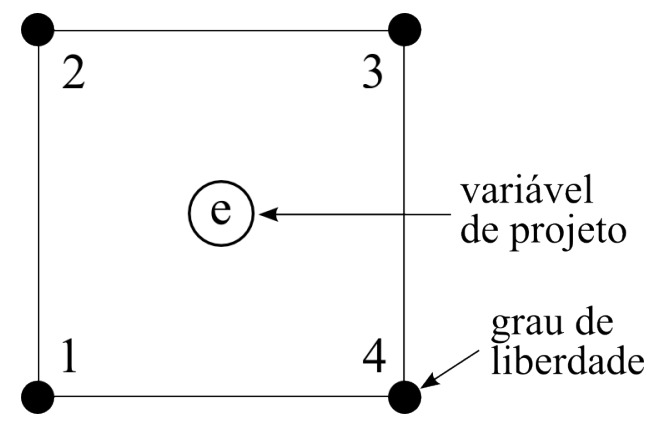

Figura 4.4: Implementação da variável de projeto por elemento (Q4/U).

Considerando a definição de flexibilidade média (Eq. 3.9), previamente apresentada em sua formulação contínua, é necessário reescrevê-la em seu formato discreto de maneira a viabilizar o seu cálculo com os resultados obtidos através da formulação matricial do MEF. Podemos definir a flexibilidade média na forma discreta como:

$$
L=\mathbf{v}^{T} \mathbf{F}=\mathbf{v}^{T} \mathbf{K} \mathbf{v}
$$

onde $\mathbf{v}$ é o vetor de deslocamento resultante da aplicação da carga $\mathbf{F}$ e $\mathbf{K}$ é a matriz de rigidez global da estrutura. Portanto, o problema de minimização da flexibilidade estrutural (Eq. 3.10) pode ser reescrito na forma discreta da seguinte maneira:

$$
\begin{array}{ll}
\underset{\gamma}{\operatorname{Minimizar}} & \mathbf{v}^{T} \mathbf{K v} \text { (flexibilidade média) } \\
\text { Sujeito a } & \mathbf{K v}=\mathbf{F} \text { (equilíbrio estático) } \\
& \sum_{i=1}^{n_{e}} V_{i} \gamma \leq V_{\max } \text { (restrição de volume de material) } \\
& 0<\gamma_{\min } \leq \gamma \leq 1
\end{array}
$$

Analogamente, o problema inverso (3.11) pode ser reescrito como:

$$
\begin{array}{ll}
\underset{\gamma}{\operatorname{Minimizar}} & \sum_{i=1}^{n_{e}} V_{i} \gamma(\text { volume }) \\
\text { Sujeito a } & \mathbf{K v}=\mathbf{F} \text { (equilíbrio estático) } \\
& \mathbf{v}^{T} \mathbf{K} \mathbf{v} \leq L_{\max }(\text { restrição de volume de material) } \\
& 0<\gamma_{\min } \leq \gamma \leq 1
\end{array}
$$

Com relação a Variação Total (Eq. 3.12), que será utilizada para calcular o Perímetro 
P da topologia, Zhang e Duysinx (2003) propõe a seguinte definição na forma discreta:

$$
P(\gamma)=\sum_{k=1}^{n_{l}} l_{k}\left(d_{i}-d_{j}\right)^{2}
$$

onde $n_{l}$ é o numero total de interfaces entre os elementos da malha e $l_{k}$ denota o comprimento da aresta da interface $k$ entre dois elementos adjacentes com pseudo-densidades $d_{i}$ e $d_{j}$, conforme ilustrado na Fig. 4.5. Para o cálculo do perímetro das arestas limítrofes do domínio, a densidade do meio externo é tomada como zero.
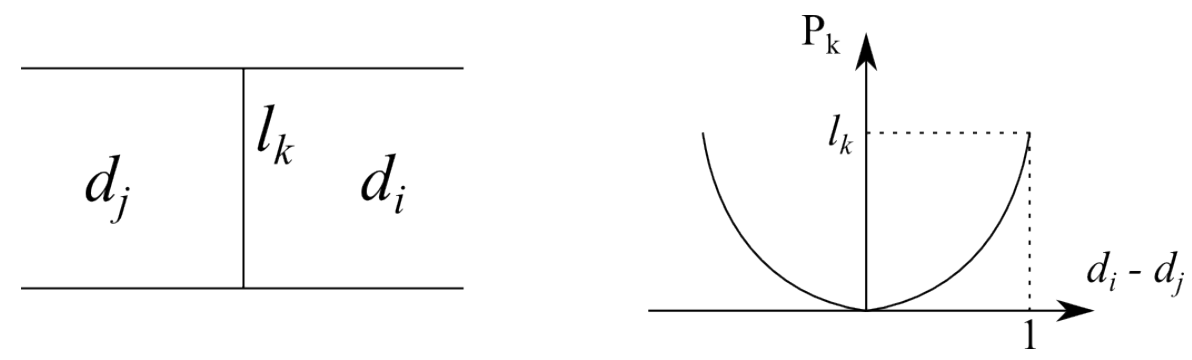

Figura 4.5: Perímetro associado com uma aresta.

Dessa forma, a formulação inversa com controle de perímetro apresentada em (3.13) pode ser reescrita como:

$$
\begin{array}{cl}
\underset{\gamma}{\operatorname{Minimizar}} & \sum_{i=1}^{n_{e}} V_{i} d_{i} \text { (volume de material) } \\
\text { Sujeito a } & \mathbf{K} \mathbf{v}=\mathbf{F} \text { (equilíbrio estático) } \\
& \mathbf{v}^{T} \mathbf{K} \mathbf{v} \leq L_{\max }(\text { restrição de flexibilidade média) } \\
& \sum_{k=1}^{n_{l}} l_{k}\left(d_{i}-d_{j}\right)^{2} \geq P_{\min } \text { (restrição de perímetro) } \\
& \mathbf{d}=f(\gamma) \\
& 0<\gamma_{\min } \leq \gamma \leq 1
\end{array}
$$

onde $n_{e}$ é o numero total de elementos finitos na malha, $V_{i}$ é o volume de um elemento, $L_{\text {max }}$ é o limite máximo permitido para a flexibilidade média e $P_{\min }$ o valor mínimo para o perímetro da topologia. O valor $\gamma_{\min }$ é inserido para evitar instabilidades numéricas no momento do cálculo da matriz de rigidez inversa.

\subsubsection{Análise de Sensibilidades}

Neste trabalho utiliza-se o método analítico para o cálculo das sensibilidades do problema de OT, sendo a seguir apresentado o cálculo das sensibilidades na forma discreta, isto é, com o problema discretizado em elementos finitos. O MDF é utilizado apenas para 
verificação das sensibilidades obtidas pelo método analítico (Apêndice B).

O gradiente da flexibilidade média em relação à pseudo-densidade $d_{e}$ do elemento $e$ é calculado da seguinte maneira:

$$
\frac{\partial L}{\partial d_{e}}=\frac{\partial \mathbf{v}^{T}}{\partial d_{e}} \mathbf{K} \mathbf{v}+\mathbf{v}^{T} \frac{\partial \mathbf{K}}{\partial d_{e}} \mathbf{v}+\mathbf{v}^{T} \mathbf{K} \frac{\partial \mathbf{v}}{\partial d_{e}}
$$

o subíndice $e$ faz referência aos graus de liberdade específicos do elemento que está sendo considerado.

Derivando a equação de equilíbrio estático $\mathbf{K v}=\mathbf{F}$ em relação à pseudo-densidade $d_{e}$, tem-se:

$$
\frac{\partial \mathbf{K}}{\partial d_{e}} \mathbf{v}+\mathbf{K} \frac{\partial \mathbf{v}}{\partial d_{e}}=\frac{\partial \mathbf{F}}{\partial d_{e}}
$$

Como neste trabalho não são consideradas forças de corpo, isto é, F é constante e independente de $d_{e}$, então $\frac{\partial \mathbf{F}}{\partial d_{e}}=0$ :

$$
\frac{\partial \mathbf{K}}{\partial d_{e}} \mathbf{v}+\mathbf{K} \frac{\partial \mathbf{v}}{\partial d_{e}}=0 \Rightarrow \frac{\partial \mathbf{v}^{T}}{\partial d_{e}}=-\mathbf{v}^{T} \frac{\partial \mathbf{K}}{\partial d_{e}} \mathbf{K}^{-1}
$$

onde foi levado em conta o fato de $\mathbf{K}$ ser simétrica e $\operatorname{assim} \mathbf{K}^{T}=\mathbf{K}$ e $\left(\mathbf{K}^{-1}\right)^{T}=\mathbf{K}^{-1}$. Substituindo o resultado (4.21) em (4.19), tem-se:

$$
\frac{\partial L}{\partial d_{e}}=-\mathbf{v}^{T} \frac{\partial \mathbf{K}}{\partial d_{e}} \mathbf{v}
$$

Falta um último passo no cálculo das sensibilidades que é incluir os efeitos da projeção (Seção 3.4), uma vez que as sensibilidades fornecidas ao otimizador devem ser dadas em relação as variáveis de projeto $\left(\frac{\partial L}{\partial \gamma_{i}}\right)$ e não em relação as pseudo-densidades $\left(\frac{\partial L}{\partial d_{e}}\right)$. A partir da Eq. (3.8) é possível obter a seguinte relação entre as duas sensibilidades:

$$
\frac{\partial L}{\partial \gamma_{i}}=\sum_{i \in S_{e}} \frac{\partial L}{\partial d_{e}} \frac{\partial d_{e}}{\partial \gamma_{i}}
$$

onde:

$$
\frac{\partial d_{e}}{\partial \gamma_{i}}=\frac{w\left(\overline{\mathrm{x}}^{i}-\overline{\mathrm{x}}^{e}\right)}{\sum_{i \in S_{e}} w\left(\overline{\mathrm{x}}^{i}-\overline{\mathrm{x}}^{e}\right)}
$$

De forma análoga a Eq. (4.23), a sensibilidade do perímetro é dada por:

$$
\frac{\partial P}{\partial \gamma_{i}}=\sum_{i \in S_{e}} \frac{\partial P}{\partial d_{e}} \frac{\partial d_{e}}{\partial \gamma_{i}}
$$

onde:

$$
\frac{\partial P}{\partial d_{e}}=2 \sum_{k=1}^{4} l_{k}\left|d_{e}-d_{j}\right|
$$




\subsubsection{Fluxograma da Implementação}

O fluxo do software de otimização topológica, implementado neste trabalho em Matlab, é mostrado na Fig. 4.6.

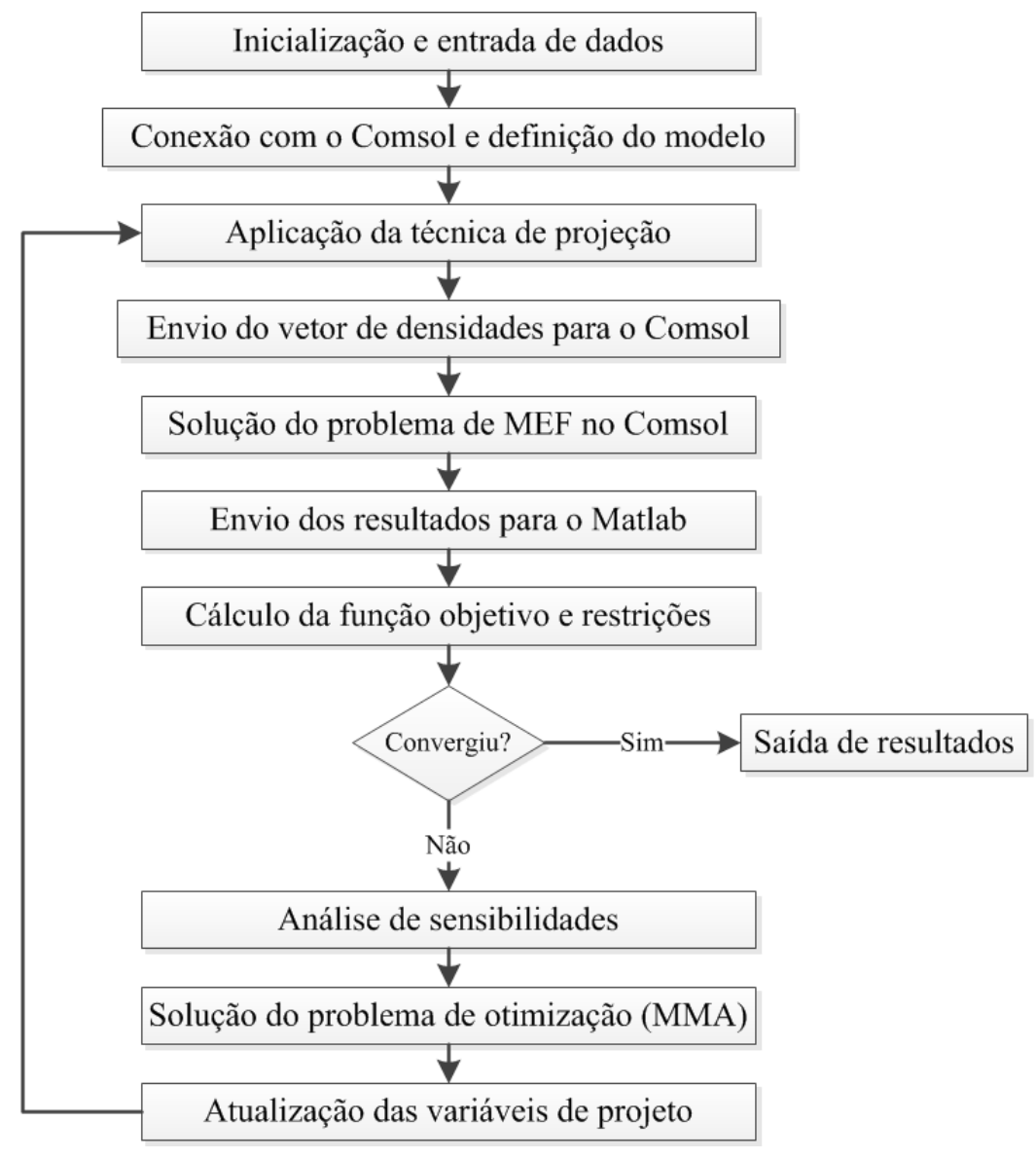

Figura 4.6: Fluxograma da Implementação do MOT.

Inicialmente, o software precisa receber as informações sobre a geometria, pontos de fixação e aplicação de cargas do domínio inicial (domínio fixo estendido de projeto). Tanto a geração da malha como a resolução do problema de elementos finitos são realizados no software comercial Comsol. Os resultados do MEF (deslocamentos nodais e matriz de rigidez global) são importados para o Matlab, onde é feito o cálculo da função objetivo e das restrições do problema, utilizando a forma matricial obtida anteriormente. Este cálculo é repetido a cada nova iteração. O detalhamento da comunicação entre o Comsol e algoritmo de otimização em Matlab é apresentada no Apêndice C.

As variáveis de projeto $\gamma$ podem assumir valores entre 0 e 1 em cada elemento finito. Elas são atualizadas a cada iteração pelo "Método das Assíntotas Móveis" (SVANBERG, 1987), que resolve o problema de otimização. Este método, explicado em maiores detalhes na Seção 4.3, exige informações sobre a sensibilidade da função objetivo e das restrições 
do problema, cujos cálculos são apresentados na Seção 4.2.3. Após algumas iterações, o processo pela busca do ponto ótimo é interrompido quando é verificada a convergência no valor da função objetivo, isto é, quando o mesmo não apresenta mais variação significativa.

No Apêndice D é apresentado um estudo comparativo com o trabalho de Pedersen (2001), com o objetivo de validar o algoritmo implementado pelo autor.

\subsection{Método das Assíntotas Móveis}

O "Método das Assíntotas Móveis" ou Method of Moving Asymptotes (MMA) (SVANBERG, 1987) é um algoritmo de otimização genérico baseado em técnicas de programação matemática. Trata-se de um método de primeira ordem e que, portanto, necessita de informações sobre os valores da função objetivo e restrições do problema e de suas derivadas (gradientes) em relação às variáveis de projeto. É atualmente um dos algoritmos mais utilizados na literatura sobre otimização (PEDERSEN, 2001; GUEST; PRéVOST; BELYTSCHKO, 2004; PEDERSEN; SESHIA, 2004; OLESEN; OKKELS; BRUUS, 2006; LE et al., 2010).

O MMA resolve problemas de otimização no formato apresentado em (4.27), cujas variáveis de projeto são $\mathbf{x}=\left(x_{1}, \ldots, x_{n}\right)^{T} \in \mathbb{R}^{n}, \mathbf{y}=\left(y_{1}, \ldots, y_{m}\right)^{T} \in \mathbb{R}^{m}$ e $z \in \mathbb{R}$ :

$$
\begin{array}{cl}
\underset{\mathbf{x}, \mathbf{y}, z}{\operatorname{Minimizar}} & f_{0}(\mathbf{x})+a_{0} z+\sum_{i=1}^{m}\left(c_{i} y_{i}+\frac{1}{2} d_{i} y_{i}^{2}\right) \\
\text { Sujeito a } & h_{i}(\mathbf{x})-a_{i}(z)-y_{i} \leq 0, \quad i=1, \ldots, m \\
& \mathbf{x} \in X, \quad \mathbf{y} \geq 0, \quad z \geq 0
\end{array}
$$

sendo $X=\left\{\mathbf{x} \in \mathbb{R}^{n} \mid x_{j}^{\text {min }} \leq x_{j} \leq x_{j}^{\text {max }}, \quad j=1, \ldots, n\right\}$, onde $x_{j}^{\text {min }}$ e $x_{j}^{\text {max }}$ são números reais que satisfazem $x_{j}^{\text {min }}<x_{j}^{\text {max }}$ para todo $j, f_{0}, h_{1}, \ldots, h_{m}$ são funções reais, contínuas e diferenciáveis em $X, a_{0}, a_{i}, c_{i}$ e $d_{i}$ são números reais que satisfazem $a_{0}>0, a_{i} \geq 0, c_{i} \geq$ $0, d_{i} \geq 0$ e $c_{i}+d_{i}>0$ para todo $i$, e também $a_{i} c_{i}>a_{0}$ para todo $i$ com $a_{i}>0$.

Em (4.27), as variáveis de otimização "naturais" são $x_{1}, \ldots, x_{n}$, enquanto que $y_{1}, \ldots, y_{m}$ e $z$ são variáveis "artificiais", que facilitam a formulação e solução de algumas classes de problemas, como mínimos quadrados ou problemas minmax. A forma padrão para problemas de otimização, que é a utilizada neste trabalho, pode ser descrita da seguinte 
maneira:

$$
\begin{array}{cl}
\underset{\mathbf{x}}{\operatorname{Minimizar}} & f_{0}(\mathbf{x}) \\
\text { Sujeito a } & h_{i}(\mathbf{x}) \leq 0, \quad i=1, \ldots, m \\
& \mathbf{x} \in X
\end{array}
$$

Para tornar o problema (4.28) (quase) equivalente ao problema (4.27), deve-se fazer $a_{0}=1$ e $a_{i}=0$ para todo $i>0$ e então $z=0$ em toda solução ótima de (4.27). Além disso, $d_{i}=1$ e $c_{i}=$ "um número grande" para todo $i$, de forma que as variáveis $y_{i}$ se tornem muito custosas do ponto de vista do otimizador. Então, tipicamente $\mathbf{y}=\mathbf{0} \mathrm{em}$ qualquer solução ótima de (4.27) e o x correspondente é uma solução ótima de (4.28).

De acordo com Svanberg (2002), a principal vantagem do problema (4.27) é que ele sempre apresenta soluções viáveis e pelo menos uma solução ótima, mesmo que não existam soluções viáveis para o problema (4.28).

De maneira simplificada, no MMA é resolvida uma sequência de subproblemas convexos, sendo que cada um deles pode ser entendido como uma aproximação em relação ao problema original, no entanto, tal aproximação é válida apenas entre os limites determinados pelas assíntotas móveis, que são atualizadas a cada iteração. A solução de cada subproblema fornece subsídios para a construção do próximo, assim, esse processo iterativo continuará até que haja a convergência para a solução ótima. Os detalhes de implementação são discutidos em Svanberg (1987), Senne (2009). Uma versão globalmente convergente do método é proposta em Svanberg (2002). Algumas considerações práticas relativas ao uso do MMA são feitas a seguir.

Em muitas aplicações, as restrições estão na forma $g_{i}(\mathbf{x}) \leq g_{i}^{\max }$, onde $g_{i}$ representa uma restrição de volume de material, por exemplo, e $g_{i}^{\max }$ seria o limite máximo permitido para o volume de material a ser distribuído. Isto significa que $h_{i}(\mathbf{x})=g_{i}(\mathbf{x})-g_{i}^{\max } \mathrm{em}$ (4.27) e (4.28). Sendo assim, para o método funcionar bem, as restrições devem ser escaladas de maneira que $1 \leq g_{i}^{\max } \leq 100$ para cada $i$. De maneira semelhante, a função objetivo $f_{0}(\mathbf{x})$ deve ser preferencialmente escalada de maneira que $1 \leq f_{0}(\mathbf{x}) \leq 100$ e, finalmente, as variáveis $x_{j}$ devem preferencialmente ser escaladas de maneira que $0,1 \leq$ $x_{j}^{\max }-x_{j}^{\min } \leq 100$.

Com relação aos "números grandes" nos coeficientes $c_{i}$ mencionados acima, deve-se evitar números "extremamente grandes" (como $\left.10^{10}\right)$. É mais recomendável começar com valores "razoavelmente grandes" e depois, se ficar constatado que nem todos $y_{i}=0$ na solução ótima, aumentar os valores correspondentes de $c_{i}$ de um fator de 100 e resolver 
o problema novamente. Se as funções e variáveis tiverem sido escaladas adequadamente, como explicado no parágrafo anterior, então valores "razoavelmente grandes" para os parâmetros $c_{i}$ podem ser, por exemplo, $c_{i}=1000$ ou $c_{i}=10000$.

Finalmente, com relação à restrição de caixa $x_{j}^{\text {min }} \leq x_{j} \leq x_{j}^{\text {max }}$, às vezes pode ser o caso de algumas variáveis $x_{j}$ não terem limites superiores ou inferiores prescritos. Nesse caso, é sempre possível escolher limites artificiais de forma que estes sejam satisfeitos para toda solução realística $\mathbf{x}$. 


\section{Resultados e discussões}

Neste capítulo serão apresentados inicialmente dois problemas com o propósito de validar a teoria exposta nos capítulos anteriores, tanto para Otimização Topológica (OT) quanto para Otimização Paramétrica com incertezas (RBDO). Na sequência, um estudo de caso detalhado sobre o Projeto AcelerAD será apresentado e resolvido primeiramente por RBDO e depois por OT.

\subsection{Problema da treliça de 10 barras}

Um problema já bastante discutido na literatura relacionada a RBDO é o da treliça de 10 barras ilustrada na Fig. 5.1 (LEE, 1987; THANEDAR; KODIYALAM, 1992; LUO; GRANDHI, 1997; LEE; YANG; RUY, 2002; AGARWAL, 2004). Ela é construída em Alumínio com módulo de elasticidade $E=10^{7} \mathrm{psi}$, densidade $0,1 \mathrm{lb} / \mathrm{in}^{3}$ e sujeita a um carregamento externo $F=10^{5} l b$, e deve ser otimizada com o objetivo de reduzir o seu peso, sendo que o deslocamento vertical máximo do nó 2 não pode ultrapassar 2 in. As variáveis de projeto consideradas são as seções transversais $A_{i}$ de cada uma de suas barras, as quais não podem ser inferiores a $0,10 \mathrm{in}^{2}$. O sistema americano de unidades é utilizado nesse problema para facilitar a comparação com os resultados existentes na literatura.

Em primeiro lugar é avaliado o problema de otimização determinístico que servirá como base de comparação para os resultados obtidos no estudo considerando incertezas. Em ambos os casos foi utilizado o algoritmo MMA, com ponto de partida em $A_{i}=10$, aliado ao MEF, com discretização em elementos de treliça (dois deslocamentos como graus de liberdade por nó), para a realização das análises estruturais.

É importante mencionar que o elemento adotado (treliça) é diferente e muito mais simples do que aquele discutido na Seção 4.2.1 e utilizado no MOT. Para uma explicação detalhada sobre a sua teoria e implementação numérica, o leitor é direcionado para Reddy (1993). O cálculo das sensibilidades para este problema é muito parecido com o que está ilustrado na Seção 4.2.3 para OT, já que ambos necessitam da avaliação da flexibilidade média. A principal diferença é que o gradiente neste caso deve ser calculado em relação 


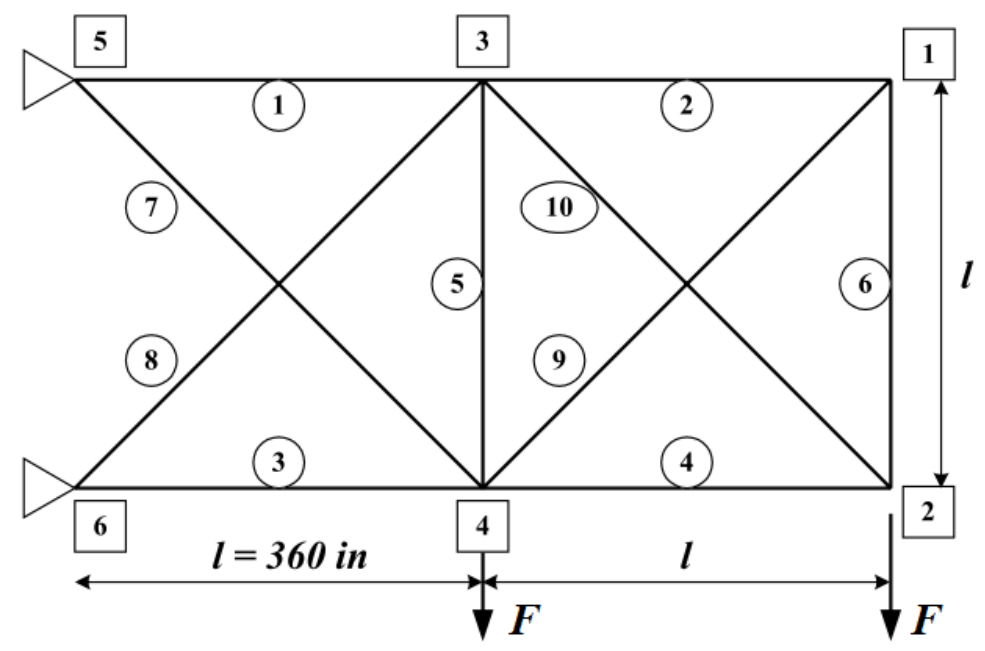

Figura 5.1: Problema de otimização de uma viga em balanço.

as variáveis A (área das seções transversais das barras da treliça) ao invés das pseudodensidades $\gamma$. Este cálculo está apresentado no Apêndice E.

A otimização determinística gera uma estrutura com peso final de 4879, $37 l b$, sendo que os valores de cada seção transversal $A_{i}$ estão apresentados na segunda coluna da Tab. 5.1. Luo e Grandhi (1997) trabalhando com um problema idêntico obteve um peso final de 4885, $28 \mathrm{lb}$, valor ligeiramente superior ao obtido neste trabalho.

Tabela 5.1: Valores ótimos para as médias das áreas das seções transversais $A_{i}$.

\begin{tabular}{c|c|c|c}
\hline Barra & determ. & $\beta=3$ & Lee $(2002)$ \\
\hline 1 & 31,58 & 38,73 & 39,16 \\
2 & 0,10 & 0,10 & 0,10 \\
3 & 21,84 & 26,99 & 27,67 \\
4 & 15,32 & 19,44 & 19,16 \\
5 & 0,10 & 0,10 & 0,10 \\
6 & 0,10 & 0,10 & 0,10 \\
7 & 2,80 & 3,26 & 2,64 \\
8 & 22,46 & 28,37 & 28,03 \\
9 & 21,67 & 27,16 & 27,49 \\
10 & 0,10 & 0,10 & 0,10 \\
\hline Peso $(l b)$ & 4879,37 & 6074,52 & 6072,10 \\
Conf. & $50 \%$ & $99,87 \%$ & $99,87 \%$ \\
\hline
\end{tabular}

Para o caso do problema de otimização probabilístico, as propriedades estatísticas utilizadas estão resumidas na Tab. 5.2. Neste exemplo, todas as variáveis de projeto são aleatórias do tipo gaussiana, assim como o carregamento $F$ e o módulo de elasticidade $E$ e a função de estado limite é não linear (deslocamento no nó 2 da treliça). Um índice de confiabilidade alvo $\beta \geq 3$ é aplicado sobre a restrição de deslocamento para que a confiabilidade da estrutura seja superior a 99,87\%. A configuração obtida na otimização 
determinística possui confiabilidade próxima de 50\%, o que indica que esta configuração é inadequada e precisa ser reavaliada para atingir a confiabilidade desejada.

Tabela 5.2: Propriedades estatísticas para o problema da treliça de 10 barras

\begin{tabular}{llccc}
\hline & Descrição & Distribuição & Média & CoV \\
\hline$E$ & Módulo de Elasticidade $[p s i]$ & Normal & $10^{7}$ & 0,05 \\
$F$ & Carreg. de projeto $[l b]$ & Normal & $10^{5}$ & 0,05 \\
$A_{i}$ & Área da seção $(i=1,2, \ldots, 10)\left[i n^{2}\right]$ & Normal & $\mu_{A_{i}}$ (var. projeto) & 0,05 \\
\hline
\end{tabular}

Utilizando o método PMA para o cálculo de probabilidades foi possível obter um peso final de 6074, 52 lb com os valores para as médias de cada uma das seções transversais indicados na terceira coluna da Tab. 5.1. No total foram necessárias 33 iterações do problema de otimização propriamente dito e 172 iterações da busca pelo ponto MPTP. Todos estes valores estão muito próximos dos apresentados por Lee, Yang e Ruy (2002) e também listados na Tab. 5.1.

Como últimas observações vale citar que, neste exemplo, a variação do módulo de elasticidade do material $E$ apresenta o efeito mais importante sobre a confiabilidade da estrutura. Além disso, o mesmo problema repetido com a utilização do método RIA, ao invés do PMA, para o cálculo de probabilidades falhou em convergir para o resultado ótimo, da mesma forma que ocorreu em Lee, Yang e Ruy (2002).

\subsection{Projeto de mola plana por OT}

Um caso já bastante estudado na literatura relacionada a Otimização Topológica é o exemplo da coluna cônica (GUEST, 2009), ilustrado na Fig. 5.2. Um carregamento unitário é aplicado no centro da aresta direita e todos os graus de liberdade ao longo da aresta esquerda estão restringidos. O domínio é discretizado em uma malha de 120x120 elementos de tamanho unitário e é utilizada a técnica de projeção com raio mínimo $r_{\min }=2$.

A solução ótima para este problema utilizando a formulação convencional de minimização de flexibilidade (4.15) e restrição de volume de 50\% está ilustrada na Fig. 5.3, na qual também são indicados o tamanho do membro mínimo e a flexibilidade média obtida (L). Variando-se o limite superior da restrição de volume $\left(V_{\max }\right)$ obtém-se os resultados ilustrados na Fig. 5.4.

Observando os resultados apresentados nas Figuras 5.3 e 5.4 fica claro que a formulação convencional é bastante limitada para a obtenção de estruturas flexíveis aplicáveis na prática, já que todo ganho de flexibilidade é alcançado apenas pela redução da seção 


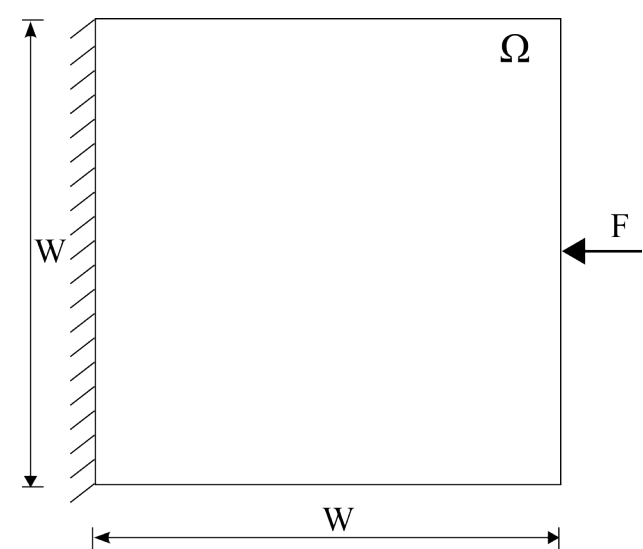

Figura 5.2: Domínio Fixo Estendido de Projeto para o problema da coluna cônica.

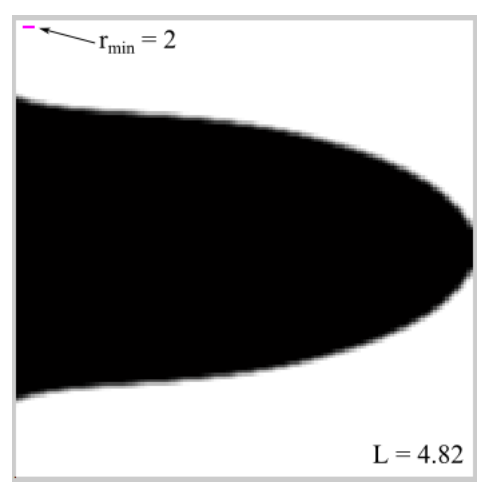

Figura 5.3: Resultado obtido para restrição de volume de $50 \%$ com a formulação (4.15).

transversal da viga. Além da estrutura obtida ser muito frágil, ela deverá se deformar por flambagem, que é um fenômeno não-linear e portanto indesejado para a aplicação vislumbrada neste trabalho (sensores).

A formulação inversa (4.16) é a primeira proposta para tentar aumentar o nível de flexibilidade dos resultados, nela objetiva-se a minimização do volume com níveis especificados de flexibilidade. O objetivo final é a obtenção de estruturas em zig-zag similares a ilustrada na Fig. 5.5, a qual apresenta volume de material $V=13 \%$ e flexibilidade média $L=1,2 \times 10^{5}$.

A Fig. 5.6 ilustra alguns resultados obtidos com a formulação inversa. A convergência do algoritmo de otimização mostrou-se satisfatória apenas no caso (a), para todos os demais foi bastante instável. Isso fica evidenciado pela topologia acinzentada obtida (valores de pseudo-densidades entre 0,5 e 0,6), o que é indesejável do ponto de vista de fabricação. O aparecimento de regiões com escala de cinza ocorre por que estas apresentam menor volume e maior flexibilidade, ou seja, satisfazem numericamente as condições do problemas.

Apesar da topologia apresentada na Fig. 5.6(a) ainda estar distante, do ponto de vista de flexibilidade, da estrutura em zig-zag, trata-se de um resultado positivo e muito mais interessante do que os obtidos anteriormente através da formulação convencional (4.15).

Em seguida foi testada a formulação (4.18), na qual, além da restrição de flexibilidade, é também incluída uma restrição de perímetro. Na Fig. 5.7 pode-se observar alguns resultados obtidos com essa nova formulação. No quadro, $L$ indica o valor da flexibilidade média especificada, que aumenta de cima para baixo, e $P$ o perímetro da topologia, que aumenta da esquerda para a direita.

Note que com essa formulação o algoritmo de otimização utiliza principalmente três 


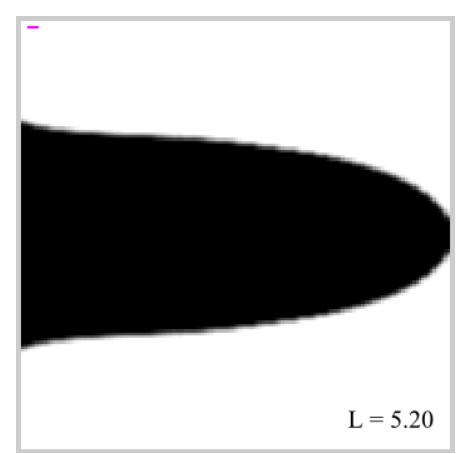

(a) $V_{\max }=40 \%$

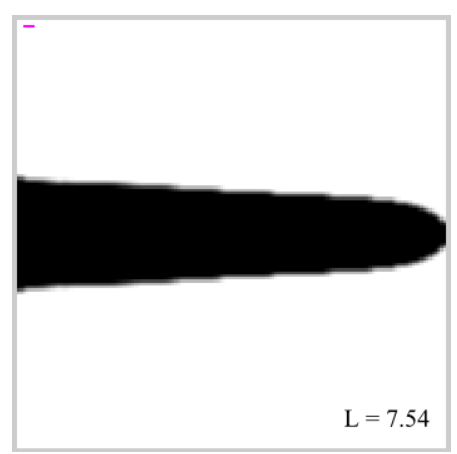

(c) $V_{\max }=20 \%$

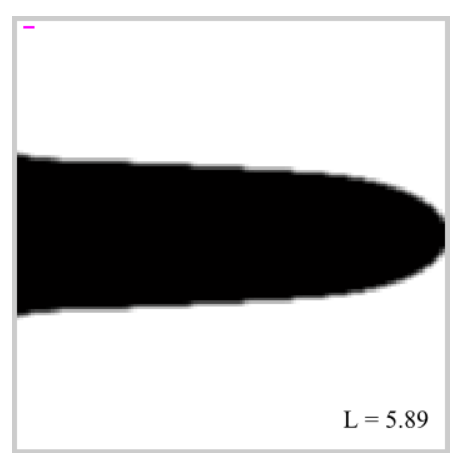

(b) $V_{\max }=30 \%$

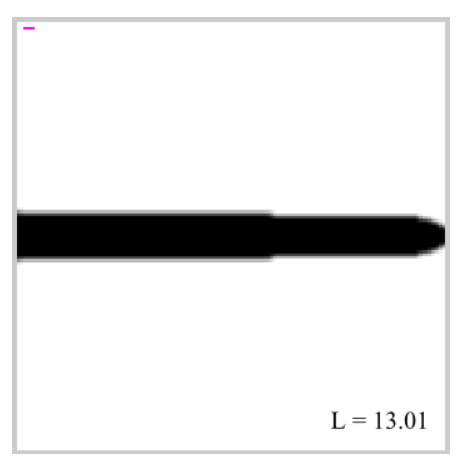

(d) $V_{\max }=10 \%$

Figura 5.4: Diferentes topologias obtidas com a formulação (4.15) variando-se limite superior da restrição de volume.

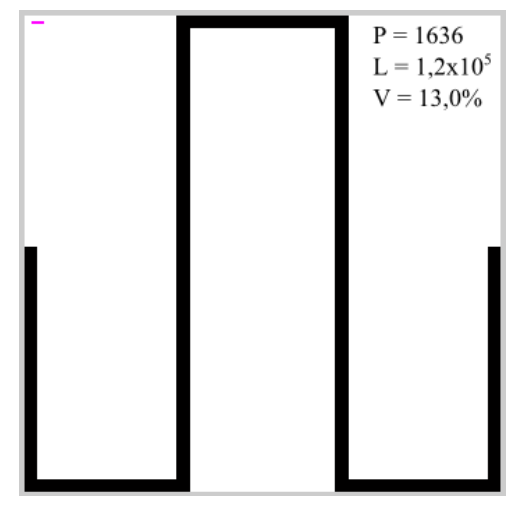

Figura 5.5: Estrutura em zig-zag que possibilita alta flexibilidade.

estratégias para alcançar o seu objetivo: 1) colocação de material nas bordas do domínio de projeto; 2) aparecimento de estruturas desconexas, como em (h), (l) e (p); 3) "pernas acinzentadas" com valores intermediários de pseudo-densidades, como em (m) e (n). Dessa forma, ele consegue satisfazer tanto a restrição de perímetro quanto de flexibilidade impostas. Os dois últimos artifícios podem, no entanto, comprometer o resultado obtido, sendo necessário uma etapa adicional de pós-processamento, que em alguns casos implica na redução do seu desempenho (rigidez). Já a estratégia (1) é bastante válida para a obtenção de estruturas altamente flexíveis.

Apesar de algumas limitações, esta formulação se mostrou bem sucedida na geração 


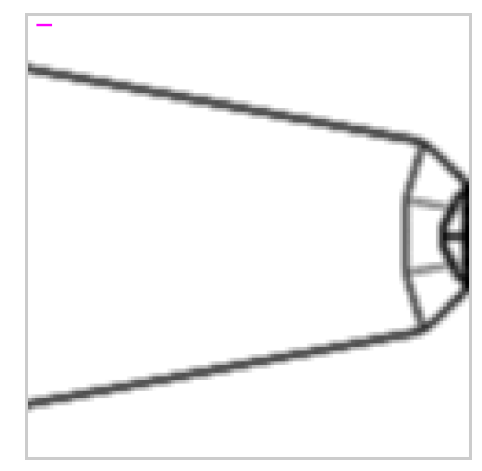

(a) $L=5 \times 10^{2}$

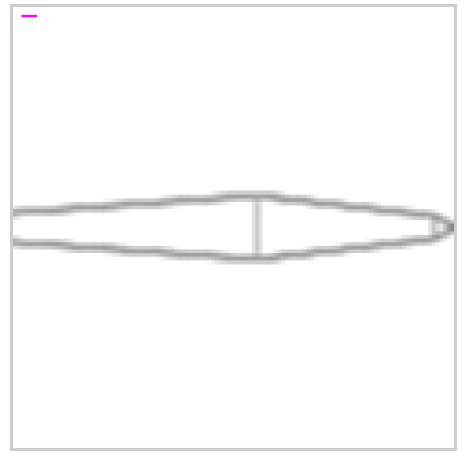

(c) $L=1 \times 10^{4}$

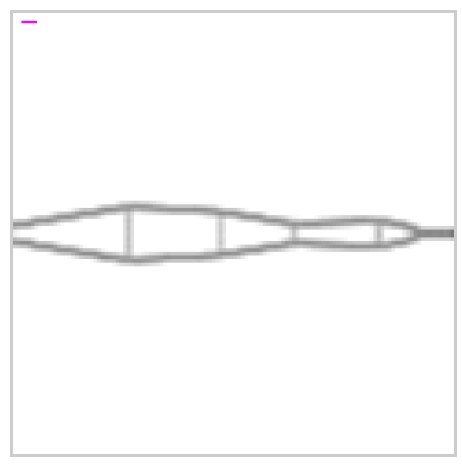

(b) $L=5 \times 10^{3}$

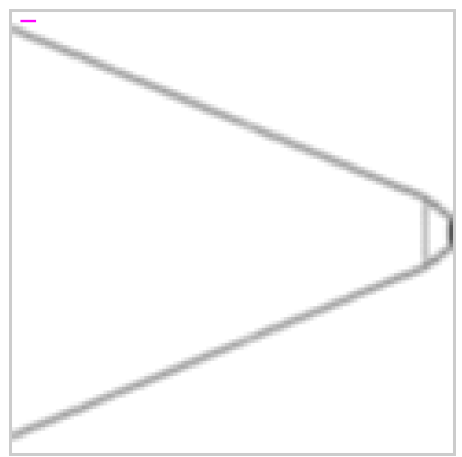

(d) $L=2 \times 10^{4}$

Figura 5.6: Topologias obtidas com diferentes níveis de flexibilidade média especificados utilizando a formulação (4.16).

de topologias com altos níveis de flexibilidade, com aplicações claras em engenharia, como em (i), (j), (k) e (o). A adição da restrição de perímetro contribui também para melhorar o padrão de convergência do otimizador, reduzindo oscilações e consequentemente diminuindo o número de iterações necessárias para se atingir os objetivos da otimização.

Um último teste para ressaltar a viabilidade da inclusão do controle sobre o perímetro no aumento da flexibilidade é ilustrado na Fig. 5.8. Neste caso foi retomada a primeira formulação discutida (4.16), na qual se objetiva a minimização da flexibilidade com restrição de volume. Para todos os casos estudados foi utilizado $V_{\max }=10 \%$ na restrição de volume. Para facilitar a comparação, em (a) está repetido o resultado já discutido da Fig. 5.4(d), sem a inclusão da restrição de perímetro. A partir de (b) inclui-se um valor mínimo para o perímetro da topologia e este é gradativamente incrementado até (f).

No canto superior esquerdo das figuras é indicado o valor de flexibilidade média $L$ para cada topologia. O resultado da Fig. 5.8(a) possui perímetro $P=186$ e flexibilidade $L=13$. A simples adição da restrição de perímetro $P_{\min }=200 \mathrm{em}$ (b) já possibilitou um aumento de quase uma ordem de grandeza na flexibilidade estrutural, em comparação a (a). É notável que existe uma relação entre o aumento do perímetro da topologia e a sua flexibilidade. No entanto, a partir de um certo ponto (nesse estudo $P_{\min } \approx 1000$ ), 


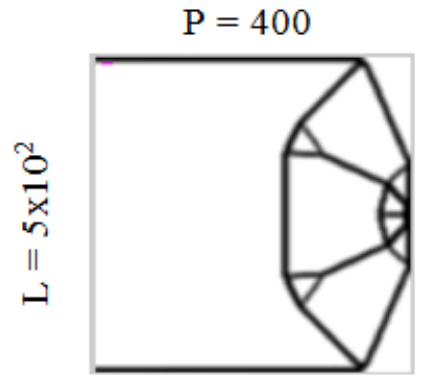

(a)

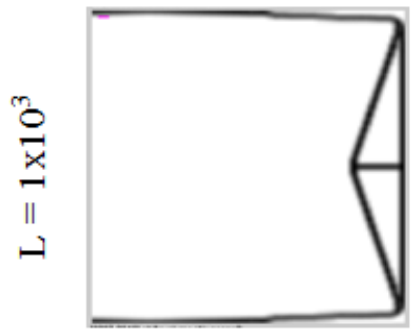

(e)

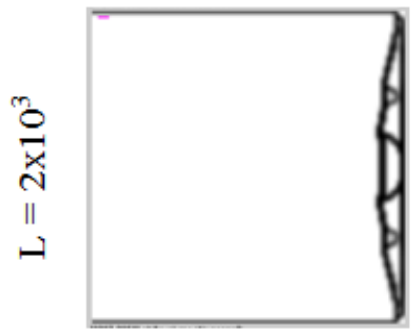

(i)

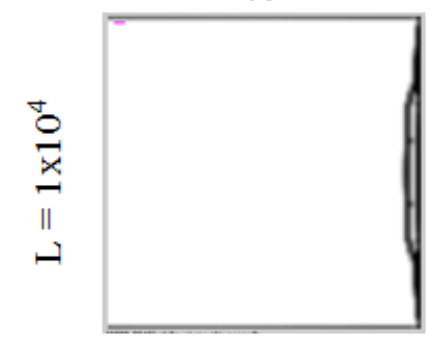

(m)

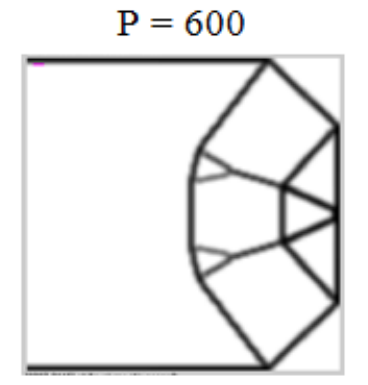

(b)

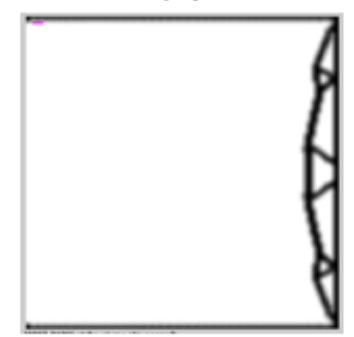

(f)

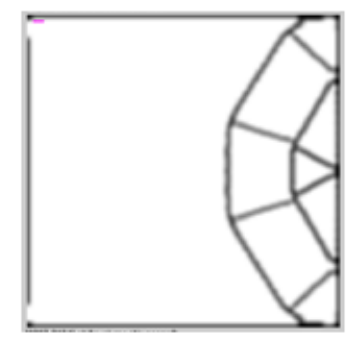

(j)

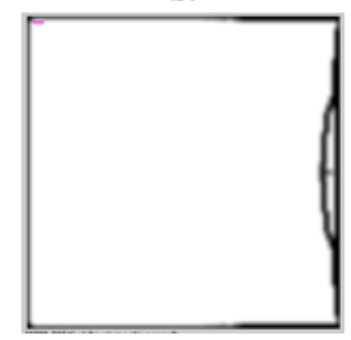

(n)

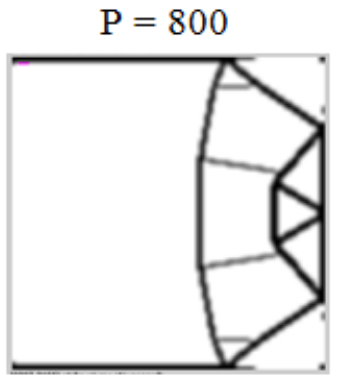

(c)

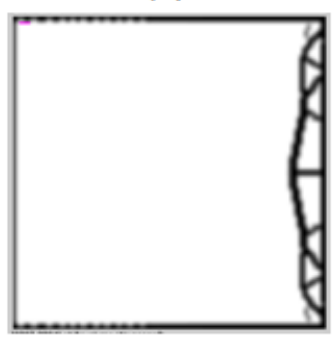

(g)

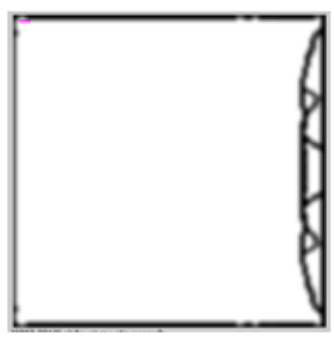

(k)

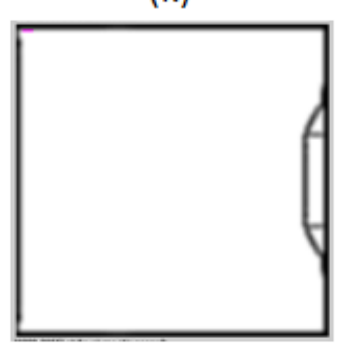

(o)

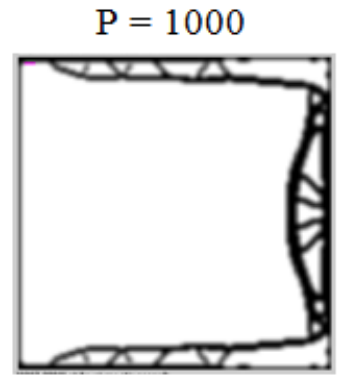

(d)

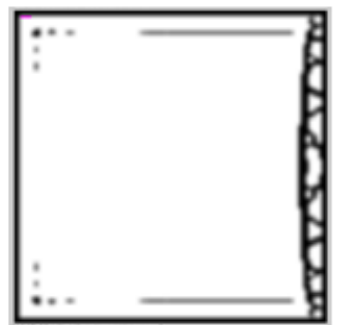

(h)

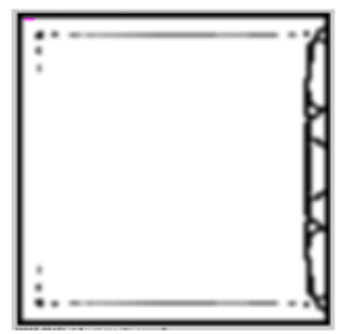

(I)

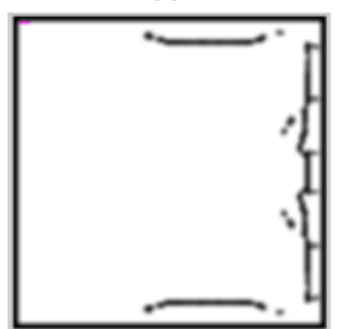

(p)

Figura 5.7: Diferentes topologias obtidas utilizando a formulação (4.18) variando-se o nível de flexibilidade exigida e o perímetro da estrutura.

começa a ocorrer o aparecimento de estruturas desconexas, que do ponto de vista de rigidez estrutural tem pouca influência, mas contribuem de forma importante para o aumento do perímetro. Essas ilhas de materiais devem ser removidas através de uma etapa intermediária de pós-processamento ou interpretação.

A Fig. 5.9 ilustra os mesmo resultados depois da etapa de pós-processamento da topologia e a Tab. 5.3 apresenta um resumo comparativo dos resultados obtidos antes e depois desta etapa. Na Tab. 5.3, $P_{\text {min }}$ indica o valor imposto na restrição de perímetro do problema de otimização, $P$ o valor de perímetro efetivamente obtido pelo otimizador e $P_{P P}$ o valor depois do pós-processamento. De forma similar, $L$ indica a flexibilidade média obtida pelo otimizador, $L_{P P}$ o seu valor após a interpretação e $\Delta L(\%)$ a diferença 


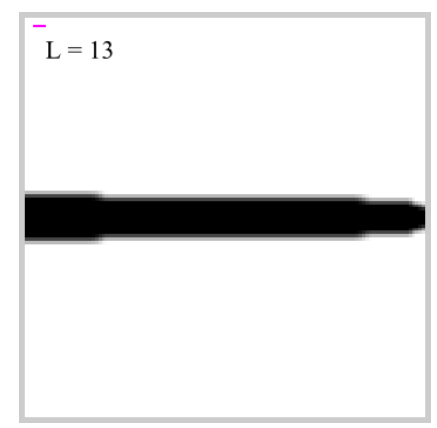

(a) $P_{\text {min }}=0$

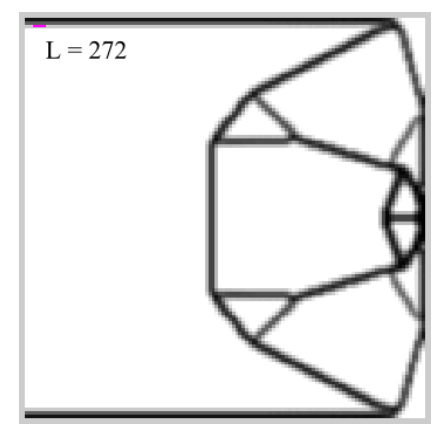

(d) $P_{\text {min }}=600$

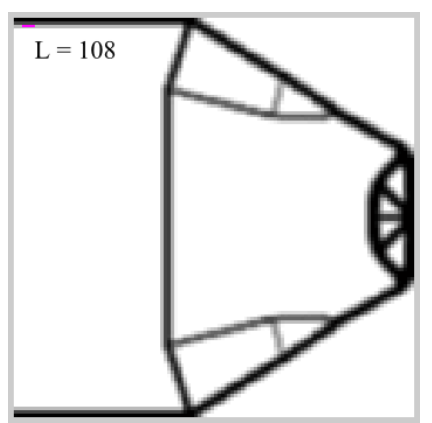

(b) $P_{\text {min }}=200$

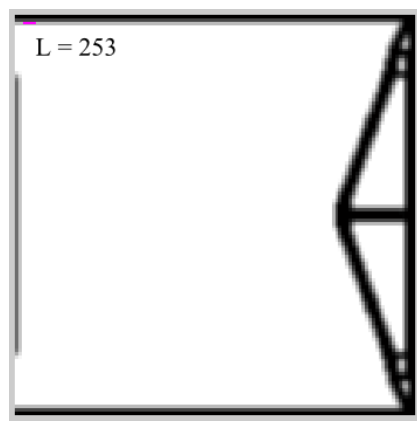

(e) $P_{\min }=800$

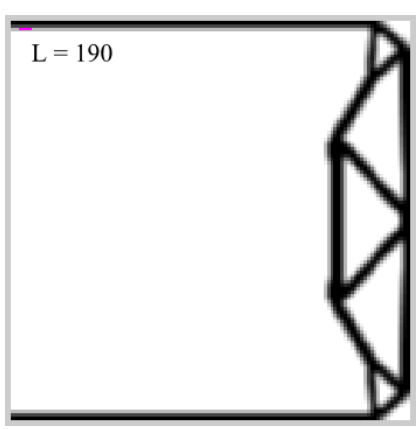

(c) $P_{\text {min }}=400$

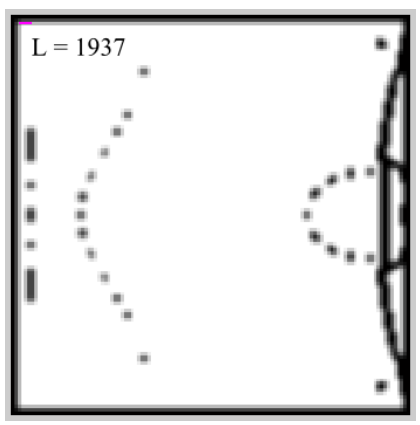

(f) $P_{\min }=1000$

Figura 5.8: Topologias obtidas para diferentes valores de perímetro impostos e restrição de volume fixa em $10 \%$.

percentual entre os dois resultados.

Note que após a interpretação dos resultados, ocorre um aumento grande no valor do perímetro de todas as configurações, devido a retomada do caráter discreto da distribuição de material, sendo este o valor real do perímetro e não mais uma aproximação como ocorre na presença de escalas de cinza. O mais importante, no entanto, é observar o comportamento da flexibilidade estrutural nestas duas situações: existe uma significativa redução depois do pós-processamento dos resultados. Em alguns casos, como em (d), a deterioração do desempenho é da ordem de 70\%. Ainda assim, o resultado em (f) apresenta flexibilidade quase duas ordens de grandeza maior do que em (a), onde não é aplicada a restrição de perímetro.

Tabela 5.3: Resumo dos resultados obtidos nas Figuras 5.8 e 5.9

\begin{tabular}{cc|c|c|c|c|c}
\hline & $P_{\min }$ & $P$ & $P_{p p}$ & $L$ & $L_{p p}$ & $\Delta L(\%)$ \\
\hline (a) & 0 & 186 & 516 & 13 & 12 & 7.7 \\
(b) & 200 & 200 & 2396 & 108 & 51 & 52.8 \\
(c) & 400 & 400 & 1910 & 190 & 108 & 43.2 \\
(d) & 600 & 600 & 2984 & 272 & 82 & 69.9 \\
(e) & 800 & 800 & 1652 & 253 & 162 & 36.0 \\
(f) & 1000 & 1000 & 1816 & 1937 & 969 & 50.0 \\
\hline
\end{tabular}

Apesar de ainda não ter sido possível obter configurações em zig-zag (como aquela 


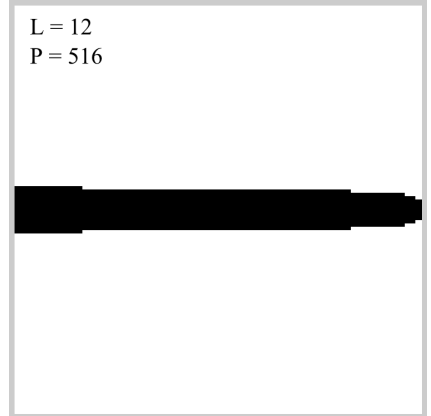

(a) $P_{\text {min }}=0$

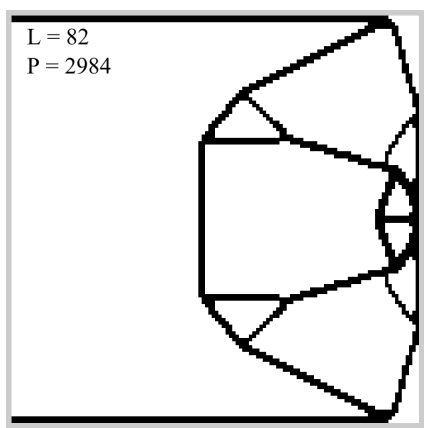

(d) $P_{\text {min }}=600$

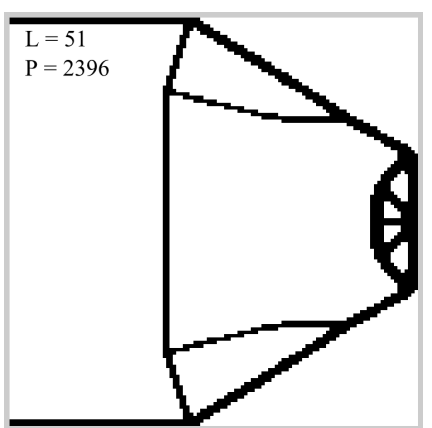

(b) $P_{\text {min }}=200$

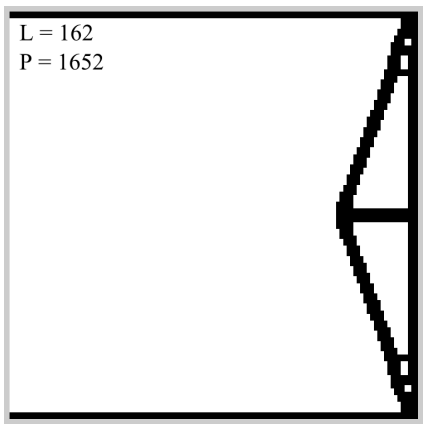

(e) $P_{\text {min }}=800$

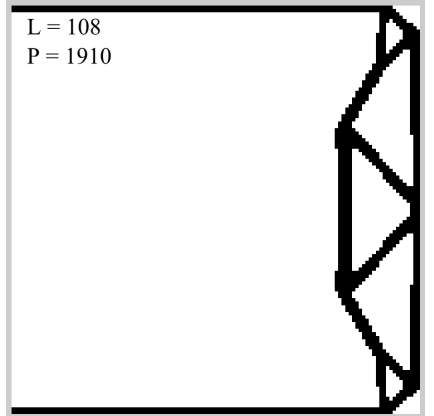

(c) $P_{\text {min }}=400$

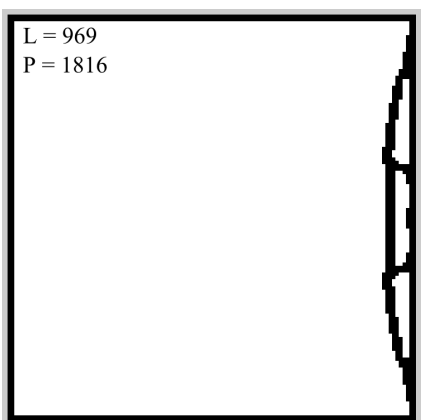

(f) $P_{\text {min }}=1000$

Figura 5.9: Topologias obtidas após o pós-processamento dos resultados da Fig. 5.8.

ilustrada na Fig. 5.5), na opinião do autor, estes resultados são suficientes para validar a utilização da restrição de perímetro para a obtenção de estruturas flexíveis. O padrão em zig-zag representa um mínimo local muito difícil de ser obtido pelo otimizador, por isso, ainda são necessárias condições adicionais para que o mesmo possa ser gerado pelo Método da Otimização Topológica.

Um caminho para viabilizar a obtenção destes resultados pelo MOT é a redução do espaço de soluções possíveis, por exemplo, através de imposição de simetria e repetição de padrão, como detalhado na Fig. 5.10. Nessas condições e mantendo-se a Formulação (4.18), obtém-se o resultado mostrado na Fig. 5.11 e pós-processado na Fig. 5.12. A Tab. 5.4 exibe o comparativo do desempenho de todas as geometrias em zig-zag apresentadas até aqui.

Com base na análise da Tab. 5.4 é possível constatar que finalmente uma estrutura em zig-zag, com desempenho equivalente ao da proposta inicial (Fig. 5.5), foi obtida utilizando o Método da Otimização Topológica. Sem dúvida este é um caso muito específico, mas serve para ilustrar a potencialidade do método aliado ao controle de perímetro para a geração de topologias altamente flexíveis. 


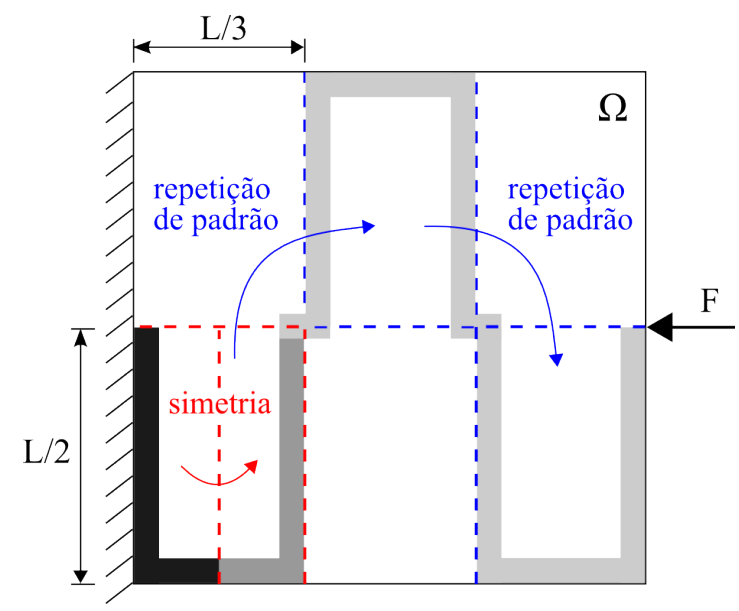

Figura 5.10: Domínio de projeto com simetria e repetição de padrão.

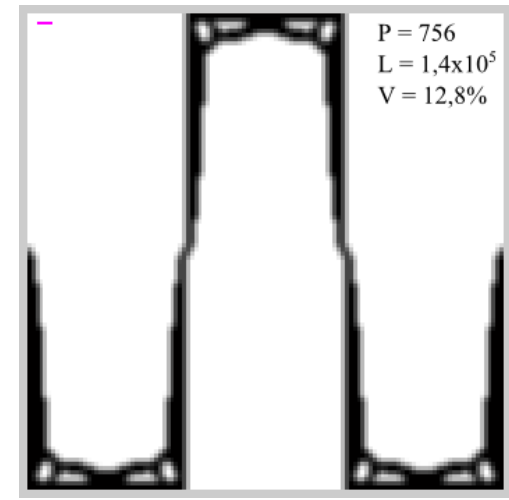

Figura 5.11: Topologia obtida com o domínio de projeto considerando simetria e repetição de padrão.

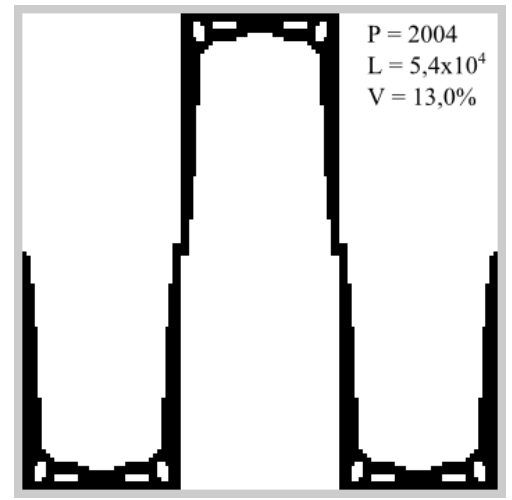

Figura 5.12: Topologia obtida depois da etapa de pós-processamento.

Tabela 5.4: Comparativo das estruturas em zig-zag

\begin{tabular}{c|c|c|c}
\hline Figura & $V(\%)$ & $P$ & $L$ \\
\hline 5.5 & 13,0 & 1636 & $1,2 \times 10^{5}$ \\
5.11 & 12,8 & 756 & $1,4 \times 10^{5}$ \\
5.12 & 13,0 & 2004 & $5,4 \times 10^{4}$ \\
\hline
\end{tabular}

\subsection{Estudo de caso: projeto AcelerAD}

Como já explicado na Seção 1.3, uma topologia inicial foi proposta pelo CSEM, com base em sua experiência anterior com o desenvolvimento de acelerômetros MEMS e todo o projeto AcelerAD foi estruturado em cima dela. A geometria sugerida está ilustrada na Fig. 5.13 e suas dimensões são apresentadas na Tab. 5.5.

As três lâminas de silício utilizadas têm orientação (100) e uma fina camada de óxido de silício (em verde na Fig. 5.13) é utilizada como isolamento elétrico entre elas. A camada do meio é definida por corrosão em solução de $\mathrm{KOH}$, que corrói o silício monocristalino anisotropicamente, ou seja, com diferentes taxas dependendo da orientação dos seus planos 

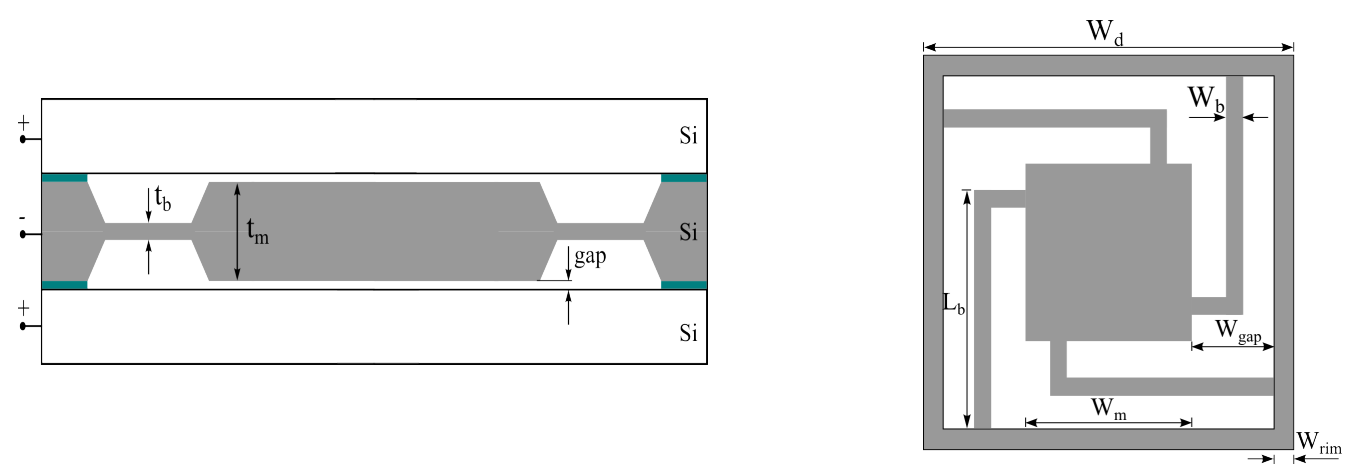

Figura 5.13: Seção transversal (esq.) e vista de topo (dir.) da geometria proposta.

Tabela 5.5: Dimensões do acelerômetro proposto

\begin{tabular}{c|c|c}
\hline Descrição & Simbolo & Valor $(\mu m)$ \\
\hline Largura da massa & $W_{m}$ & 2000 \\
Espessura da massa & $t_{m}$ & 380 \\
Largura da viga & $W_{b}$ & 200 \\
Espessura da viga & $t_{b}$ & 55 \\
Comprimento da viga & $L_{b}$ & 2820 \\
Espaço vazio & gap & 2 \\
Distância entre a massa e a borda & $W_{\text {gap }}$ & 1040 \\
Largura da borda & $W_{\text {rim }}$ & 150 \\
Largura do dispositivo & $W_{d}$ & 4380 \\
\hline
\end{tabular}

cristalinos, resultando em um ângulo de parede de 54,74 (MADOU, 2002).

O levantamento de requisitos para o dispositivo AcelerAD foi realizado através de consulta com as instituições interessadas, o que envolveu desde a Força Aérea Brasileira até empresas como a Petrobrás e a Embraer e grupos de pesquisa com foco em Veículos aéreos não tripulados (VANT). As seguintes especificações foram definidas para o acelerômetro:

- Fundo de escala mínimo de $\pm 5 \mathrm{~g}$

- Resolução de $1 \mathrm{mg} @ 1 \mathrm{~Hz}$

- Sensibilidade de $500 \mathrm{mV} / \mathrm{g}$

- Estabilidade em $48 \mathrm{hs}<5 \mathrm{mg}$

- Temperatura de operação entre $-45^{\circ} \mathrm{C}$ e $125^{\circ} \mathrm{C}$

- Tensão de operação de $5 \mathrm{~V}$

- Largura de banda de $400 \mathrm{~Hz}$

- Empacotamento: LTCC 20 
Os dois último itens não são exatamente especificações do dispositivo, mas surgiram a partir de interações com a equipe do projeto.

Antes de propor novas versões para o acelerômetro, é fundamental avaliar o atendimento dos requisitos, pelo projeto inicialmente proposto. Este estudo foi feito através de simulação computacional em Teves et al. (2011). De acordo com os autores, os principais requisitos estão sendo satisfeitos. Além disso, é desejável que as mesmas técnicas e processos de fabricação possam ser utilizados nas diferentes versões do acelerômetro. Por essas duas razões, o projeto otimizado deverá partir da solução já existente e acrescentar melhorias localizadas, de forma a tornar o desempenho do dispositivo ainda mais interessante para aplicações aeroespaciais.

Neste trabalho, apenas é abordada a otimização da geometria do sistema mecânico, sem qualquer consideração com relação à eletrônica ou ao sistema de controle do acelerômetro. Por isso, alguns dos requisitos listados não serão considerados, como a estabilidade, tensão elétrica de operação e resolução.

Vale destacar também que o mecanismo de transdução capacitivo é pouco influenciado por variações de temperatura, diferentemente do que costuma ocorrer com acelerômetros piezoresistivos, por exemplo. Somado a isso, no processo de otimização serão buscadas apenas soluções com a repetição do padrão indicada na Fig. 5.14, para que o desempenho do dispositivo seja pouco suscetível às consequências da mudança de temperatura, como a expansão térmica. Assim, o requisito de temperatura também não é considerado neste trabalho, já que o seu fator limitante deverá ser a eletrônica embarcada.

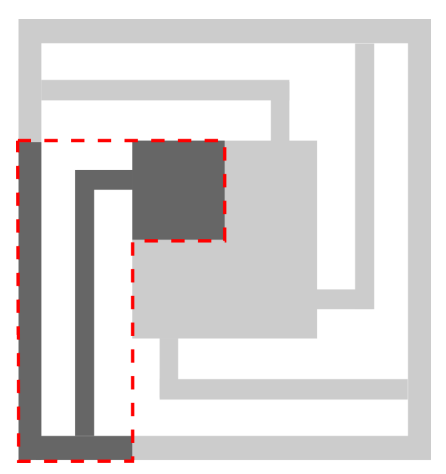

Figura 5.14: Representação da repetição de padrão considerada para o AcelerAD.

Dessa forma, serão considerados apenas os requisitos de sensibilidade, largura de banda e área do dispositivo ("footprint area"), para que o mesmo possa ser acondicionado em uma cápsula cerâmica do tipo "Low-Temperature Co-Fired Ceramic (LTCC)" de 20 pinos.

O comportamento mecânico do acelerômetro foi avaliado analiticamente em Rodrigues 
et al. (2011). Os parâmetros mais importantes para o estudo de otimização são discutidos a seguir.

A partir do sistema massa-mola equivalente é possível obter uma estimativa para a sua primeira frequência de ressonância $f_{n}$, dada por (RODRIGUES et al., 2011):

$$
f_{n}=\frac{1}{2 \pi} \sqrt{\frac{k_{b}}{M_{m}}}=\frac{1}{\pi} \sqrt{\frac{E}{\rho} \frac{W_{b} t_{b}^{3}}{L_{b}^{3} W_{m}^{2} t_{m}}}
$$

onde $E=170 G P a$ e $\rho=2330 \mathrm{~kg} / \mathrm{m}^{3}$ são, respectivamente, o módulo de Young e a densidade do Silício, $k_{b}$ é a constante de mola do sistema, calculada a partir das constantes de mola equivalentes das quatro vigas em "L", e $M_{m}$ é a massa inercial. Com base em (5.1) e nas dimensões dadas na Tab. 5.5 é possível obter o valor da primeira frequência de ressonância do acelerômetro com um erro inferior a $8 \%$ em relação ao valor obtido computacionalmente $(2443 \mathrm{~Hz})$. Note que este valor é suficiente para satisfazer o requisito de largura de banda do sensor, já que a mesma é tipicamente limitada a $\frac{1}{5}$ da primeira frequência de ressonância (HARRIS; CREDE, 1976).

A sensibilidade eletro-mecânica $S_{e}$, em $p F / g$, é o produto entre as sensibilidades mecânica e elétrica e é dada por (RODRIGUES et al., 2011):

$$
S_{e}=\frac{d \delta_{z}}{d a_{z}} \frac{d C_{a}}{d \delta_{z}}=\frac{9,8}{4 \pi^{2} f_{n}^{2}} \frac{C_{a}}{g a p}=\frac{9,8}{4 \pi^{2} f_{n}^{2}} \frac{2 \cdot 10^{12} \varepsilon_{0} W_{m}^{2}}{g a p^{2}}
$$

onde $C_{a}$ é a capacitância ativa do conjunto $(p F), \delta_{z}$ é o deslocamento vertical da massa de prova, $a_{z}$ é aceleração vertical a que o sistema é submetido e $\varepsilon_{0}=8,85 \cdot 10^{-12} \mathrm{~F} / \mathrm{m}$ é a constante dielétrica do vácuo, muito aproximadamente igual a constante dielétrica do ar. Note que $\frac{d C_{a}}{d \delta_{z}}$ é não-linear, o resultado apresentado é obtido após a linearização em torno de $\delta_{z}=0$ utilizando expansão de Taylor de primeira ordem. No projeto proposto inicialmente pelo CSEM, cujas dimensões estão descritas na Tab. 5.5, a sensibilidade é igual a $0,60 \mathrm{pF} / \mathrm{g}$.

A sensibilidade total do sensor $S_{t}$, em $V / g$, somente é obtida após o processamento do sinal por um "Application-Specific Integrated Circuit (ASIC)", que é um CI construído para executar uma tarefa específica, ou seja, customizado para um uso particular ao contrário dos CIs de uso geral. Assim,

$$
S_{t}=S_{e} \cdot S_{C I}
$$

onde $S_{C I}$ é dada em $V / p F$. No entanto, até o momento, as especificações do ASIC a ser utilizado no projeto AcelerAD não são conhecidas. Por isso, neste trabalho assume-se $S_{C I}>0,8 \mathrm{~V} / \mathrm{pF}$, de maneira que o requisito de sensibilidade do sensor $\left(S_{t} \geq 500 \mathrm{mV} / \mathrm{g}\right)$ 
seja satisfeito para $S_{e} \simeq 0,60 \mathrm{pF} / \mathrm{g}$.

\subsection{RBDO aplicado ao projeto AcelerAD}

Inicialmente é feito um estudo de otimização paramétrica determinística, isto é, sem considerar qualquer variável aleatória no problema. Em seguida, diferentes incertezas e níveis de confiabilidade são especificados e os resultados obtidos pelo RBDO são comparados com o projeto inicial e com o ótimo determinístico. As análises estruturais necessárias para esses estudos são feitas com base nas fórmulas analíticas (5.1) e (5.2).

Em todos os casos apresentados abaixo foi utilizado o MMA como otimizador.

\subsubsection{Otimização determinística}

A Tab. 5.6 lista todas as variáveis de projetos $\mathbf{s}$ utilizadas nos estudos, assim como os seus limites superiores e inferiores. Além destas restrições, é especificado também um limite inferior para a primeira frequência de ressonância (Eq. 5.1) e outro para a sensibilidade (Eq. 5.2) do acelerômetro. A função objetivo utilizada é a largura do dispositivo $W_{d}=$ $2 W_{\text {gap }}+W_{m}+2 W_{\text {rim }}$. As dimensões apresentadas na Tab. 5.5 foram adotadas como valores iniciais para a otimização.

Tabela 5.6: Variáveis de projeto adotadas na otimização paramétrica

\begin{tabular}{c|c|c}
\hline Variável & Limite Inf. $(\mu m)$ & Limite Sup. $(\mu m)$ \\
\hline$W_{m}$ & 500 & 2500 \\
$t_{m}$ & 250 & 500 \\
$W_{b}$ & 100 & 300 \\
$t_{b}$ & 10 & 100 \\
$L_{b}$ & 2000 & 3000 \\
$g a p$ & 2 & 10 \\
$W_{\text {gap }}$ & 600 & 1200 \\
$W_{\text {rim }}$ & 100 & 200 \\
\hline
\end{tabular}

Com base no que foi discutido até aqui, o seguinte problema de otimização determinístico é proposto:

$$
\begin{array}{cl}
\underset{\mathbf{s}}{\operatorname{Minimizar}} & W_{d} \\
\text { Sujeito a } & f_{n} \geq 2500 H z \\
& S_{e} \geq 0,6 p F / g \\
& \mathbf{s}_{\mathbf{i n f}} \leq \mathbf{s} \leq \mathbf{s}_{\mathbf{s u p}}
\end{array}
$$


As topologias inicial e otimizada são exibidas lado a lado na Fig. 5.15 e Fig. 5.16 para facilitar a comparação do resultado. A Tab. 5.8 resume os resultados deste estudo, onde se pode observar uma redução de aproximadamente $26 \%$ na largura do dispositivo.

Apesar da significativa redução na largura do dispositivo, note que o projeto inicial apresenta confiabilidade de 56,10\%, enquanto o otimizado de apenas 50.00\%. Esses resultados reforçam o alerta que foi feito anteriormente a respeito de otimização determinística, isto é, quando uma estrutura é otimizada os excessos de material em geral são removidos, o que a torna ainda mais suscetível às incertezas presentes nos seus processos de fabricação ou na sua aplicação final.

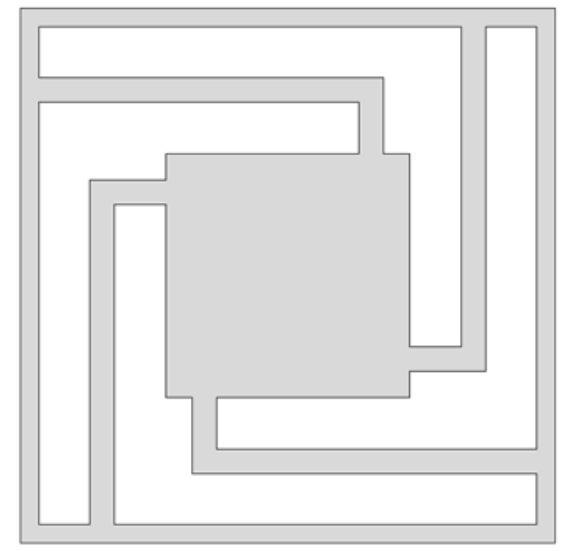

(a) projeto inicial

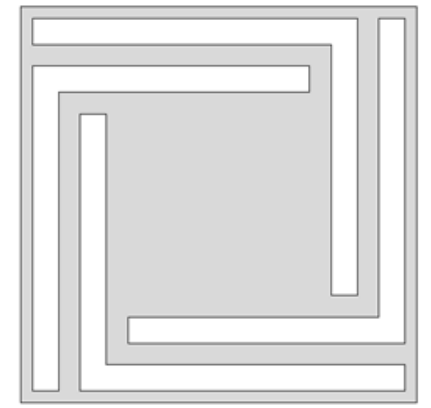

(b) ótimo determinístico

Figura 5.15: Comparativo da topologia obtida através do problema (5.4) com o projeto inicial.

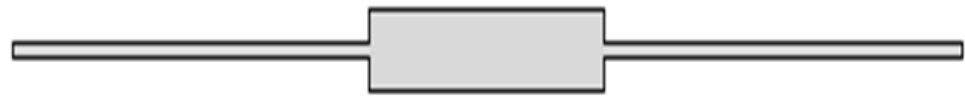

(a) projeto inicial

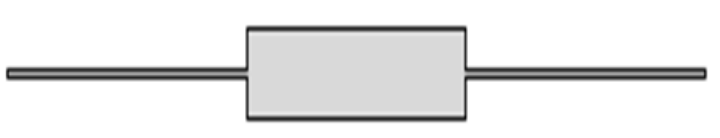

(b) ótimo determinístico

Figura 5.16: Comparativo da seção transversal obtida através do problema (5.4) com o projeto inicial. A razão de aspecto foi exagerada para facilitar a comparação das espessuras.

Como forma de validação dos resultados, a topologia ótima obtida foi simulada no software Comsol utilizando elementos de placa estrutural (Seção 4.2.1). O primeiro modo de vibrar, obtido através de uma análise modal, está ilustrado na Fig. 5.17. Note que a frequência de ressonância neste modo $(2473,95$ HZ) é bem próxima da calculada analiticamente, com uma diferença de apenas 1\%. De forma similar, a sensibilidade obtida via 
MEF é de 0,309, apenas 3\% maior que a obtida analiticamente. Esses resultados reforçam a validade das fórmulas analíticas propostas para a análise estrutural (Eq. 5.1 e Eq. 5.2).

\author{
Eigenfrequency $=2473.957711$ \\ Surface: Total displacement (m) Surface Height: Total displacement (m)
}

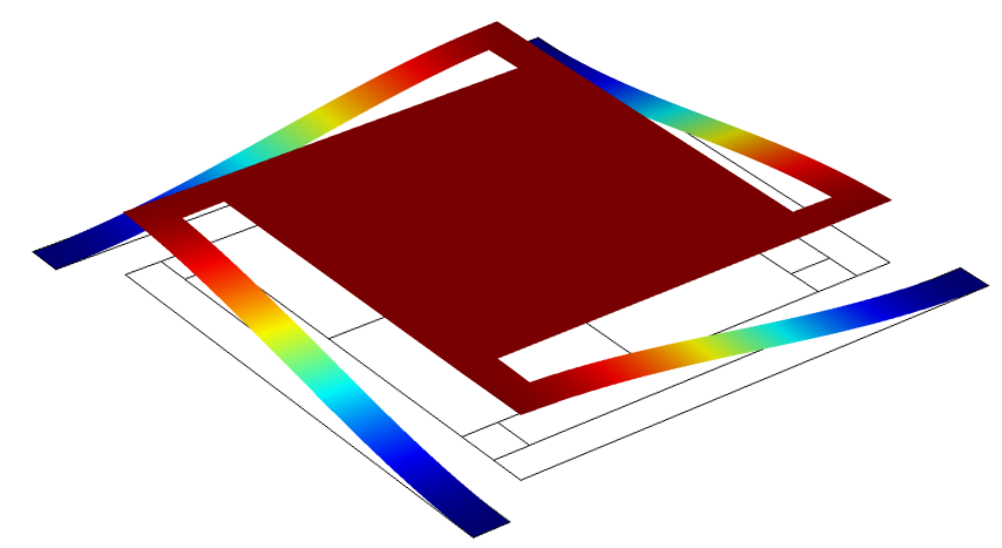

Figura 5.17: Primeira frequência de ressonância (modo pistão): 2473,95 Hz.

\title{
5.4.2 RBDO com incertezas nas propriedades do material
}

Em seguida é analisado o problema de RBDO considerando as propriedades do material como incertezas (r). Elas são consideradas variáveis gaussianas com os parâmetros estatístico apresentados na Tab. 5.7. Todas as demais condições são mantidas idênticas ao caso anterior.

Tabela 5.7: Distribuições estatísticas associadas às propriedades do material (silício)

\begin{tabular}{llccc}
\hline & Descrição & Distribuição & Média & CoV \\
\hline$E$ & Módulo de Young [GPa] & Normal & 170 & 0,10 \\
$\rho$ & Densidade $\left[\mathrm{kg}_{\mathrm{m}} \mathrm{m}^{3}\right]$ & Normal & 2330 & 0,10 \\
\hline
\end{tabular}

É importante mencionar que nenhum estudo experimental foi feito com o objetivo de avaliar se os dados tabelados descrevem adequadamente o comportamento estatístico destas variáveis aleatórias, por isso este problema deve ser entendido meramente como um exemplo de aplicação do método.

Utilizando a abordagem RIA, o novo problema de otimização é posto da seguinte 
forma:

$$
\begin{array}{cl}
\underset{\mathbf{s}}{\operatorname{Minimizar}} & W_{d} \\
\text { Sujeito a } & \beta\left(f_{n}(\mathbf{s}, \mathbf{r}) \geq 2500\right)-\bar{\beta} \geq 0 \\
& \beta\left(S_{e}(\mathbf{s}, \mathbf{r}) \geq 0,6\right)-\bar{\beta} \geq 0 \\
& \mathbf{s}_{\text {inf }} \leq \mathbf{s} \leq \mathbf{s}_{\text {sup }}
\end{array}
$$

onde $\bar{\beta}$ é o índice de confiabilidade mínimo exigido, sendo que três casos diferentes são avaliados: $\bar{\beta}=1, \bar{\beta}=2$ e $\bar{\beta}=3$, representando confiabilidades de $84,13 \%, 97,72 \%$ e $99,86 \%$, respectivamente. Para o caso determinístico avaliado anteriormente pode-se dizer que a confiabilidade é de $50 \%$.

Com as restrições impostas, o algoritmo de otimização não conseguiu convergir para uma configuração compatível com o nível de confiabilidade equivalente a $\bar{\beta}=3$. Para tornar isso possível seria necessário, entre outras variações, estender o limite superior da variável $W_{m}$ para pelo menos $2875 \mu \mathrm{m}$.

Os resultados obtidos para os outros dois valores de índice de confiabilidade estão apresentados na Fig.5.22 e Fig.5.23. A Tab. 5.8 resume os resultados de todos os estudos apresentados até aqui, inclusive os resultados referentes ao projeto inicialmente proposto pelo CSEM.

Tabela 5.8: Resultados da Otimização Paramétrica com e sem confiabilidade (dimensões em $\mu m$ )

\begin{tabular}{c|c|c|c|c}
\hline & CSEM & determ. & $\beta=1$ & $\beta=2$ \\
\hline$W_{m}$ & 2000 & 1847 & 2129 & 2464 \\
$t_{m}$ & 380 & 405 & 380 & 361 \\
$W_{b}$ & 200 & 179 & 200 & 215 \\
$t_{b}$ & 55 & 46 & 55 & 61 \\
$L_{b}$ & 2820 & 2447 & 2706 & 2733 \\
$g a p$ & 2 & 2 & 2 & 2 \\
$W_{\text {gap }}$ & 1040 & 600 & 600 & 600 \\
$W_{\text {rim }}$ & 150 & 100 & 100 & 100 \\
$f_{n}(\mathrm{~Hz})$ & 2678 & 2500 & 2684 & 2886 \\
$S_{e}(\mathrm{pF} / \mathrm{g})$ & 0,60 & 0,60 & 0,69 & 0,80 \\
$W_{d}$ & 4380 & $-25,8 \%$ & $-19,4 \%$ & $-11,8 \%$ \\
Conf. & $56,10 \%$ & $50,00 \%$ & $84,13 \%$ & $97,72 \%$ \\
\hline
\end{tabular}

A largura do dispositivo $W_{d}$ somente é dada explicitamente para a geometria proposta inicialmente pelo CSEM, para todos os demais casos ela é tabelada como a redução percentual em relação a esta geometria. Como esperado, com o aumento do índice de confiabilidade, a redução do tamanho do dispositivo é cada vez menor, no entanto, o resultado é cada vez mais robusto às variações inerentes nas propriedades do material. 


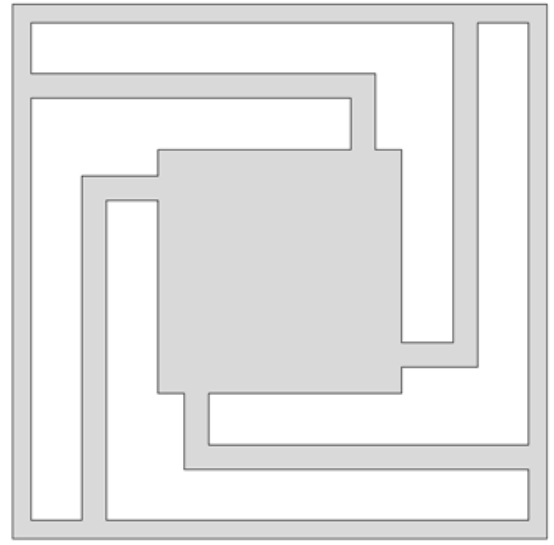

(a) projeto inicial

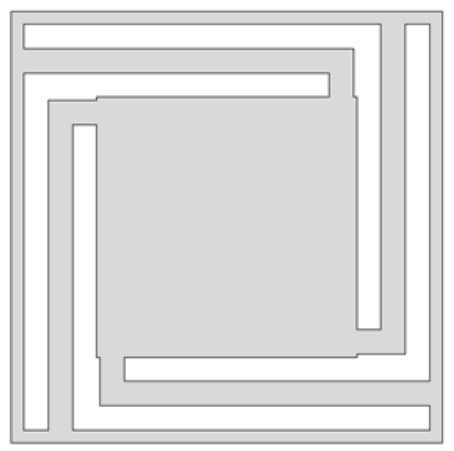

(c) $\beta=1$

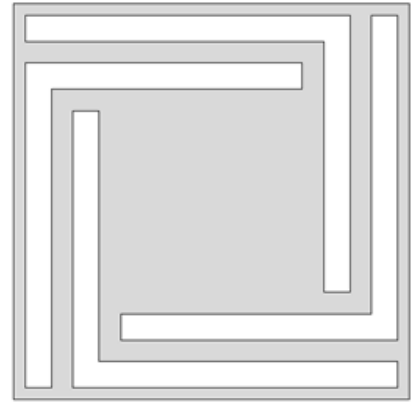

(b) ótimo determinístico

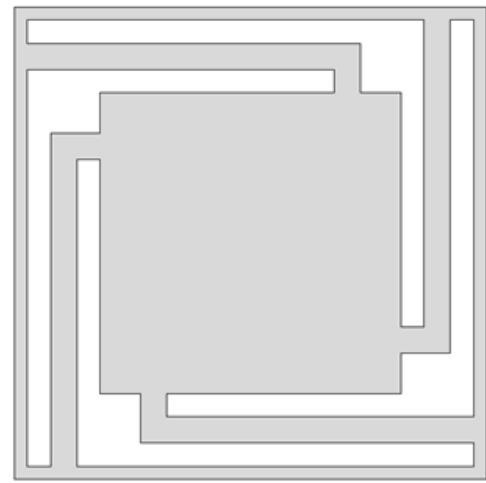

(d) $\beta=2$

Figura 5.18: Comparativo das topologias obtidas através do problema (5.5) com o ótimo determinístico e com o projeto inicial.

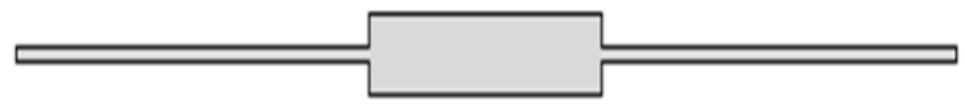

(a) projeto inicial $(\beta=0.15)$

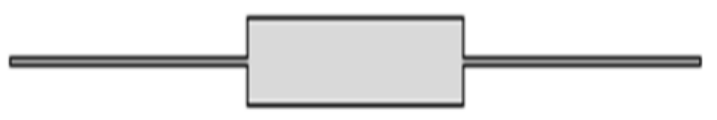

(b) ótimo determinístico $(\beta=0)$

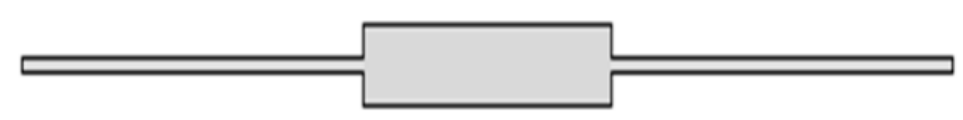

(c) $\beta=1$

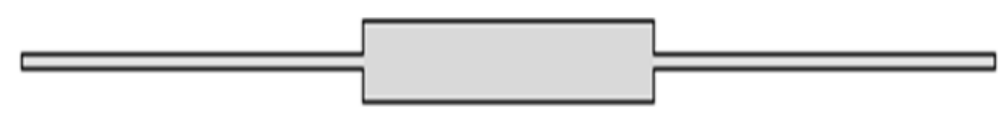

(d) $\beta=2$

Figura 5.19: Comparativo das seções transversais obtidas através do problema (5.5) com o ótimo determinístico e com o projeto inicial. A razão de aspecto foi exagerada para facilitar a comparação das espessuras. 
Note que, com as restrições aqui imposta, é possível obter uma topologia quase $12 \%$ menor do que o projeto inicialmente proposto, com aumento de confiabilidade para $97,72 \%$, isto é, a cada cem dispositivos fabricados, no máximo três podem não atender os requisitos de frequência de ressonância e sensibilidade.

Finalmente, é importante mencionar que resultados idênticos foram obtidos com a metodologia PMA, porém com ganhos de até 30\% no tempo de solução.

Como forma de validar os resultados acima obtidos, utilizou-se o método de Monte Carlo para calcular a probabilidade de falha da configuração final obtida pelo otimizador RBDO quando $\bar{\beta}=2$. As Figuras 5.20 e 5.21 e a Tab. 5.9 resumem o resultado desse estudo, o qual se baseou em 225.000 amostras com um tempo de processamento total de aproximadamente 35 minutos.

Nas Figuras 5.20 e 5.21, as duas linhas centrais perpendiculares representam o valor médio das variáveis aleatórias $E$ e $\rho$, as linhas mais claras simbolizam dois desvios-padrão da média. Os pontos plotados em verde representam uma situação de operação segura e, por outro lado, os indicados em vermelho uma situação de falha. A figura ilustra também o histórico das iterações pelo método RIA e o ponto MPFP (Seção 2.3.2).

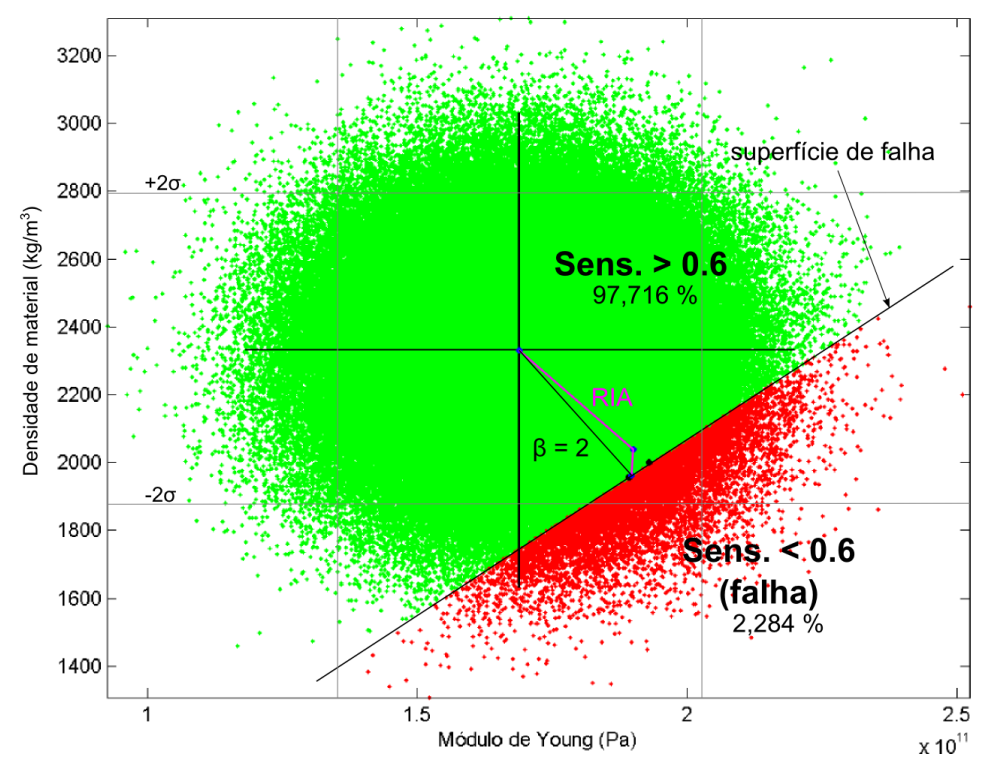

Figura 5.20: Resultado do cálculo de probabilidades para a restrição de sensibilidade utilizando o método de Monte Carlo com 225.000 amostras. O eixo horizontal representa a variação no módulo de Young $E$ e o vertical na densidade do material $\rho$.

Avaliando os resultados obtidos, pode-se afirmar que apesar do FORM utilizando o RIA ser um método aproximado e bastante simples para o cálculo de probabilidades, o mesmo mostrou-se extremamente eficaz para o problema aqui considerado. Os valores obtidos através dele foram quase coincidentes com os obtidos via Método de Monte Carlo porém com um custo computacional muitas ordens de grandeza inferior $(<1 s)$. Como fica 


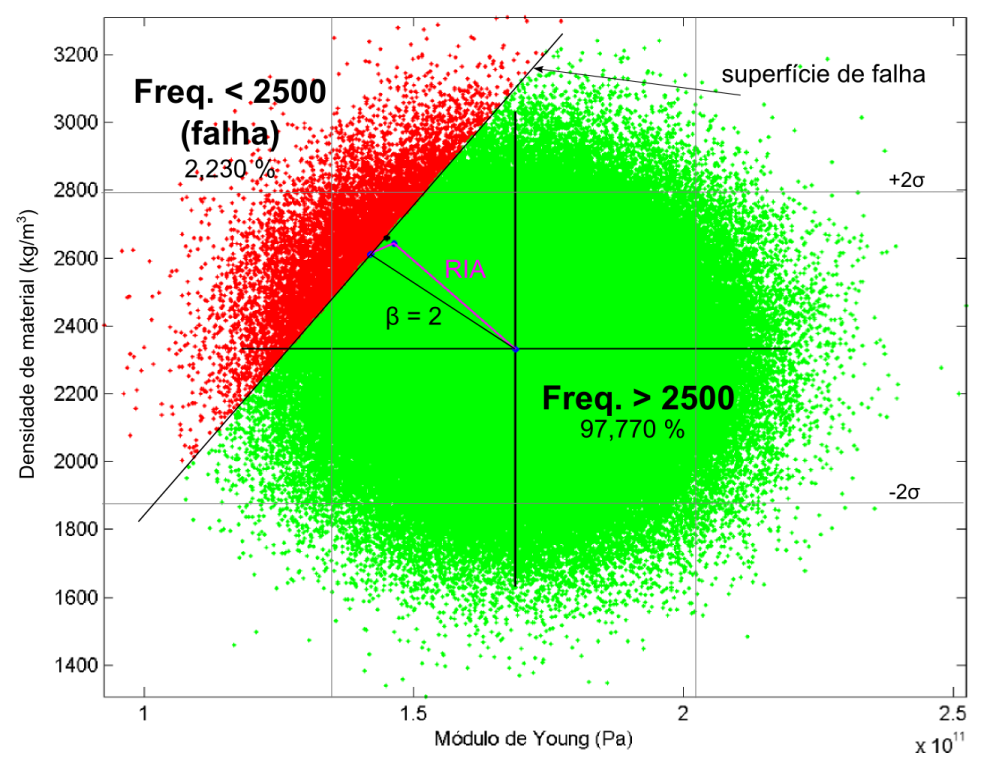

Figura 5.21: Resultado do cálculo de probabilidades para a restrição de freq. de ressonância utilizando o método de Monte Carlo com 225.000 amostras. O eixo horizontal representa a variação no módulo de Young $E$ e o vertical na densidade do material $\rho$.

Tabela 5.9: Comparativo dos valores de confiabilidade obtidos através dos métodos RIA e Monte Carlo para o AcelerAD

\begin{tabular}{c|c|c}
\hline Restrição & RIA & Monte Carlo \\
\hline Sensibilidade & $97,72 \%$ & $97,72 \%$ \\
Freq. Ressonância & $97,72 \%$ & $97,70 \%$ \\
\hline
\end{tabular}

evidente nas Figs. 5.20 e 5.21, ambas funções de estado limite são praticamente lineares, especialmente na vizinhança do ponto MPFP, satisfazendo assim a principal premissa para utilização do FORM discutida na Seção 2.3.2.

É notável que apesar da influência de $E$ e $\rho$ no cálculo da sensibilidade e frequência de ressonância não ser linear, isso não necessariamente implica que a função de estado limite seja não-linear no espaço das variáveis aleatórias. Outros autores (ALLEN et al., 2004) também observaram que sistemas altamente não-lineares, tais como não-linearidades geométricas, não produzem necessariamente superfície de falha não-linear no espaço das incertezas.

\subsubsection{RBDO com incertezas nas propriedades do material e nas dimensões do dispositivo}

Finalmente, o último caso avaliado é sem dúvida o que se aproxima mais do cenário real. Além de incertezas menores associadas às propriedades do material, neste exemplo também é considerada uma das variáveis de projeto como aleatória. Esta representa um 
parâmetro de uma distribuição estatística, no caso a média de $t_{b}$ (espessura da viga) ou $\mu_{t_{b}}$.

A espessura da viga $t_{b}$ foi adotada como variável de projeto aleatória pois experimentalmente se mostrou bastante sensível a variações na concentração da solução de $\mathrm{KOH}$ (Hidróxido de Potássio), que é utilizada na etapa de corrosão úmida do processo de fabricação do acelerômetro, e também ao tempo de exposição a esta solução. Um fator agravante é que tanto a frequência de ressonância como a sensibilidade são fortemente influenciados pela espessura da viga. As demais dimensões do dispositivo apresentaram variação muito pequena entre o valor de projeto e o valor obtido experimentalmente e por isso serão tratadas neste estudo como variáveis determinísticas.

Uma segunda consideração importante é que, devido ao processo de fabricação em questão, a largura $W_{b}$ e a espessura $t_{b}$ da viga estão necessariamente vinculadas uma a outra, através da taxa e do tempo de corrosão. Por simplicidade e com base em alguns resultados obtidos experimentalmente pela equipe de fabricação do projeto AcelerAD, foi considerada a relação $W_{b}=3 \times t_{b}$ neste estudo. Certamente existem restrições de fabricação adicionais para o dispositivo, no entanto, neste exemplo apenas esta será considerada.

A Tab. 5.10 resume todas as distribuições estatísticas envolvidas no problema e a Tab. 5.11 ilustra as variáveis de projeto e os seus respectivos limites superior e inferior. Todas as demais condições foram mantidas idênticas aos casos avaliados anteriormente.

Tabela 5.10: Propriedades estatísticas do problema

\begin{tabular}{llccc}
\hline & Descrição & Distribuição & Média & CoV \\
\hline$E$ & Módulo de Young [GPa] & Normal & 170 & 0,02 \\
$\rho$ & Densidade $\left[\mathrm{kg} / \mathrm{m}^{3}\right]$ & Normal & 2330 & 0,02 \\
$t_{b}$ & Espessura da viga $[\mu \mathrm{m}]$ & Normal & $\mu_{t_{b}}$ (var. projeto) & 0,05 \\
\hline
\end{tabular}

Tabela 5.11: Limites superior e inferior das variáveis de projeto consideradas

\begin{tabular}{c|c|c}
\hline Variável & Limite Inf. $(\mu m)$ & Limite Sup. $(\mu m)$ \\
\hline$W_{m}$ & 500 & 3000 \\
$t_{m}$ & 250 & 500 \\
$L_{b}$ & 2000 & 3000 \\
$g a p$ & 2 & 10 \\
$W_{\text {gap }}$ & 600 & 1200 \\
$W_{\text {rim }}$ & 100 & 200 \\
$E\left(t_{b}\right)$ & 10 & 100 \\
\hline
\end{tabular}

Neste caso o método RIA associado ao MMA não apresentou convergência, por isso foi utilizado o PMA para o cálculo de probabilidades. Os resultados obtidos estão detalhados na Tab. 5.12. Novamente, dentro das restrições impostas, não foi possível obter 


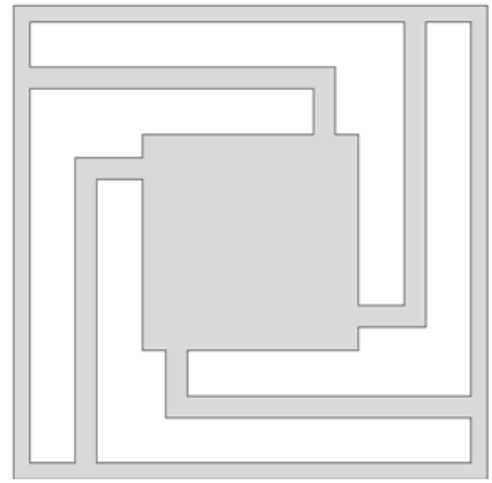

(a) projeto inicial

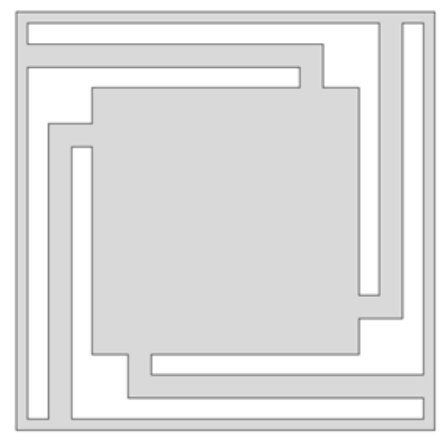

(c) $\beta=2$ (caso 1)

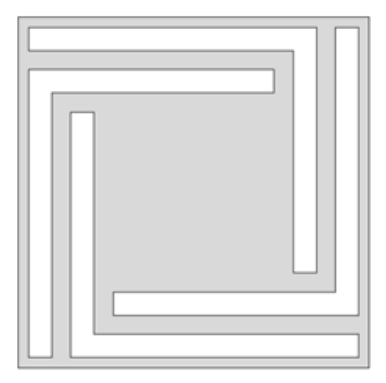

(b) ótimo determinístico

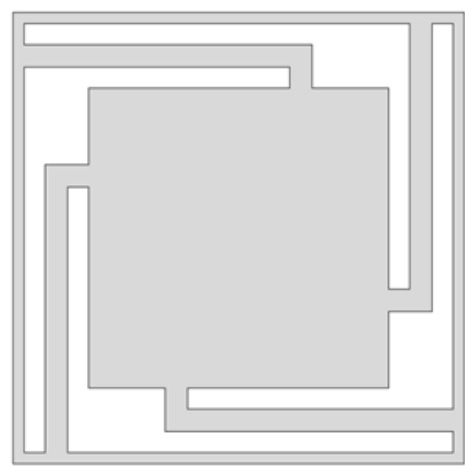

(d) $\beta=2$ (caso 2)

Figura 5.22: Comparativo das topologias obtidas.

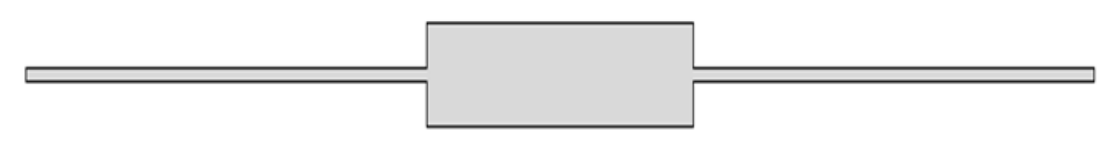

(a) projeto inicial $(\beta=0.15)$

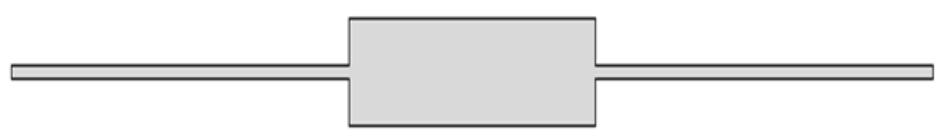

(b) ótimo determinístico $(\beta=0)$

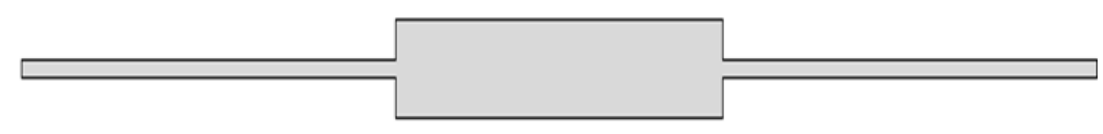

(c) $\beta=2$ (caso 1$)$

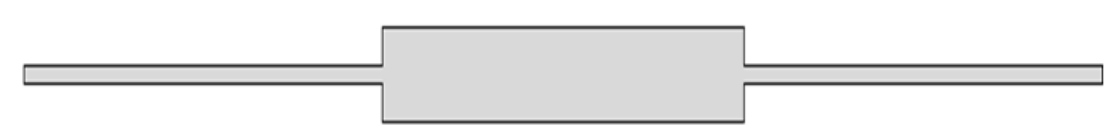

(d) $\beta=2$ (caso 2)

Figura 5.23: Comparativo das seções transversais obtidas. A razão de aspecto foi exagerada para facilitar a comparação das espessuras. 
confiabilidade superior a 97,72\%, o que equivale a $\beta=2$. A Fig. 5.11 e a Fig. 5.11 facilitam a comparação entre as diversas topologias discutidas até aqui. Em ambas as Figuras, (c) representa o resultado obtido para $\beta=2$ considerando apenas incertezas nas propriedades do material (última coluna da Tab. 5.8) e (d) considerando incertezas também na espessura da viga $t_{b}$ (última coluna da Tab. 5.12).

Tabela 5.12: Comparativo dos resultados obtidos com a geometria proposta inicialmente pelo CSEM (dimensões em $\mu m$ )

\begin{tabular}{c|c|c|c}
\hline & CSEM & $\beta=1$ & $\beta=2$ \\
\hline$W_{m}$ & 2000 & 2261 & 2771 \\
$t_{m}$ & 380 & 364 & 343 \\
$W_{b}$ & 200 & 182 & 204 \\
$t_{b}$ & 55 & 61 & 68 \\
$L_{b}$ & 2820 & 2748 & 2663 \\
$g a p$ & 2 & 2 & 2 \\
$W_{\text {gap }}$ & 1040 & 600 & 600 \\
$W_{\text {rim }}$ & 150 & 100 & 100 \\
$f_{n}(\mathrm{~Hz})$ & 2678 & 2775 & 3092 \\
$S_{e}(\mathrm{pF} / \mathrm{g})$ & 0,60 & 0,73 & 0,88 \\
$W_{d}$ & 4380 & $-16,4 \%$ & $-4,8 \%$ \\
$\mathrm{Conf}$. & $56,10 \%$ & $84,13 \%$ & $97,72 \%$ \\
\hline
\end{tabular}

Para o nível máximo de confiabilidade obtido, o tamanho do dispositivo é praticamente igual ao projeto inicial (redução de 5\%), no entanto, as dimensões da sua geometria são consideravelmente diferentes. Esse fato reforça a tese de utilização da otimização com confiabilidade, pois a simples realocação de massa em determinadas regiões do dispositivo é suficiente para aumentar de forma significativa a sua confiabilidade.

Por fim, as propriedades estatísticas apresentadas na Tab. 5.10 foram escolhidas de forma arbitrária, isto é, sem nenhum estudo experimental prévio cuidadoso, por isso este problema deve ser entendido meramente como um exemplo de aplicação do método.

\subsection{MOT aplicado ao projeto AcelerAD}

Diferentemente do que foi feito na seção anterior, agora busca-se a topologia ótima para as vigas que sustentam a massa de prova do acelerômetro. Na literatura, diversas configurações já foram propostas (Fig. 1.7), o que comprova que este não é um problema simples e que depende em grande parte da aplicação final do dispositivo. Para resolver este problema, o Domínio Fixo Estendido de Projeto (DFEP) ilustrado abaixo é utilizado, sendo as espessuras e a dimensão característica da massa de prova similares às apresentadas na Tab.5.5 para o AcelerAD. A seguir, as soluções ótimas obtidas a partir dos problemas 
(4.15) e (4.16) com e sem controle de perímetro são apresentadas e discutidas.
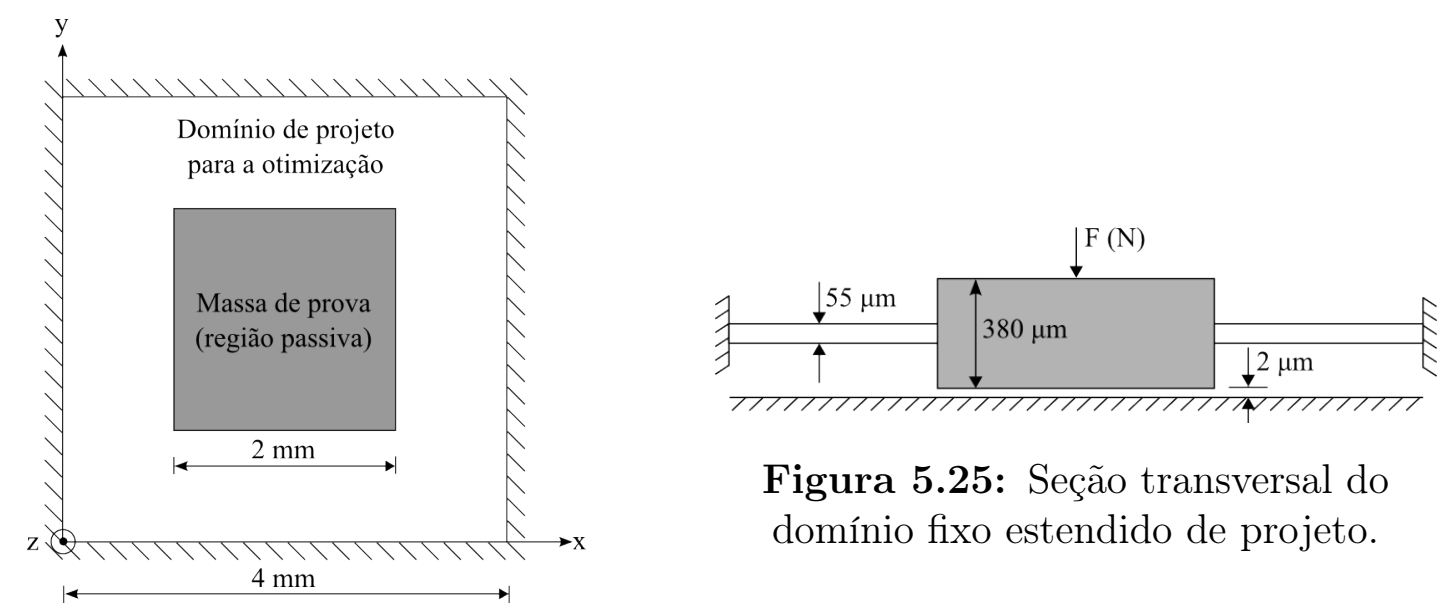

Figura 5.25: Seção transversal do domínio fixo estendido de projeto.

Figura 5.24: Domínio fixo estendido de projeto.

Em todos os estudos apresentados nesta seção, foi utilizada uma malha de 64x64 elementos, totalizando 4096 elementos finitos. Para aliviar o custo computacional resultante da discretização adotada e considerando a repetição de padrão existente (Fig. 5.14), apenas $\frac{1}{4}$ do domínio é analisado. No entanto, as topologias ótimas obtidas são ilustradas para a totalidade do domínio através de mapeamento. Por fim, foi utilizada uma estimativa inicial similar ao dispositivo do projeto AcelerAD (Fig. 5.26).

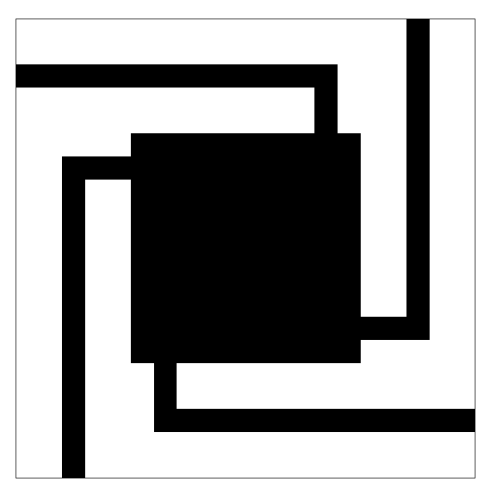

Figura 5.26: Estimativa inicial para as variáveis de projeto, similar ao projeto AcelerAD.

Primeiramente é avaliado o problema de otimização topológica definido em (4.15), isto é, o problema tradicional de minimização da flexibilidade estrutural com restrição de volume de material. Quatro casos são avaliados: volume máximo de material permitido de $60 \%, 45 \%, 35 \%$ e 30\% . Para todos os estudos foi utilizado raio de projeção $r_{\min }=100 \mu \mathrm{m}$ (Seção 3.4) e o método da continuação com o penalizador $p_{e}$ variando de 1 a 3 (Seção 3.2.2). As topologias obtidas são apresentadas na Fig. 5.27 e os valores ótimos da função objetivo (flexibilidade média) para cada problema são apresentados na Tab. 5.13. Como forma de 
comparação é também incluído na tabela o valor de flexibilidade média para o acelerômetro do projeto AcelerAD.

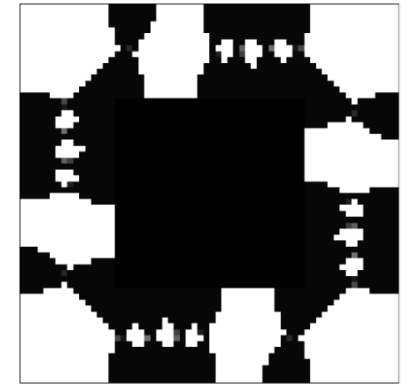

(a) $\mathrm{Vmax}=60 \%$

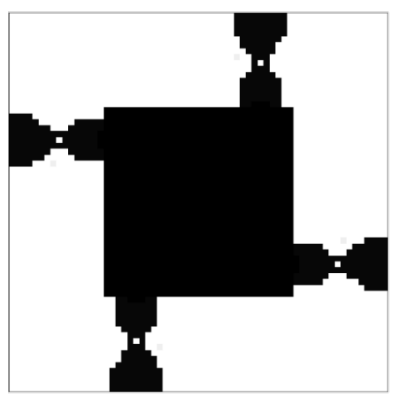

(c) $\mathrm{Vmax}=35 \%$

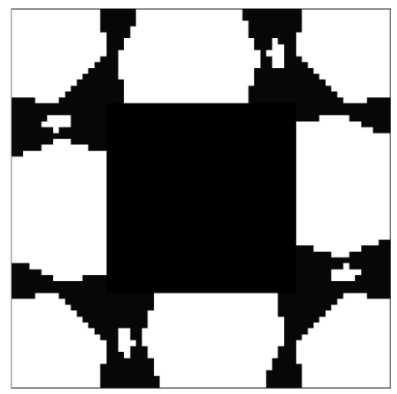

(b) $\operatorname{Vmax}=45 \%$

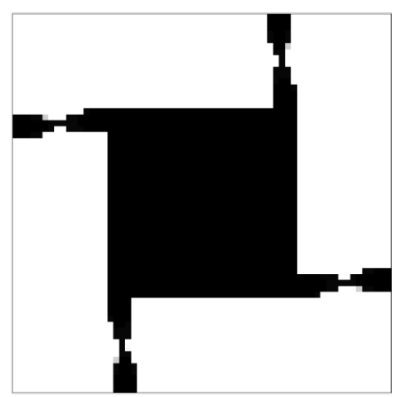

(d) $\operatorname{Vmax}=30 \%$

Figura 5.27: Topologias ótimas obtidas através do problema (4.15) para diferentes volumes de material.

Tabela 5.13: Valores ótimos da função objetivo para o problema de OT (4.15).

\begin{tabular}{cc}
\hline$V_{\max }(\%)$ & Flex. média $\left(10^{-5}\right.$ N.m $)$ \\
\hline 60 & 0,53 \\
45 & 0,91 \\
35 & 1,93 \\
30 & 3,83 \\
AcelerAD & 538,79
\end{tabular}

Com relação ao requisito de largura de banda, todas as estruturas obtidas o satisfazem com ampla margem. Por exemplo, para $V_{\max }=30 \%$, que é o resultado mais flexível e portanto o mais crítico nesse aspecto, a primeira frequência de ressonância é superior a $13 k H z$, quase seis vezes maior do que a do AcelerAD.

Resultados com restrições de volume abaixo de $30 \%$ não puderam ser obtidos pois a partir deste ponto o algoritmo de otimização começa a apresentar problemas de convergência, já que apenas a região da massa de prova (região passiva) representa 25\% do volume total do domínio, deixando muito pouco material para ser distribuído no restante do espaço.

Observando a Tab. 5.13, percebe-se que mesmo com $V_{\max }=30 \%$, o valor de flexibilidade média obtida é duas ordens de grandeza menor do que a do AcelerAD, ou seja, a 
rigidez é proporcionalmente maior. Portanto, a sensibilidade do AcelerAD é significativamente maior do que o melhor projeto obtido com a formulação (4.15), resultado este que não é satisfatório.

Dessa forma, o problema (4.16), que envolve a minimização do volume de material com restrição de flexibilidade média, é avaliado em seguida, sendo imposto um limite de flexibilidade $L_{\max }=5 \cdot 10^{-3}$, o que corresponde aproximadamente a flexibilidade apresentada pelo acelerômetro do projeto AcelerAD, como indicado na Tab. 5.13. No entanto, para esse nível de flexibilidade o algoritmo de otimização não fornece uma resposta viável, independentemente das configurações iniciais utilizadas, como raio de projeção, penalizadores, estimativa inicial, entre outras. Entende-se por viável aquelas respostas em que algoritmo não apresenta o problema de convergência citado anteriormente.

Diferentes níveis de flexibilidade foram testados, sendo que o valor limite para o qual o algoritmo fornece uma resposta viável é $L_{\max }=1 \cdot 10^{-5}$, gerando uma topologia similar a obtida com restrição de volume de $30 \%$ na análise anterior (Fig. 5.28).
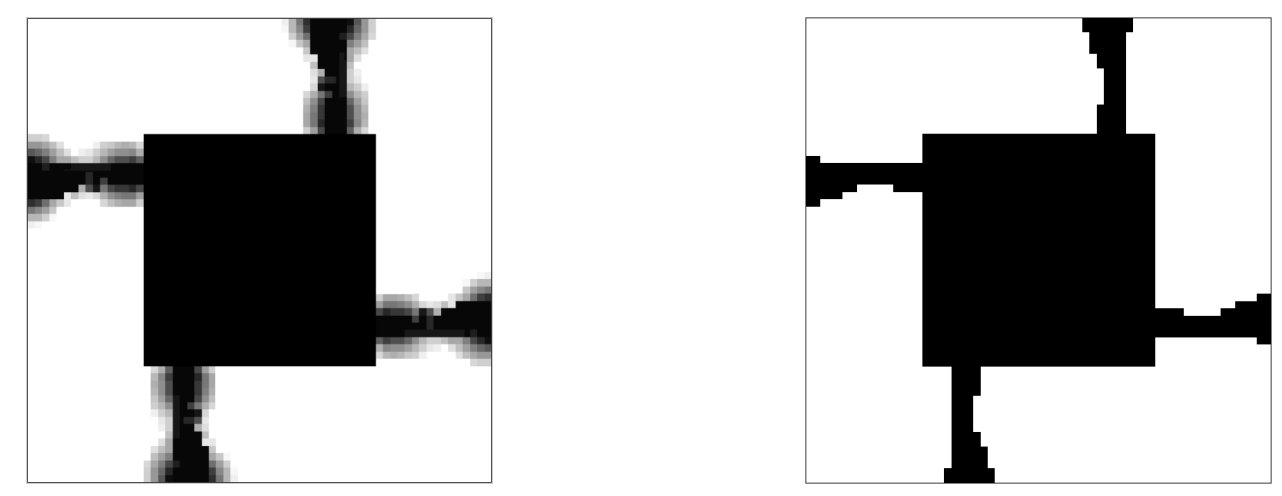

Figura 5.28: (esq) Topologia ótima obtida através do problema (4.16) com $L_{\max }=1 \cdot 10^{-5} ;$ (dir) versão pós-processada.

Com o objetivo de tentar induzir o algoritmo a gerar topologias mais flexíveis, um novo domínio de projeto é proposto (Fig. 5.29). Este é praticamente idêntico ao anterior (Fig. 5.24), porém com engastamento em um região menor do domínio, mais próxima da condição de contorno utilizada pelo AcelerAD.

Novamente, diferentes níveis de flexibilidade foram testados, sendo que o valor limite para o qual o algoritmo fornece uma resposta viável é também aproximadamente $1 \cdot 10^{-5}$. A topologia obtida para esse nível de flexibilidade é exibida na Fig. 5.30. De forma similar, alguns outros domínios de projeto foram também avaliados, envolvendo a utilização de diferentes condições de contorno ou a imposição de 'buracos' em certas regiões do domínio, no entanto, nenhum deles foi capaz de induzir o algoritmo de OT a fornecer geometrias mais flexíveis. 


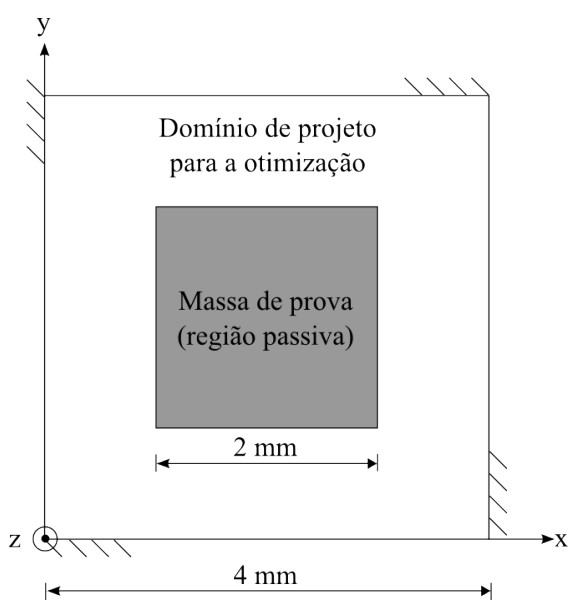

Figura 5.29: Domínio fixo estendido de projeto.

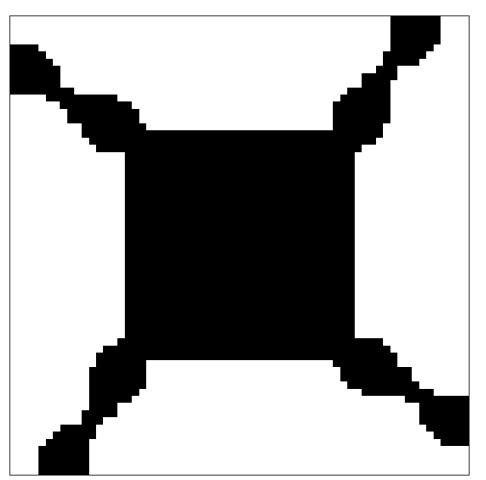

Figura 5.30: Topologia ótima obtida com o novo domínio de projeto para $L_{\max }=1 \cdot 10^{-5}$.

Uma outra observação importante é que os resultados gerados pela formulação (4.16) apresentam muita escala de cinza, o que pode ser visto como um ponto negativo. Diferentes valores de penalizadores foram testados, mas nenhum conseguiu melhorar significativamente os resultados no que diz respeito a redução de escalas de cinza. Já com a primeira formulação (4.15) quase nenhum pós-processamento é necessário, apenas o desligamento da projeção nas iterações finais já foi suficiente para acabar com densidades intermediárias, como é evidente a partir da análise da Fig. 5.27.

De forma análoga ao que foi observado no exemplo da Seção 5.2, pode-se dizer que a formulação (4.16) por si só ainda não é suficiente para gerar topologias com os níveis de flexibilidade desejados, o que evidencia a limitação das formulações tradicionais do MOT para o projeto de estruturas flexíveis. Por isso, em seguida é testada a nova formulação proposta (4.18) incluindo o controle sobre o perímetro.

Tabela 5.14: Valores de referência para o dispositivo AcelerAD.

\begin{tabular}{cc}
\hline & AcelerAD \\
\hline $\mathrm{P}(m)$ & $14,7 \times 10^{-3}$ \\
$\mathrm{~V}(\%)$ & 40 \\
$\mathrm{~L}(N . m)$ & $5,4 \times 10^{-3}$ \\
\hline
\end{tabular}

Os valores de Perímetro (P), Volume (V) e Flexibilidade (L) do dispositivo AcelerAD são apresentados na Tab 5.14 e são usados como referência para esta análise. A partir destes valores, foram testadas diferentes combinações de $P_{\min }$ e $L_{\max }$ nas restrições do problema (4.18), com e sem a utilização de estimativa inicial. Entre todos os valores testados, obteve-se o resultado mais interessante fazendo $L_{\max }=1 \times 10^{-3}$ e $P_{\min }=5 \times 10^{-3}$ com estimativa inicial. A topologia obtida está ilustrada na Fig. 5.31, assim como a sua versão pós-processada. 

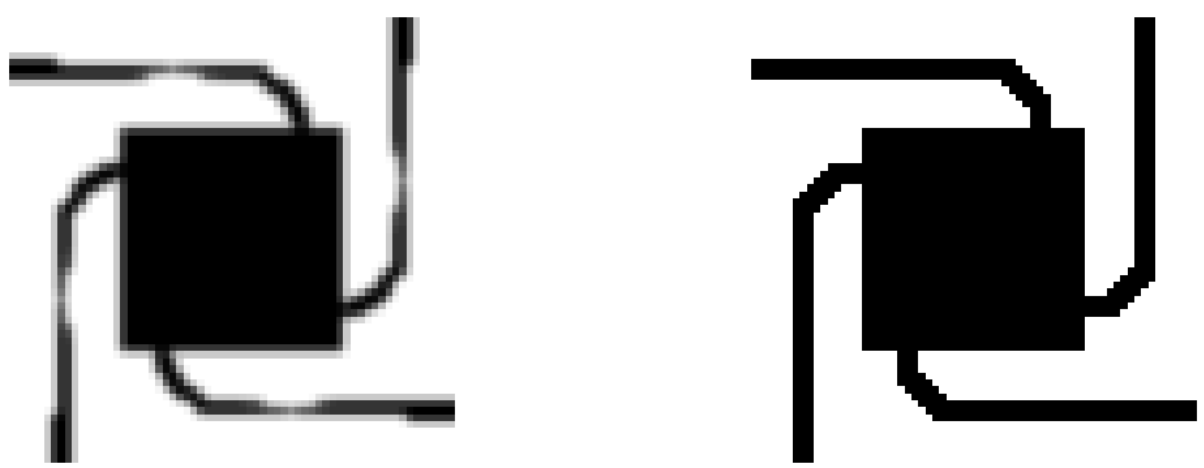

Figura 5.31: (esq) Resultado obtido para a formulação (4.18); (dir) versão pós-processada.

A topologia pós-processada resulta em uma flexibilidade $L=2,8 \times 10^{-3}$ e perímetro $P=14,5 \times 10^{-3}$, valores estes que estão bem próximos da topologia inicialmente proposta para o AcelerAD. De fato, há pouca diferença entre ambas topologias e a explicação para isso é que a inicial já representa um mínimo local bastante difícil de ser obtido pelo algoritmo de OT. Prova disso é que sem a utilização da estimativa inicial (Fig. 5.26), o algoritmo falha durante o processo iterativo de solução, devido a sobre-saltos de convergência inerentes ao MMA em casos de solicitações extremas (flexibilidade muito elevada).

Portanto, fica claro que para este problema a nova formulação proposta (4.18) não obteve desempenho tão satisfatório quanto no estudo da mola plana (Seção 5.2). Apesar disso, o resultado obtido através dela é significativamente melhor do que os demais apresentados anteriormente. 


\section{Conclusões e trabalhos futuros}

Duas metodologias diferentes para o projeto de acelerômetros MEMS foram apresentadas e avaliadas a partir de vários exemplos, incluindo um estudo de caso com o dispositivo do projeto AcelerAD.

A primeira delas, a Otimização Paramétrica com confiabilidade (RBDO), revelou-se muito importante para o projeto de estruturas com níveis especificados de confiabilidade. Tanto a utilização de fórmulas analíticas como do MEF para o cálculo das análises estruturais não tornou o custo computacional do algoritmo proibitivo, já que foi utilizado o eficiente método FORM para a avaliação das probabilidades envolvidas. Reforçando o que já foi discutido anteriormente, sistemas não-lineares não produzem necessariamente superfícies de falha não-lineares no espaço das incertezas, o que em muitos casos torna a aproximação pelo FORM bastante precisa, apesar da sua relativa simplicidade.

Uma extensão natural e bastante importante para este trabalho é a fabricação dos dispositivos aqui projetados, com o objetivo de validar experimentalmente os resultados obtidos, representando um passo além da validação computacional já realizada pelo autor.

No entanto, antes da fabricação de novas versões para o micro-acelerômetro, é importante que todas as variáveis aleatórias envolvidas no problema sejam adequadamente estimadas, o que não foi feito até o presente momento. Sendo assim, é sugerido como trabalho futuro à equipe experimental, um estudo cuidadoso neste sentido para que o projeto AcelerAD se beneficie efetivamente dos resultados deste trabalho. De forma contrária, os algoritmos desenvolvidos terão limitada utilidade prática no contexto do projeto.

A segunda abordagem apresentada para o projeto de acelerômetros MEMS foi o Método da Otimização Topológica. Inicialmente duas formulações distintas foram utilizadas: a formulação clássica de minimização da flexibilidade estrutural com restrição de volume de material, e a sua inversa. Esperava-se que a formulação inversa já fosse suficiente para o projeto de estruturas com níveis especificados de flexibilidade. No entanto, nenhuma das duas se mostrou viável para o projeto de estruturas altamente flexíveis, como é o caso das vigas de sustentação de acelerômetros: o projeto inicial do AcelerAD apresentou 
consistentemente maior sensibilidade do que todos os resultados gerados a partir da OT.

De fato, este é um problema que ainda não foi estudado pela comunidade científica de OT e, portanto, não há formulações já desenvolvidas para resolvê-lo. O autor entende que esta constatação já é uma contribuição significativa deste trabalho. Diversas formulações foram testadas e a que se mostrou mais bem sucedida foi a de minimização do volume de material, com restrição de flexibilidade e perímetro, em conjunto com a técnica de projeção. Esta é uma abordagem nova que possibilitou, até certos limites, a obtenção de estruturas altamente flexíveis.

Apesar do relativo sucesso da formulação aqui apresentada, este assunto está longe de ser esgotado. É fundamental que novas formulações para o MOT sejam propostas afim de solucionar este problema, o qual certamente possui uma ampla gama de aplicações além daquelas já discutidas. Uma possibilidade que merece ser avaliada com mais cuidado neste contexto é a utilização de restrições de flambagem ou de tensão mecânica.

Um segundo grande desafio, que ainda precisa ser vencido pelo MOT, é o controle topológico dos resultados. Por exemplo, o projeto AcelerAD tem como uma de suas premissas a fabricação do dispositivo por corrosão úmida utilizando $\mathrm{KOH}$, devido a simplicidade e baixo custo desta técnica. No entanto, este processo de fabricação exige geometrias muito regulares, com espaçamentos mínimos e máximos pré-estabelecidos e com ângulos retos, o que, com as ferramentas atualmente disponíveis em OT, não é possível de ser feito.

Existem trabalhos que propõem restrições de manufatura permitindo o controle geométrico no MOT (LIPPI, 2008), mas que são aplicáveis principalmente a manufatura tradicional (extrusão, torneamento, etc), que é muito diferente das técnicas de microfabricação. Sendo assim, mesmo que a OT consiga gerar topologias de maior desempenho para o projeto AcelerAD, estas só poderão ser fabricadas através dos mais caros e complexos processos altamente anisotrópicos, como a Corrosão Profunda por Íons Reativos ou "Deep Reactive-Ion Etching (DRIE)".

Uma vez que os dois desafios discutidos acima tenham sido superados, o próximo passo natural é a inclusão de incertezas também no MOT, como foi feito para a Otimização Paramétrica neste trabalho. Esta é uma técnica já dominada e bastante discutida na literatura relacionada à OT (MAUTE; FRANGOPOL, 2003; KHARMANDA et al., 2004; MELLO, 2010) e é conhecida como Otimização Topológica baseada em Confiabilidade ou "Reliability-based Topology Optimization (RBTO)". A importância da avaliação das aleatoriedades envolvidas na operação e fabricação de sistemas mecânicos já foi evidenciada neste trabalho, especialmente no contexto dos dispositivos MEMS. 
Na maioria dos exemplos apresentados neste trabalho foi utilizado o software comercial Comsol para a realização das análises estruturais por MEF. A grande vantagem em se utilizar um software comercial, em comparação à implementação de um algoritmo próprio, é a economia de tempo proporcionada pela utilização de uma solução pronta. No entanto, esta opção impôs algumas dificuldades ao autor, como o alto tempo de comunicação para troca de informações entre o algoritmo de otimização em Matlab e o Comsol. Para domínios muito discretizados, acima de 8000 elementos, a comunicação falhou com frequência, impedindo a continuação da otimização. Por outro lado, para discretizações menores o tempo de comunicação é bem razoável e não chega a prejudicar.

Além disso, devido a forma indireta como o vetor de pseudo-densidades é interpretado pelo Comsol, o algoritmo de OT foi com frequência interrompido por falha na análise estrutural, nos casos em que uma flexibilidade muito alta era exigida. O Comsol converte internamente a função interpoladora de pseudo-densidades em propriedades do material de cada elemento da malha, para posterior construção das matrizes de rigidez local e global. Nesse processo, caso haja variações bruscas de densidade de um elemento para outro, o seu algoritmo iterativo de solução pode falhar em convergir. De fato, é comum em casos extremos que o MMA apresente sobressaltos de convergência, resultando em fortes variações de pseudo-densidade entre elementos vizinhos.

Para contornar essas dificuldades, o ideal é a implementação do algoritmo de MEF diretamente no Matlab. Naturalmente, quando é necessária a modelagem por elementos complexos, como aqueles adotados neste trabalho, esta é uma tarefa bastante desafiadora. No entanto, o autor acredita que resultados melhores do que aqueles aqui apresentados possam ser obtidos utilizando esta estratégia.

Com base em tudo o que foi discutido neste trabalho, o autor acredita que o projeto adotado pelo instituto Suíço CSEM para o micro-acelerômetro é realmente adequado e deve satisfazer os principais requisitos solicitados. Como ficou claro na aplicação do MOT, em termos de topologia, o projeto está bem próximo de um ótimo global para a aplicação objetivada, especialmente quando se considera todas as restrições de fabricação existentes. No entanto, suas dimensões podem ainda ser otimizadas levando em consideração o caráter aleatório inerente aos dispositivos MEMS.

Finalmente, em trabalhos futuros, novos requisitos de projeto podem ser considerados no estudo de acelerômetros. Alem disso, os algoritmos aqui desenvolvidos podem ser aplicados em outras situações, seja em sensores similares como giroscópios MEMS, ou até mesmo em atuadores, como componentes de um exoesqueleto. Esta última é uma linha de pesquisa importante liderada pelo Prof. Arturo Forner-Cordero do PMR/EPUSP e que 
pode gerar trabalhos futuros em conjunto. Em ambos os casos, serão necessárias adaptações aos algoritmos e formulações propostas, mas os resultados aqui obtidos poderão ser utilizados como ponto de partida. 


\section{Referências}

AGARWAL, H. Reliability Based Design Optimization: Formulations and Methodologies. Tese (Doutorado) — University of Notre Dame, 2004.

ALLEN, M.; MAUTE, K. Reliability-based design optimization of aeroelastic structures. Structural and Multidisciplinary Optimization, v. 27, p. 228-242, 2004.

ALLEN, M.; RAULLI, M.; MAUTE, K.; FRANGOPOL, D. M. Reliability-based analysis and design optimization of electrostatically actuated mems. Computers 8 Structures, v. 82, n. 13-14, p. $1007-1020,2004$.

ALVAREZ, M. J.; GIL-NEGRETE, N.; ILZARBE, L.; TANCO, M.; VILES, E.; ASENSIO, A. A computer experiment application to the design and optimization of a capacitive accelerometer. Applied Stochastic Models in Business and Industry, v. 25, n. 2, p. 151-162, 2009.

AMBROSIO, L.; BUTTAZZO, G. An optimal design problem with perimeter penalization. Calculus of Variations and Partial Differential Equations, v. 1, p. 55-69, 1993.

AMINI, B. V.; AYAZI, F. Micro-gravity capacitive silicon-on-insulator accelerometers. Journal of Micromechanics and Microengineering, v. 15, n. 11, p. 2113, 2005.

ANALOG-DEVICES. ADXL203: Precision 1.7g Dual-Axis iMEMS Accelerometer, Data sheet. [S.l.: s.n.], 2010.

AOUES, Y.; CHATEAUNEUF, A. Benchmark study of numerical methods for reliability-based design optimization. Structural and Multidisciplinary Optimization, v. 41, p. 277-294, 2010.

BAO, M.; YANG, H. Squeeze film air damping in mems. Sensors and Actuators A: Physical, v. 136, n. 1, p. $3-27,2007$.

BARBOUR, N.; SCHMIDT, G. Inertial sensor technology trends. Proceedings of the IEEE Symposium on AUV Technology, p. 55-62, 1998.

BATHE, K. J. Finite Elements Procedures. New Jersey: Prentice Hall, 1996.

BATHE, K.-J.; DVORKIN, E. N. A four-node plate bending element based on mindlin/reissner plate theory and a mixed interpolation. International Journal for Numerical Methods in Engineering, v. 21, n. 2, p. 367-383, 1985.

BECKERS, M. Topology optimization using a dual method with discrete variables. Structural and Multidisciplinary Optimization, v. 17, p. 14-24, 1999. 
BELIVEAU, A.; SPENCER, G.; THOMAS, K.; ROBERSON, S. Evaluation of mems capacitive accelerometers. Design Test of Computers, IEEE, v. 16, n. 4, p. $48-56$, oct-dec 1999.

BENDSOE, M. P. Optimal shape design as a material distribution problem. Structural and Multidisciplinary Optimization, v. 1, p. 193-202, 1989.

BENDSOE, M. P.; KIKUCHI, N. Generating optimal topologies in structural design using a homogenization method. Computer Methods in Applied Mechanics and Engineering, v. 71, p. 197-224, 1988.

BENDSOE, M. P.; SIGMUND, O. Topology Optimization: Theory, Methods and Applications. [S.l.]: Springer Verlag, 2003.

BOCHOBZA-DEGANI, O.; SETER, D. J.; SOCHER, E.; NEMIROVSKY, Y. Comparative study of novel micromachined accelerometers employing midos. Sensors and Actuators A: Physical, v. 80, n. 2, p. 91 - 99, 2000.

BOURDIN, B. Filters in topology optimization. International Journal for Numerical Methods in Engineering, v. 50, n. 9, 2001.

BRUNS, T. E.; TORTORELLI, D. A. Topology optimization of non-linear elastic structures and compliant mechanisms. Computer Methods in Applied Mechanics and Engineering, v. 190, p. 3443 - 3459, 2001.

CARDOSO, E. L. Controle de Complexidade na Otimização Topológica de Estruturas Contínuas. Dissertação (Mestrado) — PROMEC-UFRGS, 2000.

CHAE, J.; KULAH, H.; NAJAFI, K. An in-plane high-sensitivity, low-noise micro-g silicon accelerometer with cmos readout circuitry. Microelectromechanical Systems, Journal of, v. 13, n. 4, p. 628 - 635, aug. 2004.

CHAPELlE, D.; BATHE, K. J. The Finite Element Analysis of Shells: Fundamentals. [S.l.]: Springer, 2003.

CHENG, K.-T.; OLHOFF, N. An investigation concerning optimal design of solid elastic plates.

CHENG, K.-T.; OLHOFF, N. Regularized formulation for optimal-design of axisymmetric plates.

COULTATE, J. Optimal and robust design of a mems accelerometer. Tese (Doutorado) - University of Nottingham, United Kingdom, 2007.

COUltate, J. K.; FOX, C. H.; MCWILliAm, S.; MALVERN, A. R. Application of optimal and robust design methods to a mems accelerometer. Sensors and Actuators A: Physical, v. 142, n. 1, p. $88-96,2008$.

DíAZ, A.; SIGMUND, O. Checkerboard patterns in layout optimization. Structural and Multidisciplinary Optimization, v. 10, p. 40-45, 1995.

DEDE, E. M. Multiphysics topology optimization of heat transfer and fluid flow systems. Proceedings of the COMSOL Conference 2009, 2009. 
DESROCHERS, S.; PASINI, D.; ANGELES, J. Optimum design of a compliant uniaxial accelerometer. Journal of Mechanical Design, v. 132, n. 4, 2010.

ENEVOLDSEN, I.; SøRENSEN, J. D. Reliability-based optimization in structural engineering. Structural Safety, v. 15, n. 3, p. 169-196, 1994.

ENGESSER, M.; FRANKE, A.; MAUTE, M.; MEISEL, D.; KORVINK, J. A robust and flexible optimization technique for efficient shrinking of mems accelerometers. Microsystem Technologies, v. 16, p. 647-654, 2010.

FRANGOPOL, D. M. Structural Design Optimization Considering Uncertainties. [S.l.]: Taylor \& Francis, 2008.

GUEST, J. Imposing maximum length scale in topology optimization. Structural and Multidisciplinary Optimization, v. 37, p. 463-473, 2009.

GUEST, J. K.; PRéVOST, J. H.; BELYTSCHKO, T. Achieving minimum length scale in topology optimization using nodal design variables and projection functions. International Journal for Numerical Methods in Engineering, v. 61, n. 2, p. 238-254, 2004.

HABER, R. B.; JOG, C. S.; BENDSOE, M. P. A new approach to variable-topology shape design using a constraint on perimeter. Structural and Multidisciplinary Optimization, v. 11, p. 1-12, 1996.

HARRIS, C. M.; CREDE, C. E. Shock and Vibration Handbook. New York: McGraw-Hill, 1976.

HASOFER, A. M.; LIND, N. C. Exact and invariant second-moment code format. Journal of the Engineering Mechanics Division, v. 100, n. 1, p. 111-121, 1974.

IEEE. Ieee standard for inertial sensor terminology. IEEE Std 528-2001, 2001.

JEAN-MICHEL, S. Market opportunities for advanced mems accelerometers and overview of actual capabilities vs. required specifications. Position Location and Navigation Symposium (PLANS), 2004.

JENSEN, J. S.; SIGMUND, O. Systematic design of photonic crystal structures using topology optimization: Low-loss waveguide bends. Applied Physics Letters, v. 84, n. 12, p. 2022-2024, 2004.

JONSMANN, J.; SIGMUND, O.; BOUWSTRA, S. Compliant thermal microactuators. Sensors and Actuators A: Physical, v. 76, n. 1-3, p. 463 - 469, 1999.

JUNG, H.-S.; CHO, S. Reliability-based topology optimization of geometrically nonlinear structures with loading and material uncertainties. Finite Elements in Analysis and Design, v. 41, n. 3, p. $311-331,2004$.

KAAJAKARI, V. Practical MEMS. Las Vegas: Small Gear Publishing, 2009. ISBN 978-0-9822991-0-4.

KHARMANDA, G.; MOHAMED, A.; LEMAIRE, M. Efficient reliability-based design optimization using a hybrid space with application to finite element analysis. Structural and Multidisciplinary Optimization, v. 24, p. 233-245, 2002. 
KHARMANDA, G.; OLHOFF, N.; MOHAMED, A.; LEMAIRE, M. Reliability-based topology optimization. Structural and Multidisciplinary Optimization, v. 26, p. 295-307, 2004.

KOHN, R. V.; VOGELIUS, M. Relaxation of a variational method for impedance computed tomography. Communications on Pure and Applied Mathematics, v. 40, n. 6, p. $745-777,1987$.

KOVACS, G. T. Micromachined Transducers Sourcebook. [S.l.]: McGraw-Hill, 1998.

KRISHNAN, G.; ANANTHASURESH, G. K. Evaluation and design of displacementamplifying compliant mechanisms for sensor applications. Journal of Mechanical Design, ASME, v. 130, n. 10, p. 102304, 2008.

KRISHNAN, G.; KSHIRSAGAR, C. U.; ANANTHASURESH, G. K.; BHAT, N. Micromachined high-resolution accelerometers. J. Indian Institute of Science, v. 87, n. 3, 2007.

KUEHNEL, W.; SHERMANB, S. A surface micromachined silicon accelerometer with on-chip detection circuitry. Sensors and Actuators A-Physical, v. 45, p. 7-16, November 1994.

LE, C.; NORATO, J.; BRUNS, T.; HA, C.; TORTORELLI, D. Stress-based topology optimization for continua. Structural and Multidisciplinary Optimization, v. 41, p. 605-620, 2010.

LEE, J.-O.; YANG, Y.-S.; RUY, W.-S. A comparative study on reliability-index and target-performance-based probabilistic structural design optimization. Computers $\&$ Structures, v. 80, n. 3-4, p. 257 - 269, 2002.

LEE, S. J. Reliability-Based Optimal Structural and Mechanical Design. Tese (Doutorado) — University of Arizona, 1987.

LEMKE, B.; LIU, Z.; KORVINK, J. G. Implementation of structural topology optimization in comsol. Proceedings of the COMSOL Conference 2006, 2006.

LIPPI, T. N. Restrições de manufatura aplicadas ao Método da Otimização Topológica. Dissertação (Mestrado) — Escola Politécnica da Universidade de São Paulo, 2008.

LIU, G. J.; JIANG, T.; WANG, A. L. Robust optimization of an accelerometer considering fabrication errors. Materials Science Forum, v. 628, ago. 2009.

LIU, M.; MAUTE, K.; FRANGOPOL, D. M. Multi-objective design optimization of electrostatically actuated microbeam resonators with and without parameter uncertainty. Reliability Engineering 65 System safety, 92, n. 10, p. 1333-1343, OCT 2007.

LIU, P.-L.; KIUREGHIAN, A. D. Optimization algorithms for structural reliability. Structural Safety, v. 9, n. 3, p. 161 - 177, 1991.

LIU, Z.; KORVINK, J.; HUANG, R. Structure topology optimization: fully coupled level set method via femlab. Structural and Multidisciplinary Optimization, v. 29, p. 407-417, 2005. 
LONG, C. S.; LOVEDAY, P. W.; GROENWOLD, A. A. Effects of finite element formulation on optimal plate and shell structural topologies. Finite Elem. Anal. Des., v. 45, p. 817-825, September 2009.

LUO, H.; ZHANG, G.; CARLEY, L.; FEDDER, G. A post-cmos micromachined lateral accelerometer. Microelectromechanical Systems, Journal of, v. 11, n. 3, p. $188-195$, jun. 2002.

LUO, X.; GRANDHI, R. Astros for reliability-based multidisciplinary structural analysis and optimization. Computers \&5 Structures, v. 62, p. 737-745, 1997.

LURIE, K. A.; CHERKAEV, A. V.; FEDOROV, A. V. Regularization of optimal design problems for bars and plates, part 1. Journal of Optimization Theory and Applications, v. 37, p. 499-522, 1982.

LURIE, K. A.; CHERKAEV, A. V.; FEDOROV, A. V. Regularization of optimal design problems for bars and plates, part 2. Journal of Optimization Theory and Applications, v. 37 , p. $523-543,1982$.

MA, Z.-D.; KIKUCHI, N.; CHENG, H.-C. Topological design for vibrating structures. Computer Methods in Applied Mechanics and Engineering, v. 121, n. 1-4, p. 259 - 280, 1995.

MACDONALD, G. A. A review of low cost accelerometers for vehicle dynamics. Sensors and Actuators, v. 21, p. 303-307, February 1990.

MADOU, M. J. Fundamentals of Microfabrication: the science of miniaturization. [S.1.]: CRC Press, 2002. 752 p.

MADSEN H.O.; KRENK, S. L. N. Methods of Structural Safety. [S.l.]: Dover Publications, 2006.

MAUTE, K.; FRANGOPOL, D. M. Reliability-based design of mems mechanisms by topology optimization. Computers \& Structures, v. 81, n. 8-11, p. 813-824, 2003.

MELLO, L. A. M. Estudo do aumento do desempenho de um sistema de tomografia de impedância elétrica através do método da otimização topológica. Tese (Doutorado) Escola Politécnica da Universidade de São Paulo, 2010.

MESSAC, A.; ISMAIL-YAHAYA, A. Multiobjective robust design using physical programming. Structural and Multidisciplinary Optimization, v. 23, p. 357-371, 2002.

MICHELL, A. The limits of economy of material in frame structures. Philosophical Magazine, v. 8, p. 589-597, 1904.

MLEJNEK, H. P. Some aspects of the genesis of structures. Structural and Multidisciplinary Optimization, v. 5, p. 64-69, 1992.

MOGAMI, K.; NISHIWAKI, S.; IZUI, K.; YOSHIMURA, M.; KOGISO, N. Reliabilitybased structural optimization of frame structures for multiple failure criteria using topology optimization techniques. Structural and Multidisciplinary Optimization, v. 32, p. 299-311, 2006. 
MUKHERJEE, T.; ZHOU, Y.; FEDDER, G. Automated optimal synthesis of microaccelerometers. In: Micro Electro Mechanical Systems, 1999. MEMS '99. Twelfth IEEE International Conference on. [S.1.: s.n.], 1999. p. $326-331$.

NETO, P.; CYMBALISTA, M. Probabilidades. [S.l.]: Edgard Blücher Ltda, 2000.

NIKOLAIDIS, E.; BURDISSO, R. Reliability based optimization: A safety index approach. Computers $\&$ Structures, v. 28, n. 6, p. $781-788,1988$.

NISHIWAKI, S.; FRECKER, M. I.; MIN, S.; KIKUCHI, N. Topology optimization of compliant mechanisms using the homogenization method. International Journal for Numerical Methods in Engineering, v. 42, n. 3, p. 535 - 559, 2008.

OLESEN, L. H.; OKKELS, F.; BRUUS, H. A high-level programming-language implementation of topology optimization applied to steady-state navier-stokes flow. International journal for numerical methods in engineering, v. 65, p. 975-1001, 2006.

PARK, I.; LEE, C.; JANG, H.; OH, Y.; HA, B. Capacitive sensing type surface micromachined silicon accelerometer with a stiffness tuning capability. In: Micro Electro Mechanical Systems, 1998. MEMS 98. Proceedings., The Eleventh Annual International Workshop on. [S.l.: s.n.], 1998. p. $637-642$.

PAUliNO, G.; SILVA, E. C. N. Design of functionally graded structures using topology optimization. Materials Science Forum, v. 492, p. 435 - 440, 2005.

PEDERSEN, C. B. W.; SESHIA, A. A. On the optimization of compliant force amplifier mechanisms for surface micromachined resonant accelerometers. Journal of Micromechanics and Microengineering, v. 14, n. 10, p. 1281, 2004.

PEDERSEN, N. L. Maximization of eigenvalues using topology optimization. Structural and Multidisciplinary Optimization, v. 20, p. 2-11, 2000.

PEDERSEN, N. L. On topology optimization of plates with prestress. International Journal for Numerical Methods in Engineering, v. 51, n. 2, p. 225-239, 2001.

QIAO, D.; PANG, G.; MUI, M.-K.; LAM, D. A single-axis low-cost accelerometer fabricated using printed-circuit-board techniques. Electron Device Letters, IEEE, v. 30, n. 12 , p. $1293-1295,2009$.

QU, X.; HAFTKA, R. Reliability-based design optimization using probabilistic sufficiency factor. Structural and Multidisciplinary Optimization, v. 27, p. 314-325, 2004.

RACKWITZ, R.; FIESSLER, B. Structural reliability under combined random load sequence. Computers \&f Structures, v. 9, p. 489-494, 1978.

RAULLI, M.; MAUTE, K. Topology optimization of electrostatically actuated microsystems. Structural and Multidisciplinary Optimization, v. 30, n. 5, p. 342-359, 2005.

REDDY, J. N. An Introduction to the Finite Element Method. [S.1.]: McGraw-Hill, 1993. REDDY, J. N. An Introduction to Continuum Mechanics. [S.1.]: Cambridge University Press, 2007. 
RENAUD, J. E. Automatic differentiation in robust optimization. AIAA Journal, v. 35, p. 1072-1079, 1997.

RODRIGUES, J.; TEVES, A.; PASSARO, A.; GóES, L.; SILVA, E.; MATEUS, C. Static mechanical analysis of a silicon bulk-micromachined accelerometer. In: Congresso Brasileiro de Engenharia Mecânica, 2011. COBEM 2011. Proceedings of the 21st Brazilian Congress of Mechanical Engineering. [S.l.: s.n.], 2011.

ROYLANCE, L. M.; ANGELL, J. B. A batch-fabricated silicon accelerometer. IEEE Trans. Electron Devices, v. 26, p. 1911-1917, December 1979.

ROZVANY, G. I. N.; OLHOFF, N.; CHENG, K.-T.; TAYLOR, J. E. On the solid plate paradox in structural optimizationy. Journal of Structural Mechanics, v. 10, n. 1, p. $1-32,1982$.

ROZVANY, G. I. N.; ZHOU, M.; BIRKER, T. Generalized shape optimization without homogenization. Structural and Multidisciplinary Optimization, v. 4, p. 250-252, 1992.

RUBIO, W.; SILVA, E.; NISHIWAKI, S. Piezoresistive sensor design using topology optimization. Structural and Multidisciplinary Optimization, v. 36, p. 571-583, 2008.

RUBIO, W. M. Projeto de MEMS Eletrotermomecânicos Usando o Método de Otimização Topológica. Dissertação (Mestrado) - Escola Politécnica da Universidade de São Paulo, 2005.

RUDOLF, F.; JORNOD, A.; BERGQVIST, J.; LEUTHOLD, H. A miniature silicon accelerometer with built damping. Sensors and Actuators A-Physical, p. 297-302, February 1990.

SCHUëLLER, G.; JENSEN, H. Computational methods in optimization considering uncertainties - an overview. Computer Methods in Applied Mechanics and Engineering, v. 198, n. 1, p. $2-13,2008$.

SEIDEL, H.; RIEDEL, H.; KOLBECK, R.; MüCK, G.; KUPKE, W.; KöNIGER, M. Capacitive silicon accelerometer with highly symmetrical design. Sensors and Actuators A: Physical, v. 21, n. 1-3, p. $312-315,1990$.

SELVAKUMAR, A.; AYAZI, F.; NAJAFI, K. A high sensitivity z-axis torsional silicon accelerometer. In: Electron Devices Meeting, 1996. IEDM '96., International. [S.l.: s.n.], 1996. p. $765-768$.

SENNE, T. Otimização topologica de mecanismos flexíveis. Dissertação (Mestrado) - Instituto de Matemática, Estatística e Computação Científica da Universidade de Campinas, 2009.

SIGMUND, O. Design of multiphysics actuators using topology optimization - part i: One-material structures. Computer Methods in Applied Mechanics and Engineering, v. 190, n. 49-50, p. $6577-6604,2001$.

SIGMUND, O. Morphology-based black and white filters for topology optimization. Structural and Multidisciplinary Optimization, v. 33, p. 401-424, 2007.

SIGMUND, O.; PETERSSON, J. Numerical instabilities in topology optimization: A survey on procedures dealing with checkerboards, mesh-dependencies and local minima. Structural Optimization, v. 16, p. 68-75, 1998. 
SILVA E. C. N.; NISHIWAKI, S. K. N. Compliant thermal microactuators. IEEE Transactions on Ultrasonics, Ferroelectrics, and Frequency Control, v. 47, n. 3, p. 657 $671,2000$.

STOLPE, M.; SVANBERG, K. An alternative interpolation scheme for minimum compliance topology optimization. Structural and Multidisciplinary Optimization, v. 22, p. 116-124, 2001.

STRANG, G.; KOHN, R. V. Optimal design in elasticity and plasticity. International Journal for Numerical Methods in Engineering, v. 22, n. 1, p. 183-188, 1986.

SUZUKI, K.; KIKUCHI, N. A homogenization method for shape and topology optimization. Computer Methods in Applied Mechanics and Engineering, v. 93, n. 3, p. $291-318,1991$.

SVANBERG, K. The method of moving asymptotes: a new method for structural optimization. International Journal for Numerical Methods in Engineering, v. 24, n. 2, p. 359-373, 1987.

SVANBERG, K. A class of globally convergent optimization methods based on conservative convex separable approximations. IAM Journal on Optimization, v. 12, n. 2, p. $555-573,2002$.

TAKAO, H.; FUKUMOTO, H.; ISHIDA, M. A cmos integrated three-axis accelerometer fabricated with commercial submicrometer cmos technology and bulk-micromachining. Electron Devices, IEEE Transactions on, v. 48, n. 9, p. 1961 -1968, set. 2001.

TEVES, A.; RODRIGUES, J.; PASSARO, A.; SILVA, E.; MATEUS, C.; GóES, L. Investigating the performance of a mems capacitive accelerometer using finite element analysis. In: Congresso Brasileiro de Engenharia Mecânica, 2011. COBEM 2011. Proceedings of the 21st Brazilian Congress of Mechanical Engineering. [S.1.: s.n.], 2011.

TEVES, A.; SILVA, E. Design of capacitive bulk-micromachined accelerometers using the topology optimization method. In: Congresso Brasileiro de Engenharia Mecânica, 2011. COBEM 2011. Proceedings of the 21st Brazilian Congress of Mechanical Engineering. [S.l.: s.n.], 2011.

THANEDAR, P. B.; KODIYALAM, S. Structural optimization using probabilistic constraints. Structural and Multidisciplinary Optimization, v. 4, p. 236-240, 1992.

TOSSERAMS, S.; ETMAN, L.; ROODA, J. A micro-accelerometer mdo benchmark problem. Structural and Multidisciplinary Optimization, v. 41, p. 255-275, 2010.

TU, J.; CHOI, K. K.; PARK, Y. H. A new study on reliability-based design optimization. Journal of Mechanical Design, v. 121, n. 4, p. 557-564, 1999.

WANG, S.; KANG, J.; NOH, J. Topology optimization of a single-phase induction motor for rotary compressor. Magnetics, IEEE Transactions on, v. 40, n. 3, p. 1591 - 1596, 2004 .

YADI, N.; AYAZI, F.; NAJAFI, K. Micromachined inertial sensors. Proceedings of the IEEE, v. 86, n. 8, p. 1640-1659, August 1998. 
YANG, R.; GU, L. Experience with approximate reliability-based optimization methods. Structural and Multidisciplinary Optimization, v. 26, p. 152-159, 2004.

YAZDI, N.; NAJAFI, K. An all-silicon single-wafer micro-g accelerometer with a combined surface and bulk micromachining process. Journal ofMicroelectromechanical Systems, v. 9, n. 4, p. $544-550$, dez. 2000.

YOO JEONGHOON; KIKUCHI, N. Topology optimization in magnetic fields using the homogenization design method. International Journal for Numerical Methods in Engineering, v. 48, n. 10, p. 1463 - 1479, 2000.

YOON, G. H.; SIGMUND, O. A monolithic approach for topology optimization of electrostatically actuated devices. Computer Methods in Applied Mechanics and Engineering, v. 197, n. 45-48, p. 4062 - 4075, 2008.

YOUN, B.; CHOI, K.; YANG, R.-J.; GU, L. Reliability-based design optimization for crashworthiness of vehicle side impact. Structural and Multidisciplinary Optimization, v. 26, p. 272-283, 2004.

YOUN, B. D.; CHOI, K. K. An investigation of nonlinearity of reliability-based design optimization approaches. Journal of Mechanical Design, v. 126, n. 3, p. 403-411, 2004.

YOUN, B. D.; CHOI, K. K. Selecting probabilistic approaches for reliability-based design optimization. AIAA Journal, v. 42, 2004.

ZHANG, W.; DUYSINX, P. Dual approach using a variant perimeter constraint and efficient sub-iteration scheme for topology optimization. Computers \& Structures, v. 81, p. $2173-2181,2003$. 


\section{Apêndice A - Validação do algoritmo de otimização com confiabilidade}

O algoritmo de OP considerando incertezas (RBDO) é validado através da comparação com os resultados obtidos por Lee, Yang e Ruy (2002) para o problema da viga em balanço detalhado na sequência. As principais características deste problema são: 1) variáveis aleatórias gaussianas e não gaussianas; 2) apenas variáveis de projeto determinísticas; 3) funções de estado limite não lineares.

Uma viga em balanço de largura $b$ e profundidade $d$, como mostrado na Fig. A.1, está sujeita a um carregamento oscilatório de fadiga $Q_{1}$ e a um carregamento aleatório de projeto $Q_{2}$. O objetivo deste problema é a minimização do peso da estrutura, sendo a área da seção transversal adotada como função objetivo e as quatro seguintes equações de estado-limite como restrições probabilísticas:

$$
\begin{aligned}
& g_{1}=\frac{0.3 E b^{3} d}{L^{2}}-Q_{2} \leq 0 \\
& g_{2}=A-N_{0} \frac{6 Q_{1} L}{b d^{2}} \leq 0 \\
& g_{3}=\Delta_{0}-\frac{4 Q_{2} L^{3}}{E b d^{3}} \leq 0 \\
& g_{4}=R-\frac{6 Q_{2} L}{b d^{2}} \leq 0
\end{aligned}
$$

onde $L=30 \mathrm{in}, N_{0}=2 \times 10^{6}$ ciclos, $\Delta_{0}=0,15 \mathrm{in}$. As equações (A.1) definem falha por (1) flambagem; (2) fadiga na junta soldada; (3) deflexão excessiva e (4) tensão mecânica superior ao limite de elasticidade do material. As propriedades estatísticas das variáveis aleatórias estão resumidas na Tab. A.1. Foram adotados os seguintes índices de confiabilidade: 3,0 para $g_{1}$ e $g_{2}$ e 2,0 para $g_{3}$ e $g_{4}$ e os resultados obtidos são comparados com os resultados de Lee, Yang e Ruy (2002).

O Coeficiente de Variação (CoV) é dado pela razão entre o desvio padrão $\sigma$ e a média $\mu$ de uma distribuição estatística. Os parâmetros característicos da distribuição log-normal 

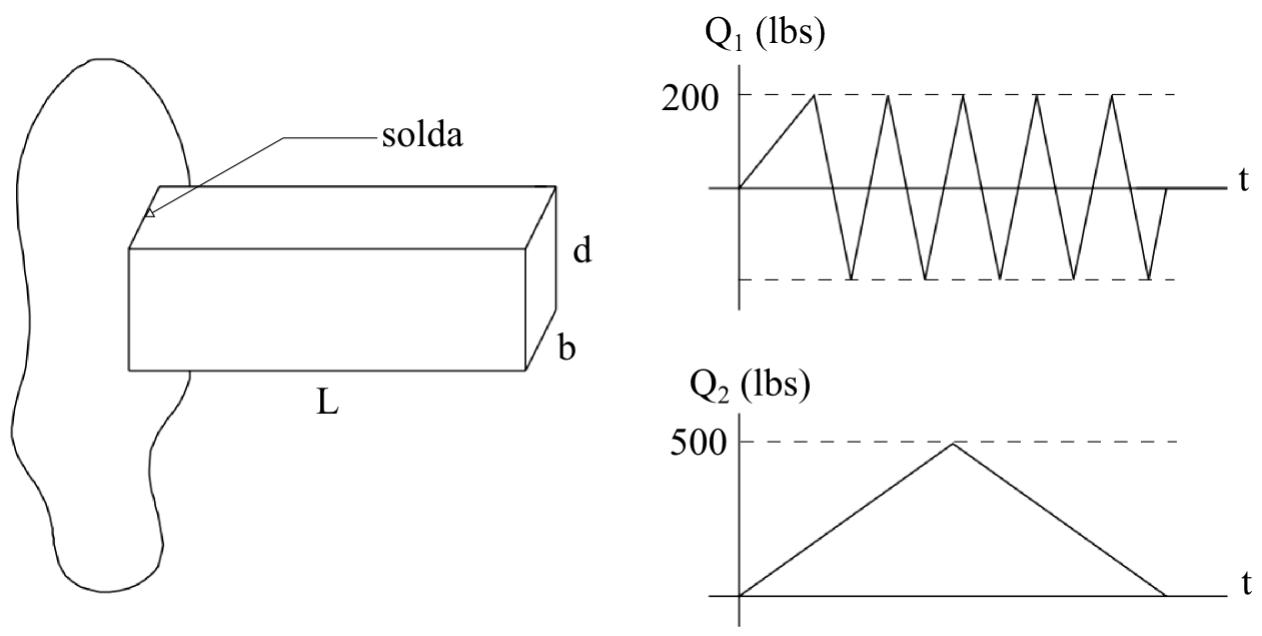

Figura A.1: O problema de otimização de uma viga em balanço.

Tabela A.1: Distribuições das variáveis aleatórias envolvidas no problema da viga em balanço $\left({ }^{*}\right.$ denota mediana $\left.m_{0}\right)$

\begin{tabular}{lllccc}
\hline & & Descrição & Distribuição & Média & CoV \\
\hline 1 & $Q_{1}$ & Carreg. de fadiga [klb] & Log-normal & $0,4^{*}$ & 0,15 \\
2 & $Q_{2}$ & Carreg. de projeto [klb] & Log-normal & $0,5^{*}$ & 0,15 \\
3 & $E$ & Módulo de elasticidade [ksi] & Normal & $3 \times 10^{4}$ & 0,10 \\
4 & $A$ & Coef. de resist. à fadiga [ksi] & Log-normal & $1,46 \times 10^{10 *}$ & 0,50 \\
5 & $R$ & Tensão de escoamento [ksi] & Weibull & 50,0 & 0,12 \\
\hline
\end{tabular}

$\bar{\mu}$ e $\bar{\sigma}$ podem ser calculados da seguinte maneira (YOUN; CHOI, 2004a):

$$
\begin{aligned}
\bar{\mu} & =\ln \left(m_{0}\right) \\
\bar{\sigma}^{2} & =\ln \left(1+C o V^{2}\right)
\end{aligned}
$$

onde $m_{0}$ representa a mediana. Já para a distribuição de Weibull, a constante de forma $\kappa$ e a constante de escala $\eta$ são obtidas através das seguintes relações (YOUN; CHOI, 2004a):

$$
\begin{aligned}
\mu & =\eta \Gamma\left(1+\frac{1}{\kappa}\right) \\
\sigma^{2} & =\eta^{2}\left[\Gamma\left(1+\frac{2}{\kappa}\right)-\Gamma^{2}\left(1+\frac{1}{\kappa}\right)\right]
\end{aligned}
$$

onde $\Gamma(\alpha)=\int_{0}^{\infty} e^{-x} x^{\alpha-1} d x, \alpha>0$ é conhecida como função gama. De posse desses dados (resumidos na Tab. A.2) é possível iniciar o estudo de otimização com o RBDO. O otimizador utilizado é o MMA e tanto o PMA como o RIA são avaliados para o cálculo de probabilidades segundo o FORM.

As Figuras A.2 e A.3 apresentam o histórico das iterações para a otimização determinística e probabilística com o PMA, respectivamente, além do ponto inicial $(2,2)$, indicado 
Tabela A.2: Parâmetros característicos das distribuições probabilísticas envolvidas no problema da viga em balanço

\begin{tabular}{ccc}
\hline Distribuição & Parâmetro 1 & Parâmetro 2 \\
\hline 1 & $\bar{\mu}_{1}=-0,91$ & $\bar{\sigma}_{1}=0,15$ \\
2 & $\bar{\mu}_{2}=-0,69$ & $\bar{\sigma}_{2}=0,15$ \\
3 & $\mu_{3}=30000$ & $\sigma_{3}=3000$ \\
4 & $\bar{\mu}_{4}=23,404$ & $\bar{\sigma}_{4}=0,47$ \\
5 & $\kappa_{5}=51,08$ & $\eta_{5}=25,48$ \\
\hline
\end{tabular}

em rosa, e o ponto ótimo $\left(b^{*}, d^{*}\right)$, indicado em preto, para os dois casos. Na Fig. A.3 as linhas sólidas representam as restrições obtidas assumindo que todos os índices de confiabilidade alvo são zero, enquanto as linhas pontilhadas correspondem aos valores de índices de confiabilidade definidos acima.

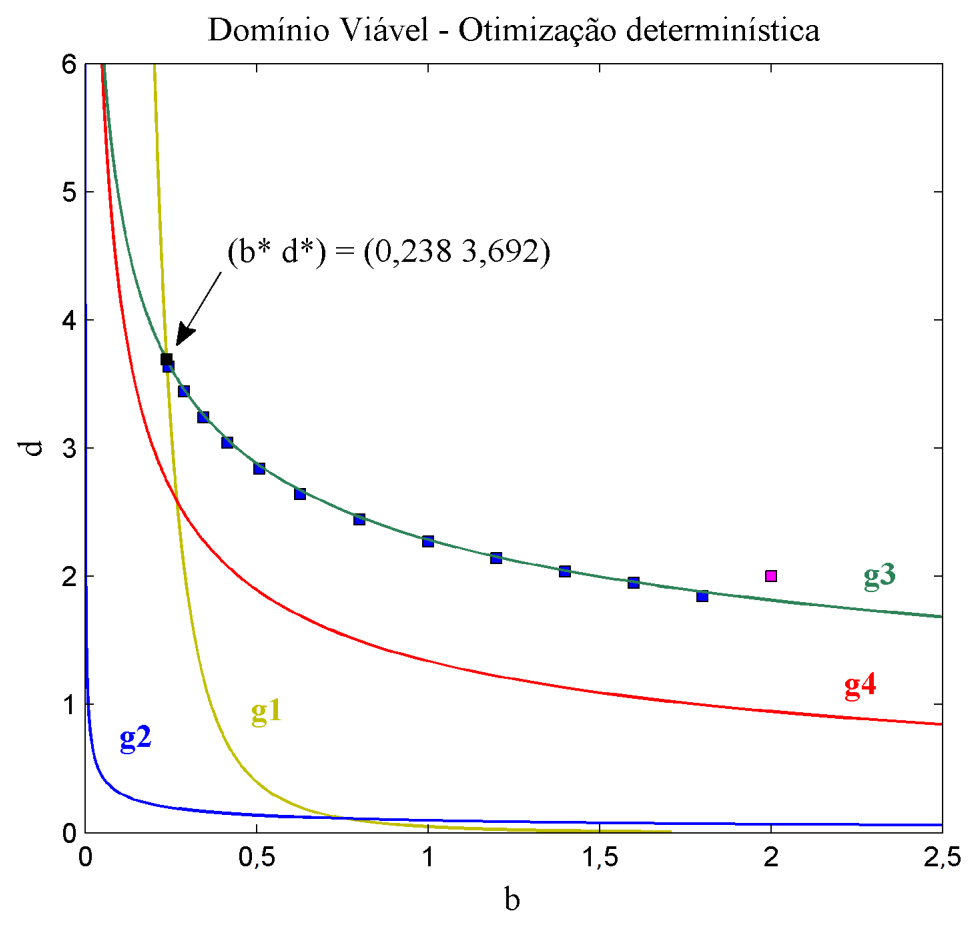

Figura A.2: Histórico de iterações para o problema de otimização determinístico.

Ainda com relação às Fig. A.2 e A.3, pode ser visto que os pontos ótimos para os dois casos não são coincidentes, como já era esperado. Sendo que no caso probabilístico, ele está localizado dentro da região viável de maneira a satisfazer a margem de segurança dada pelos índices de confiabilidade alvo. O valor ótimo para a função objetivo no caso determinístico é $0,8801 i n^{2}$ (redução de $77,9 \%$ em relação ao valor inicial) e para o caso probabilístico é 1, 1087in² (redução de 72,3\%).

Tanto o RIA quanto o PMA originaram resultados idênticos, com o mesmo número de 


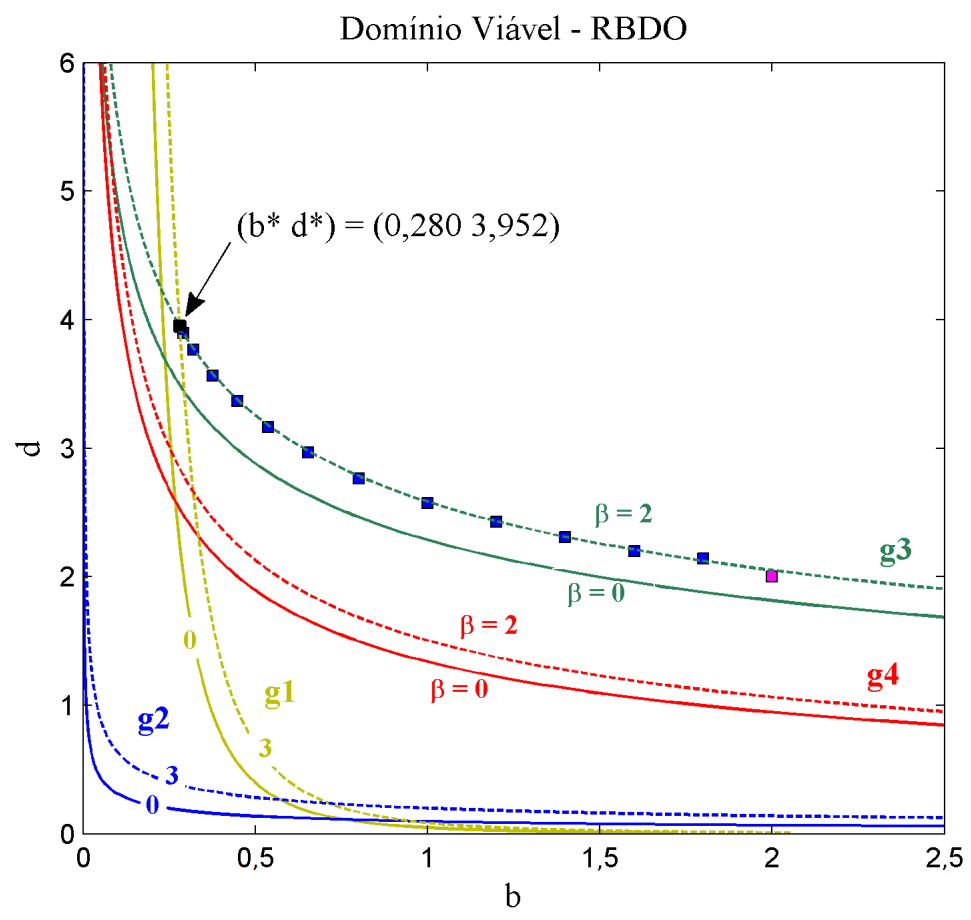

Figura A.3: Histórico de iterações para o problema de otimização probabilístico com o PMA.

iterações globais, isto é, 16. No entanto o RIA necessita de mais iterações para encontrar o ponto ótimo do problema de confiabilidade no espaço normalizado. Para o problema aqui considerado, o RIA é $22 \%$ mais lento do que o PMA e é $88 \%$ mais lento do que o caso determinístico.

Os resultados ilustrados acima são idênticos aos obtidos por Lee, Yang e Ruy (2002), com a única diferença de que foi reportado um total de 11 iterações globais para se chegar ao ponto ótimo, 5 a menos do que o necessário neste trabalho. Assim, pode-se dizer que o algoritmo de RBDO implementado pelo autor é válido e efetivo. 


\section{Apêndice B - Verificação das sensibilidades do problema de OT mediante o MDF}

O Método de Diferenças Finitas (MDF) proporciona uma efetiva, embora computacionalmente custosa, maneira de verificar as sensibilidades calculadas analiticamente, seja com métodos diretos ou adjuntos. A análise consiste em rodar uma iteração do problema (3.10), cujo objetivo é a minimização da flexibilidade média, com diferentes discretizações, calculando tanto a sensibilidade analítica $\left(\mathbf{S}_{\mathbf{1}}\right)$ quanto a sensibilidade pelo MDF $\left(\mathbf{S}_{\mathbf{2}}\right)$. A razão entre as sensibilidades será considerada satisfatória quando resultar em uma diferença menor ou igual a $2 \%$, isto é, $0,98 \leq \frac{\mathbf{S}_{1}}{\mathbf{S}_{2}} \leq 1,02$.

Os gráficos abaixo (Fig. B.1 - B.3) apresentam discretizações crescentes variando de 16 até 256 elementos. No eixo horizontal é plotado o número do elemento $e$, no vertical o

valor associado a razão $r_{\text {sens }}^{e}=\frac{S_{1}^{e}}{S_{2}^{e}}$. Em verde está ilustrado o valor unitário e em vermelho os limites máximos aceitáveis para a variação de $r_{\text {sens }}^{e}$, ou seja, $2 \%$.

Note que em todos os casos, a razão $\mathbf{r}_{\text {sens }}$ apresenta valor satisfatório, melhorando com o aumento da discretização adotada. É interessante também observar o tempo $\Delta t$ necessário para o cálculo de ambas as sensibilidades (Tab. B.1).

Tabela B.1: Comparação entre o custo computacional de $S_{1}$ e $S_{2}$

\begin{tabular}{c|c|c}
\hline Discretização & $\Delta t_{S_{1}}$ & $\Delta t_{S_{2}}$ \\
\hline 16 elementos & $6,3 \mathrm{~s}$ & $2 \mathrm{~min}$ \\
64 elementos & $6,3 \mathrm{~s}$ & $7 \mathrm{~min}$ \\
256 elementos & $7,1 \mathrm{~s}$ & $30 \mathrm{~min}$ \\
\hline
\end{tabular}

Os resultados apresentados acima validam o cálculo de sensibilidades pelo método analítico implementado pelo autor, além de ressaltarem a eficiência computacional deste método. 


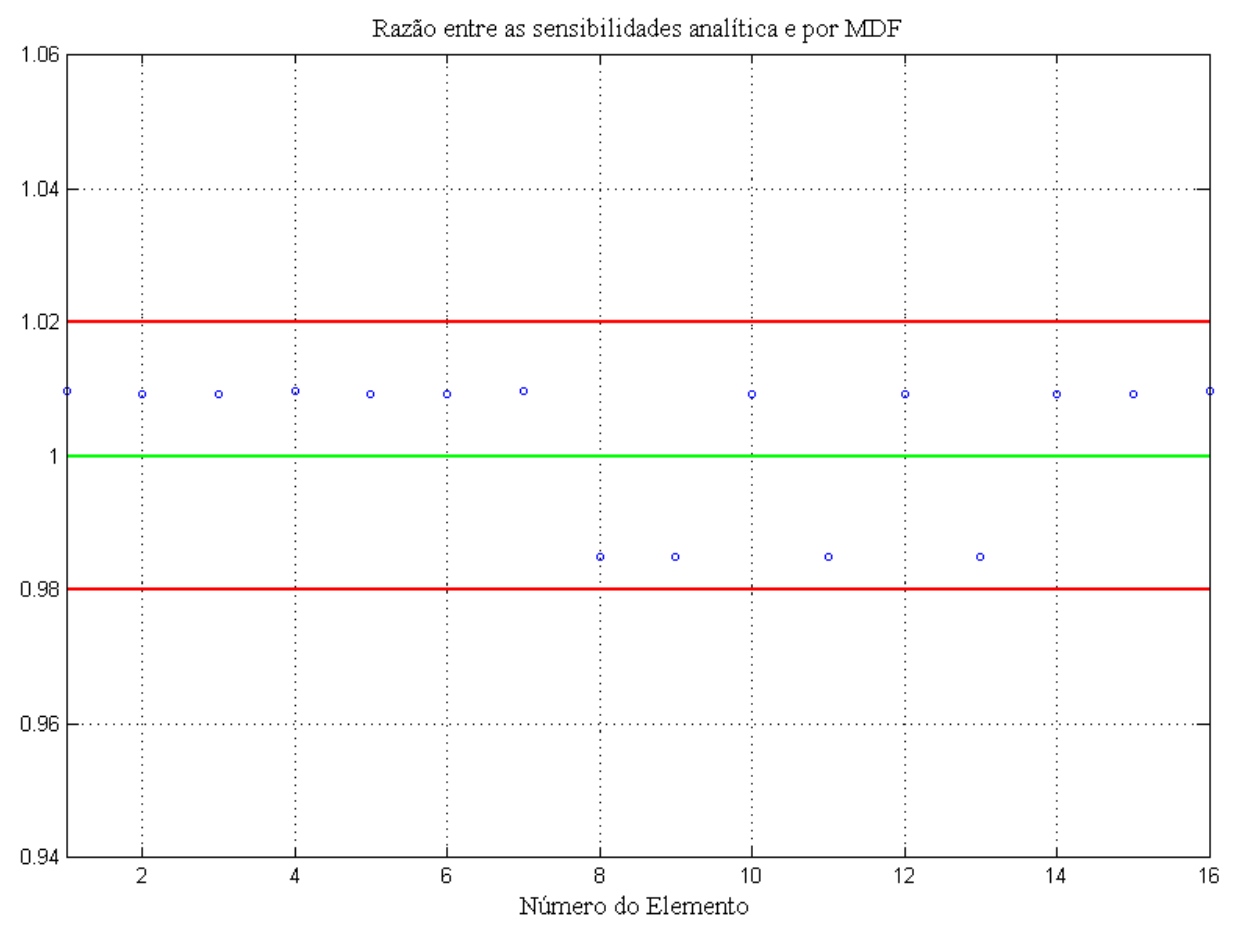

Figura B.1: Razão entre as sensibilidade com discretização de 16 elementos

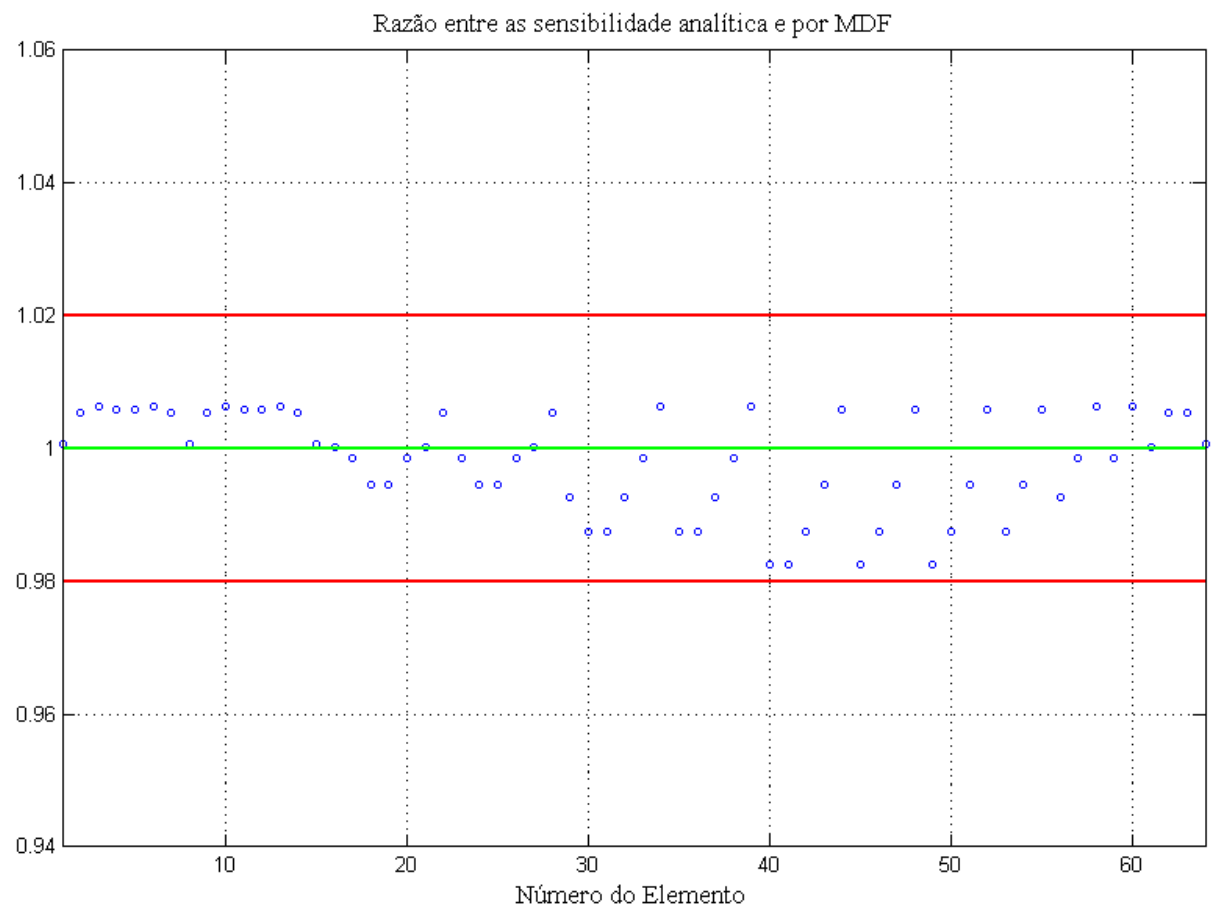

Figura B.2: Razão entre as sensibilidade com discretização de 64 elementos 


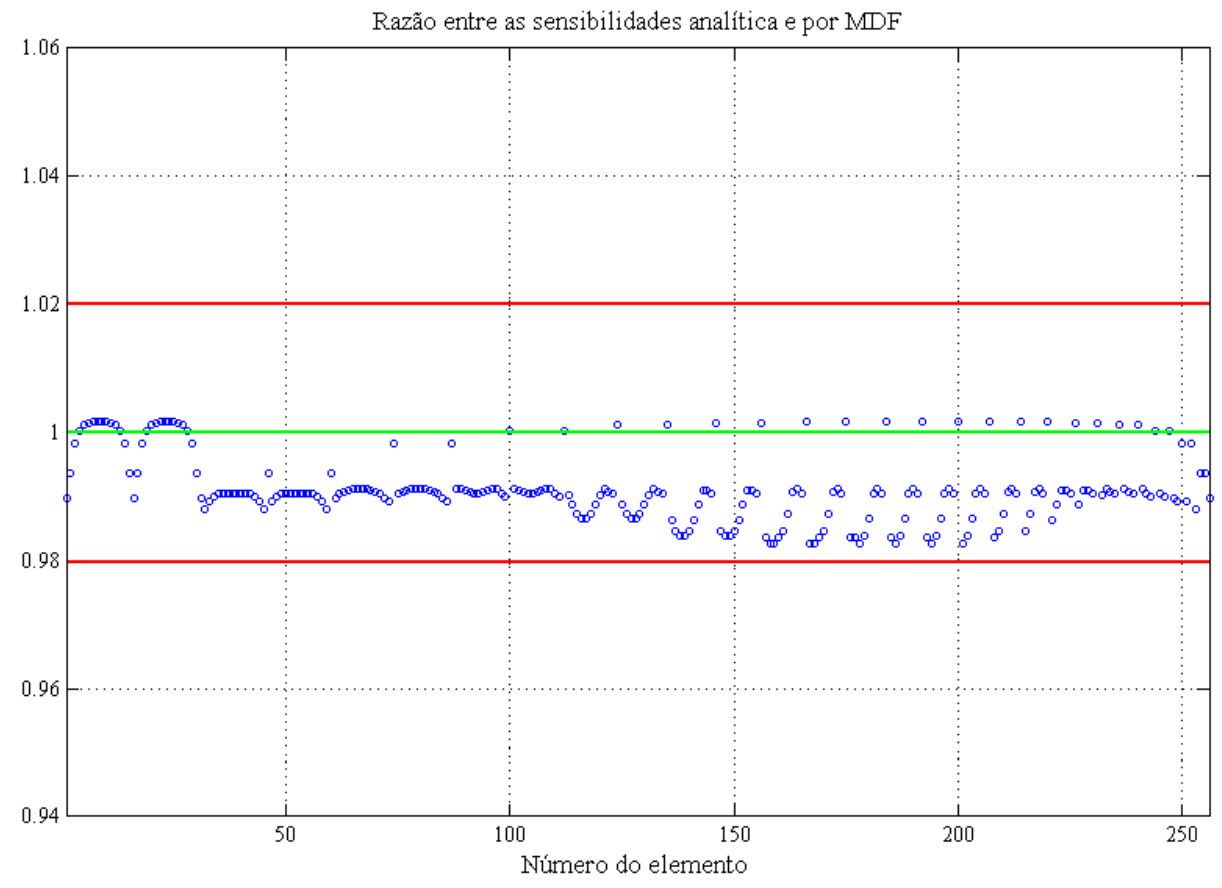

Figura B.3: Razão entre as sensibilidade com discretização de 256 elementos 


\section{Apêndice C - Comunicação entre Comsol e Matlab}

Para permitir a comunicação entre os dois softwares, é necessário em primeiro lugar a aquisição de uma licença do módulo "LiveLink for MATLAB" para o Comsol. Este pacote importa as bibliotecas do Comsol no Matlab permitindo assim a criação de geometrias, estudos, físicas e todas as demais funcionalidades do Comsol iterativamente a partir da linha de comando ou de funções em Matlab.

Como ilustrado no fluxograma apresentado na Seção 4.2.4, ao final de cada iteração, o vetor de densidades é atualizado pelo otimizador. Após a aplicação da técnica de projeção, este vetor é enviado para o Comsol através de um arquivo "txt" (chamado neste trabalho de "rho_design.txt") contendo as coordenadas x e y do centro de cada elemento e sua respectiva pseudo-densidade.
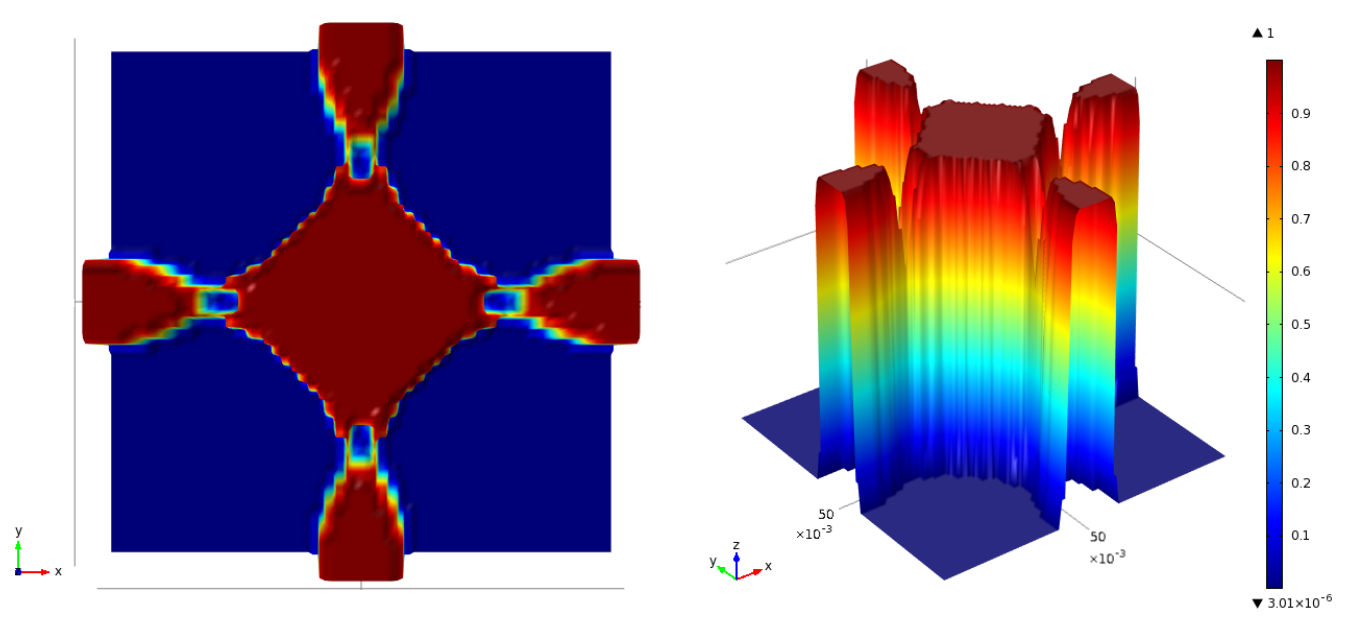

Figura C.1: Interpolação do vetor de densidades no software Comsol.

A partir desses dados é construída uma função interpoladora no software, como está ilustrado na Fig. C.1, a qual não tem relação direta com as propriedades do material dos elementos da sua malha. O valor do módulo de Young é obtido pela sobreposição da função interpoladora com a malha de elementos finitos, utilizando para isso o modelo de 
material SIMP (Seção 3.2.2), afim de compor as matrizes de rigidez local. A Fig. C.2 mostra a distribuição do valor do módulo de Young E, resultante da aplicação do SIMP com penalização $p_{e}=3$, sobreposta com a malha de elementos finitos adotada. Note que o valor da propriedade não é necessariamente constante dentro do elemento.

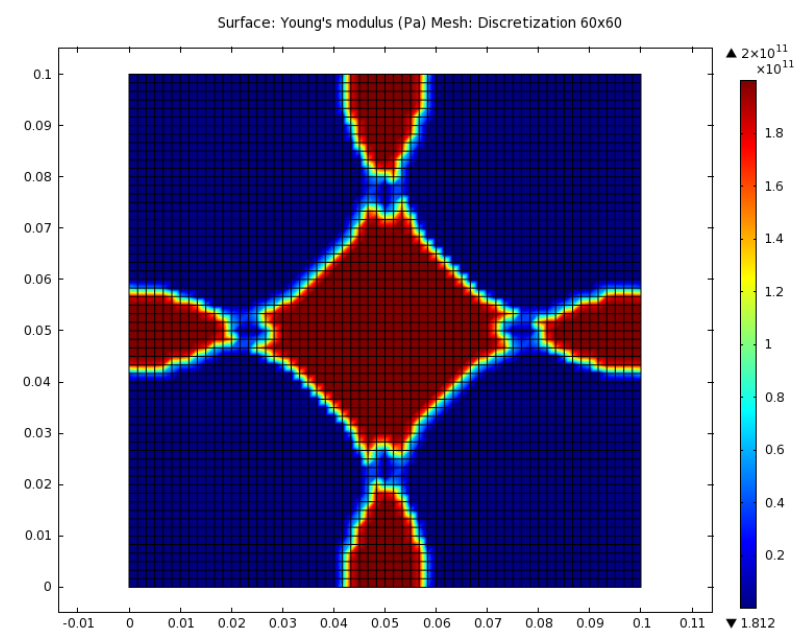

Figura C.2: Distribuição do valor do módulo de Young E, resultante da aplicação do SIMP.

Como exemplo, abaixo está apresentada a função em Matlab "setAplication.m" que define partes importantes da aplicação do Comsol (a criação da geometria e da malha não estão ilustradas). Este trecho é responsável pela criação da função interpoladora, das propriedades do material, da física de placas, do estudo estacionário e também pela inserção do modelo de material SIMP. O código abaixo está devidamente comentado para permitir uma melhor compreensão do que é realizado em cada um dos blocos da função.

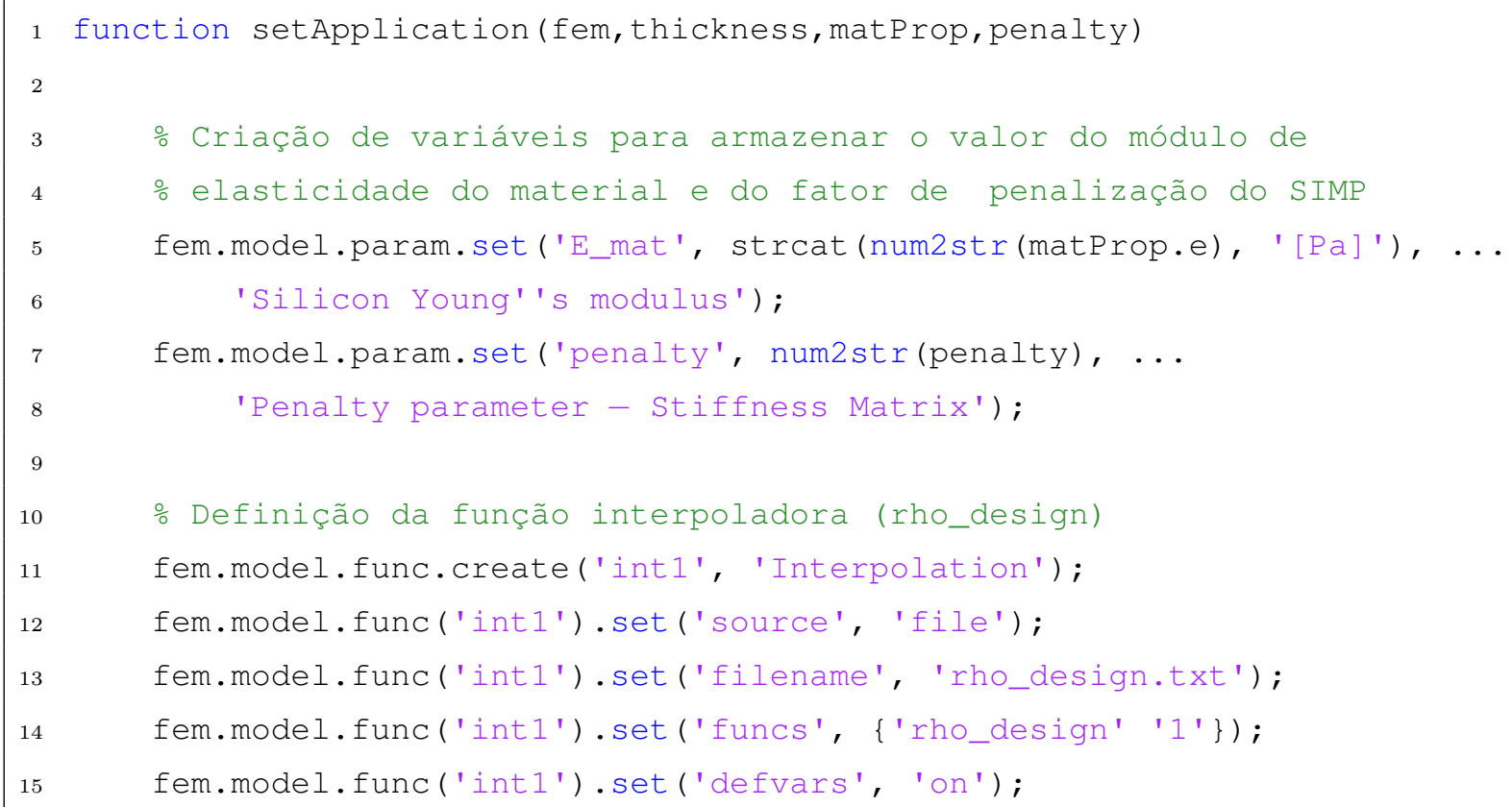




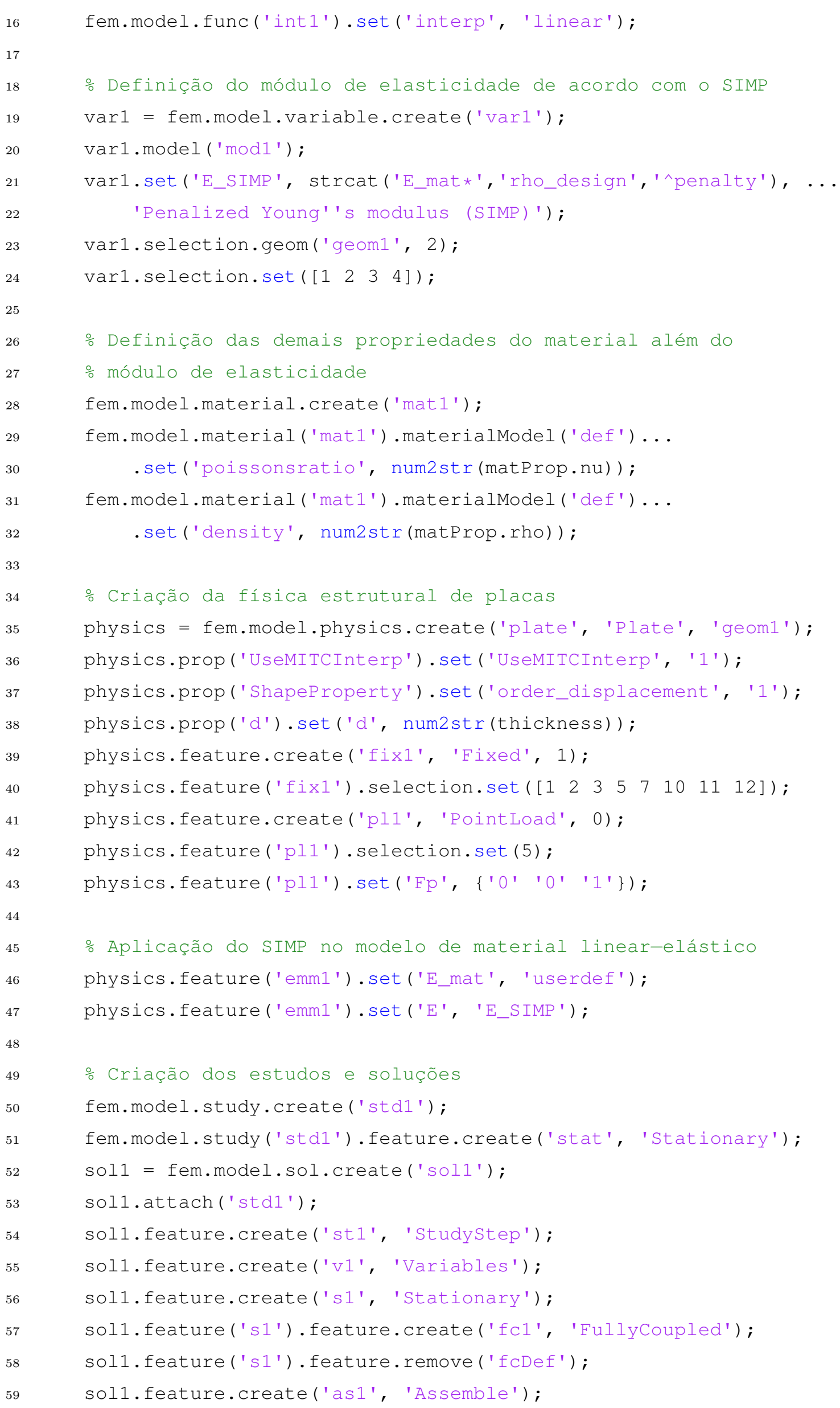




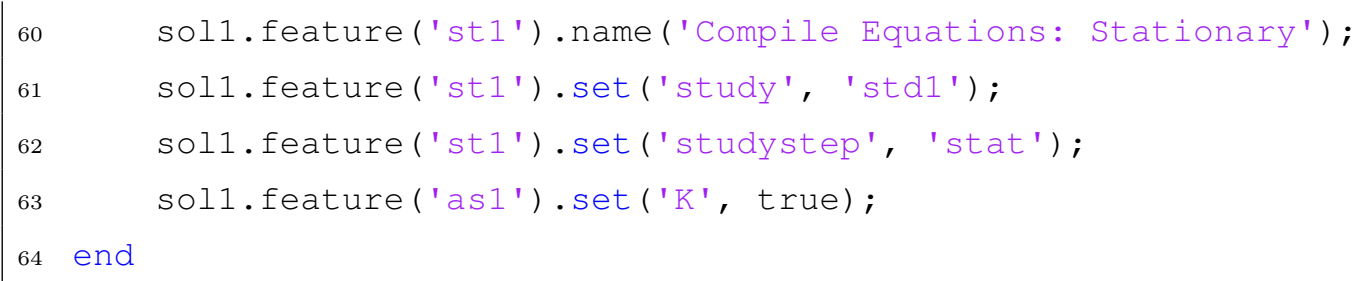




\section{Apêndice D - Validação do algoritmo de otimização topológica}

É realizada a validação do algoritmo de OT através da comparação com os resultados de Pedersen (2001). Para este problema a estrutura a ser otimizada é uma placa quadrada com dimensões $0,1 m \times 0,1 m$ e espessura de $0,001 m$. Devido à simetria, apenas um quarto do domínio é considerado na otimização e a discretização adotada é de 30 x 30 elementos. O material utilizado possui as seguintes propriedades: módulo de elasticidade $E=200 \times 10^{9} \mathrm{~N} / \mathrm{m}^{2}$, coeficiente de poisson $\nu=0,3$ e densidade $\rho=7800 \mathrm{~kg} / \mathrm{m}^{3}$. O volume máximo de material permitido corresponde a $25 \%$ do domínio completamente cheio. Com relação às condições de contorno, uma força unitária é aplicada no ponto central do domínio e dois casos de fixação são avaliados: 1) placa simplesmente apoiada nas suas bordas e 2) placa engastada nas suas bordas. O objetivo é a maximização da rigidez.

Os resultados deste problema de otimização são mostrados na Fig. D.1 para a placa simplesmente apoiada e Fig. D.2 para a placa engastada. As topologias ótimas obtidas são bem similares às apresentadas em Pedersen (2001), sendo que pequenas diferença podem ser explicadas pela adotação de modelos de materiais e técnicas de projeção diferentes nos dois trabalhos: os resultados abaixo apresentados foram obtidos com o penalizador $p_{e}$ do modelo SIMP variando de 1 a 3 nas 20 primeiras iterações (método da continuidade) e com o raio mínimo da técnica de projeção igual a $r_{\text {min }}=2,5 \mathrm{~mm}$ (ilustrado em azul nas figuras). Devido à similaridade entre os resultados é possível assegurar a consistência e a validade do algoritmo de OT implementado pelo autor. 


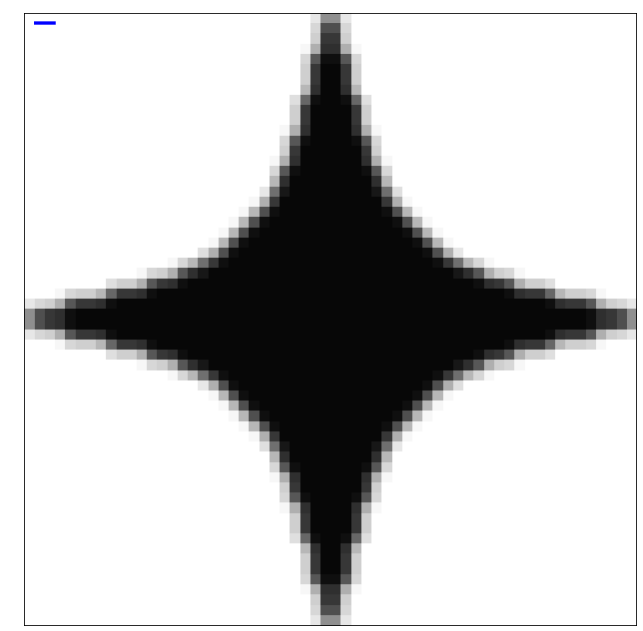

Figura D.1: Maximização da rigidez com a placa simplesmente apoiada nas bordas

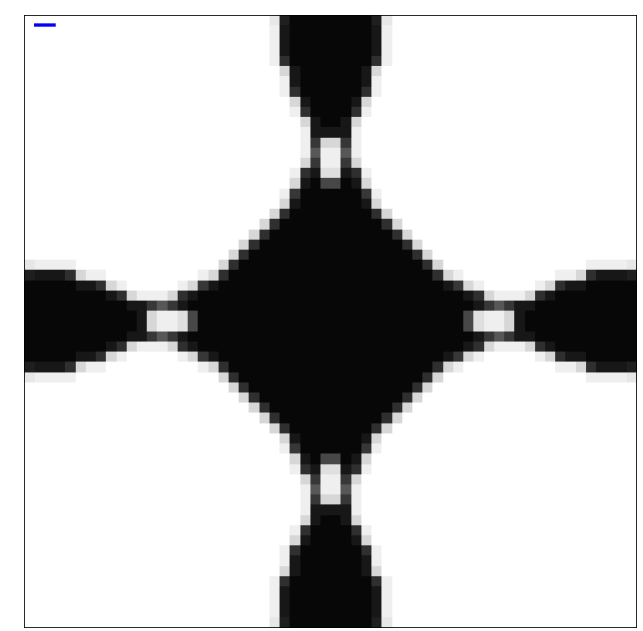

Figura D.2: Maximização da rigidez com a placa engastada nas bordas 


\section{Apêndice E - Análise de sensibilidades para o problema da treliça de 10 barras}

Como já dito anteriormente, o cálculo das sensibilidades para este problema é muito parecido com o que está ilustrado na Seção 4.2.3 para OT, já que ambos necessitam da avaliação da flexibilidade média. A principal diferença é que o gradiente neste caso deve ser calculado em relação as variáveis A (área das seções transversais das barras da treliça) ao invés das pseudo-densidades $\boldsymbol{\gamma}$. Sendo assim, a partir de (4.22) tem-se que:

$$
\frac{\partial L}{\partial A_{i}}=-\mathbf{v}^{T} \frac{\partial \mathbf{K}}{\partial A_{i}} \mathbf{v}
$$

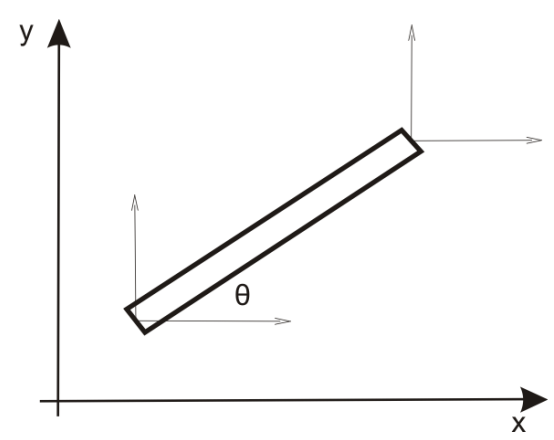

Figura E.1: Representação cartesiana 2D de uma barra de treliça e seus graus de liberdade.

A matriz de rigidez local de um elemento de treliça $i$ posicionado formando um ângulo $\theta$ com um sistema cartesiano global XY, como mostrado na Fig. E.1, é dada por:

$$
\mathbf{k}_{\mathbf{i}}=\frac{E A_{i}}{L_{i}}\left(\begin{array}{cccc}
c \theta^{2} & c s \theta & -c \theta^{2} & -c s \theta \\
c s \theta & s \theta^{2} & -c s \theta & -s \theta^{2} \\
-c \theta^{2} & -c s \theta & c \theta^{2} & c s \theta \\
-c s \theta & -s \theta^{2} & c s \theta & s \theta^{2}
\end{array}\right)
$$

onde $E$ é o módulo de elasticidade do material, $L_{i}$ o comprimento da barra $i, c \theta=\cos \theta$, $s \theta=\sin \theta$ e $\operatorname{cs} \theta=\cos \theta \sin \theta$. 
A matriz $\frac{\partial \mathbf{K}}{\partial A_{i}}$ de derivadas de $\mathbf{K}$ em relação às áreas é obtida a partir das matrizes de derivadas locais de cada elemento $d \mathbf{k}_{\mathbf{i}}$. Como fica claro a partir de (E.2), a matriz de rigidez local $\mathbf{k}_{\mathbf{i}}$ depende linearmente de $A_{i}$ e assim sua derivada em relação a esta variável de projeto é obtida através da simples divisão por esta variável. Dessa forma, a derivada da matriz de rigidez do elemento $i, d \mathbf{k}_{\mathbf{i}}$, é dada por:

$$
d \mathbf{k}_{\mathbf{i}}=\frac{\mathbf{k}_{\mathbf{i}}}{A_{i}}
$$

